Florida International University FIU Digital Commons

7-3-2014

\title{
Development of a Precast Concrete Supertile Roofing System for the Mitigation of Extreme Wind Events
}

Brandon L. Mintz

Florida International University, bmint002@fiu.edu

DOI: $10.25148 /$ etd.FI14110753

Follow this and additional works at: https://digitalcommons.fiu.edu/etd

Part of the Civil Engineering Commons, and the Structural Engineering Commons

\section{Recommended Citation}

Mintz, Brandon L., "Development of a Precast Concrete Supertile Roofing System for the Mitigation of Extreme Wind Events" (2014). FIU Electronic Theses and Dissertations. 1665.

https://digitalcommons.fiu.edu/etd/1665 


\section{FLORIDA INTERNATIONAL UNIVERSITY}

Miami, Florida

DEVELOPMENT OF A PRECAST CONCRETE SUPERTILE ROOFING SYSTEM FOR THE MITIGATION OF EXTREME WIND EVENTS

A dissertation submitted in partial fulfillment of the

requirements for the degree of

DOCTOR OF PHILOSOPHY

in

CIVIL ENGINEERING

by

Brandon Mintz

2014 
To: Dean Amir Mirmiran

College of Engineering and Computing

This dissertation, written by Brandon Mintz, and entitled Development of a Precast Concrete Supertile Roofing System for the Mitigation of Extreme Wind Events, having been approved in respect to style and intellectual content, is referred to you for judgment.

We have read this dissertation and recommend that it be approved.

Ton-Lo Wang

Yimin Zhu

$\begin{array}{r}\text { Amir Mirmiran } \\ \hline \text { Nakin Suksawang, Co-Major Professor } \\ \hline \text { Arindam Gan Chowdhury, Co-Major Professor }\end{array}$

Date of Defense: July 3, 2014

The dissertation of Brandon Mintz is approved.

Dean Amir Mirmiran

College of Engineering and Computing

Dean Lakshmi N. Reddi

University Graduate School

Florida International University, 2014 
(C) Copyright 2014 by Brandon Mintz

All rights reserved. 


\section{DEDICATION}

For Faith 


\section{ACKNOWLEDGMENTS}

I would like to thank Dr. Arindam Chowdhury and Dr. Nakin Suksawang, my advisors, for their help in writing this dissertation and carrying out this research. I appreciate their efforts. Thank you to Dr. Chowdhury for going over many edits and reading through my revisions to the papers and chapters. Thank you to Dr. Suksawang for investing time in me over the years and his contribution to this work. Thank you to Dr. Amir Mirmiran for his edits and advice on the research. Thank you to Dr. Yimin Zhu and Dr. Ton-Lo Wang for serving on the committee.

Thank you to all those that helped me in the lab to accomplish so many tests over the years. Thank you to Ramtin Kargarmoakhar for his help during the project, co-writing a paper, and helping me obtain graduate form signatures. Thank you to Edgar Polo for his help and effort in helping set up so many tests and working with me. Thank you to Juan Cesin and Andres Urrego for their help on this specific project. Thank you to Dr. Pedram Zohrevand and Dr. Chadi Younes for being friends and supporting.

Thank you to the Center of Excellence in Hurricane Damage Mitigation and Product Development at Florida International University (FIU) for their support of this research. I appreciate the means provided to carry out the study. Thank you to Dr. Emil Simiu for his appreciated comments on paper manuscripts.

Thank you to all those that helped me along the way. Thank you to my parents for their help and investing in me over the years. Thank you to Faith and Hanna for giving purpose to my life and making it worth it. Thank you to Faith for supporting me and for not letting me give up. Finally, I am grateful to God for helping me and placing this group of people around me. Without His help, this could have never happened. 


\title{
ABSTRACT OF THE DISSERTATION \\ DEVELOPMENT OF A PRECAST CONCRETE SUPERTILE ROOFING SYSTEM FOR THE MITIGATION OF EXTREME WIND EVENTS
}

\author{
by \\ Brandon Mintz \\ Florida International University, 2014 \\ Miami, Florida

\section{Professor Arindam Gan Chowdhury, Co-Major Professor \\ Professor Nakin Suksawang, Co-Major Professor}

Residential roofs have traditionally formed the weakest part of the structure. The connections of roofs to the walls has lacked a clear load path with the result that the structure is weak at this point, leading to the compromise of the structure. Indeed roofs have multiple points of failure that lead to the weakness of the residential structure as a whole. Even if structural failure does not occur, compromise the roofing membrane can lead to high repair costs and property loss. The failure lies in the complex forming of the roof components as the roof aesthetics are placed to protect the underlayment and the underlayment protects the sheathing and trusses. However, the aesthetics, such as the roof tile, not being structural can be damaged easily and lead to the compromise of the roofing system as well as endangering surrounding structures.

The shape of the roof tile lends itself well to structural design. The wave motion leads to structural redundancy and provides a significant ability to provide stiffness. Using the shape of the roof tile, a structure can be created to encapsulate the shape and provide structural strength. The aesthetics are already accounted for in the shape and the 
shape is strengthened according to necessity. A system has been devised for flexural strength and applicable connections to demonstrate the constructability and feasibility of creating and using such a system. Design concepts are accounted for, the components are tested and confirmed, and a full-scale test is carried out to demonstrate the concepts ability as a system.

The outgrowth of this work is to produce design tables that allow the designer the ability to design for certain building conditions. Taking the concepts of flexural strength and wall to roof, panel to panel, and ridge connections, the design is broken down into appropriate design parameters. Tables are developed that allow the concept to be used under different structural conditions and geographical needs. The conclusion allows us to show specifically how the concept can be applied in specific geographical regions. 


\section{TABLE OF CONTENTS}

CHAPTER

PAGE

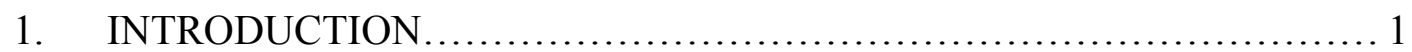

$1.1 \quad$ Problem Statement............................................... 1

1.2 Research Objectives.............................................

$1.3 \quad$ Research Methodology........................................... 4

$1.4 \quad$ Organization of Dissertation................................. 6

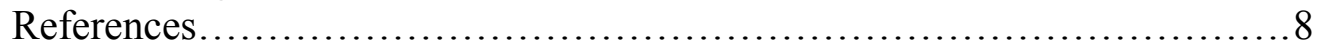

2. THE USE OF ARCHITECTURAL FEATURES FOR HURRICANE MITIGATION IN CONCRETE SUPERTILES.............................. 9

2.1 Introduction and Background ................................. 9

2.1.1 Tile Roofs........................................... 9

2.1.2 Novel Roofing System................................. 10

2.2 Novel System Features........................................ 10

2.2.1 Structural Development................................ 11

2.2.1.1 Initial Results.................................... 13

2.2.2 Aesthetic Development................................. 17

2.2.2.1 Results and Discussion............................ 18

2.2.2.2 Strength........................................... 21

2.2.2.3 Cost.......................................... 22

2.2.2.4 Energy Efficiency............................... 23

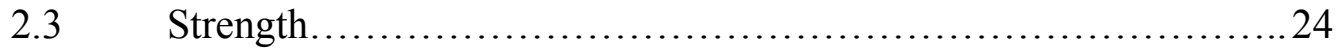

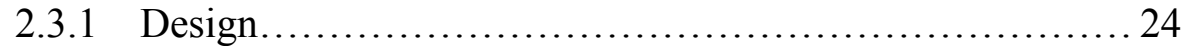

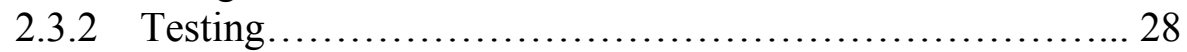

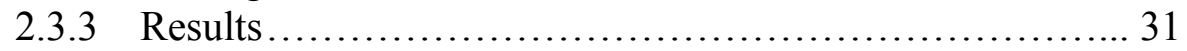

2.3.4 Loading Conditions Considered............................. 31

2.3.4.1 Maximum Uplift................................ 31

2.3.3.2 Imbalanced Loading..................................31

2.3.3.3 Maximum Positive Pressure........................ 32

2.4 Constructability and Insurance Benefits.......................... 33

2.4.1 Constructability.......................................... 33

2.4.2 Intangible Cost Reduction..................................

2.5 Energy Efficiency.................................................. 37

2.5.1 Insulation Options.................................... 37

2.5.1.1 Spray-On Insulation................................. 37

2.5.1.2 Insulated Concrete Formwork....................... 39

2.5.1.3 Conventional Batt Insulation........................... 39

2.6 Initial Development Conclusions................................... 39

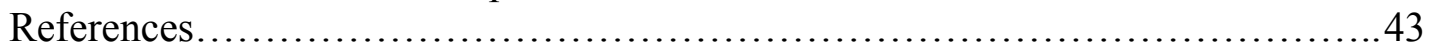

3. DESIGN, DEVELOPMENT AND TESTING OF A COMPOSITE

ROOFING SYSTEM............................................... 45 


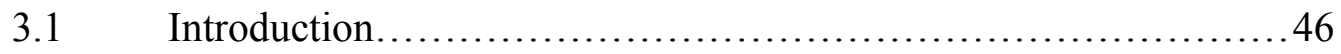

3.2 Design Concept.............................................. 48

3.3 Loading Demand and Panel Design................................49

3.4 Flexural Testing of a Strong Barrel Section....................... 51

$3.5 \quad$ Connections.................................................. 53

3.5.1 Roof Panel to Wall Connections............................53

3.5.2 Panel to Panel Connections..................................55

3.5.3 Ridge Connection.........................................56

3.6 Economic Considerations...................................... 58

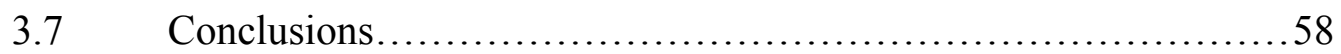

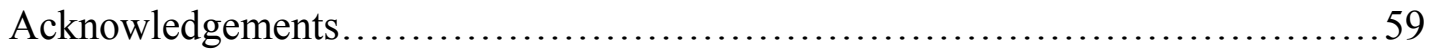

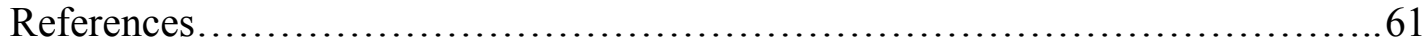

4. FULL-SCALE TESTING OF A PRECAST CONCRETE SUPTERTILE

ROOFING SYSTEM FOR HURRICANE MITIGATION.....................76

4.1 Background ................................................. 77

4.1.1 Conventional Residential Roofing Systems................. 78

4.1.2 Novel Roofing System.......................................79

4.2 Design of the Novel Roofing System ........................... 81

4.2.1 Developing Structural Capacity and Architectural Shape.. 81

4.2.2 Connections for the New Roofing System................. 81

4.3 Preliminary Cost Analysis for the New Roofing System........... 82

$4.4 \quad$ Section Design.................................................. 82

4.5 Test Setup and Instrumentation.............................. 84

4.5.1 Test specimens.............................................. 84

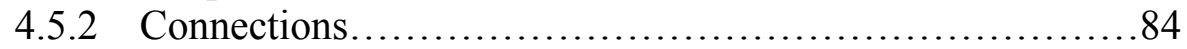

4.5.3 Loading Procedure.................................... 85

4.6 Results and Discussion...................................... 87

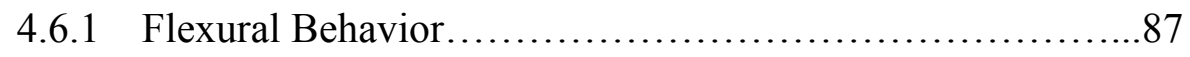

4.6.2 Panel-to-Wall Connections............................... 88

4.6.3 Panel-to-Panel Connections.................................... 89

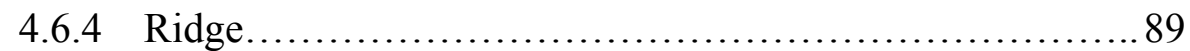

4.6.5 Example Tables........................................ 90

$4.7 \quad$ Conclusions..................................................... 91

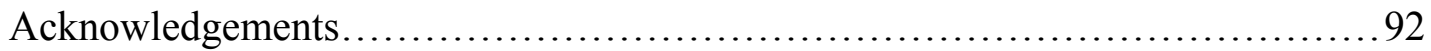

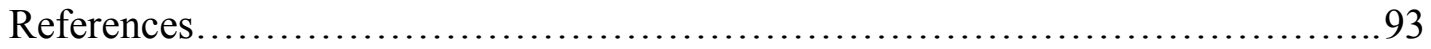

5. SUMMARY AND CONCLUSIONS.......................................... 107

5.1 Design Concept for a Supertile System.......................... 107

5.2 Component Design Parameters.....................................108

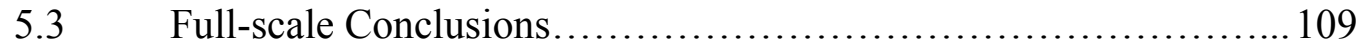

$5.4 \quad$ Future Research.......................................... 110

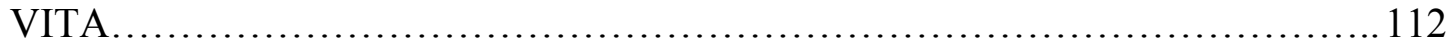




\section{LIST OF TABLES}

TABLE

Table 2.1 Section Development for a Given Section

Table 3.1. Wind Pressure Calculation Data for Miami-Dade County Using ASCE 7-10.

Table 3.2. Moments Induced by Design Wind Loads.

Table 3.3. Properties of C-grid and C-bar.

Table 3.4. Typical Span Lengths Based on Mean Roof Height and Wind Velocity. 64

Table 3.5. Typical Roof-to-Wall Connection Spacing Based on Mean Roof Height and Wind Velocity

Table 3.6. Typical Ridge Shear Connector Spacing Based on Mean Roof Height and Wind Velocity.............................................. 64

Table 3.7. Construction Costs for the New Roofing System.....................65

Table 3.8. Construction Costs for Conventional Tile Roofing System............. 65

Table 4.1 Strength of the Connections.................................... 95

Table 4.2 Construction Costs for Conventional Roofing Systems................ 95

Table 4.3 Anticipated Initial Material Cost of the Novel Roofing System......... 95

Table 4.4 Calculated Loading and Actual Loading Applied for Each Load Step.... 96

Table 4.5 Properties of C-grid and C-bar................................ 96

Table 4.6 Maximum Moment and Vertical Panel Deflections..................... 97

Table 4.7 Maximum Stresses at the Midspan ............................... 98

Table 4.8 Maximum Stresses at the Ridge................................ 98

Table 4.9 Design Wind Tables for Span Length Based on Mean Roof Height and Wind Velocity.......................................... 99

Table 4.10 Design Wind Tables for Panel to Roof Connections Based on Mean Roof Height and Wind Velocity... 99 
Table 4.11 Design Wind Tables for Ridge Connection Shear Connector Spacing Based on Mean Roof Height and Wind Velocity............... 99 


\section{LIST OF FIGURES}

FIGURE

Figure 2.1. Initial Design Concept....................................... 11

Figure 2.2. Test Setup for Suction (left) and Pressure (right)................. 12

Figure 2.3. Weak Direction............................................. 12

Figure 2.4. Typical Flexural Cracking in Specimens....................... 13

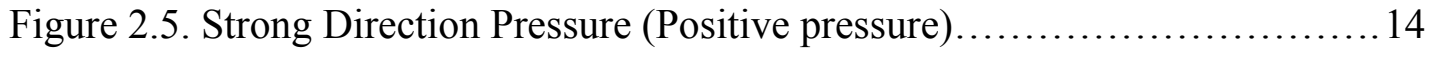

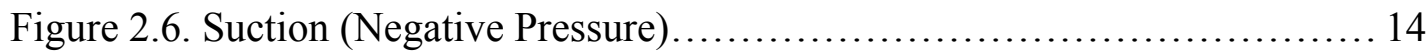

Figure 2.7. Moment-deflection Curve for Weak Direction Specimens Tested for Pressure.............................................. 15

Figure 2.8. Moment-deflection Curve for Weak Direction Specimens Tested for Suction ................................................ 16

Figure 2.9. Initial Roof Panels (left) and Foam Shaped Roof Panels (right)........ 18

Figure 2.10. Aesthetically Improvement Test.............................. 19

Figure 2.11. Deflected and Failed Specimen................................ 19

Figure 2.12. Moment vs. Displacement for the Two Phases (Initial Development [Phase I]; Aesthetic Development $[$ Phase II])................... 20

Figure 2.13. Converting a Tile Shape into an Embedded Beam Size:

(a) demonstrates the tile shape; (b) demonstrates the tile shape fill-in for an embedded beam; (c) shows that the shape can be broken into finite sections for design purposes................... 25

Figure 2.14. Showing the Tile Shape as a Graph for Structural Analysis........... 26

Figure 2.15. Strong Barrel Section..................................... 28

Figure 2.16. Strong Barrel Load Test (Positive pressure, left; negative pressure,

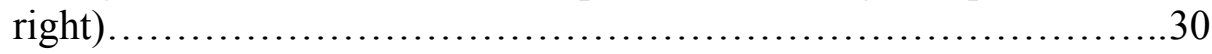

Figure 2.17. Specimen Failure Modes..................................... 32 
Figure 2.18. Example of the Tributary Loading Applied to Each Strong Barrel

Section.

Figure 2.19. Strong Barrel Testing Moment-Deflection Curves (Top, positive pressure; bottom, negative pressure) ..............................34

Figure 2.20. Construction Sequence of the Supertile System, Step 1............ 35

Figure 2.21. Construction Sequence of the Supertile System, Step 2........... 35

Figure 2.22. Construction Sequence of the Supertile System, Step 3............ 36

Figure 2.23. Spray-On Insulation Schematic...................................... 38

Figure 2.24. Insulated Concrete Form Schematic...............................40

Figure 2.25. False Ceiling with Batt Insulation Schematic......................... 41

Figure 3.1. Details of the Composite Supertile Panel Section:

(a) Reinforcement Details; (b) Panel Connection Details............. 66

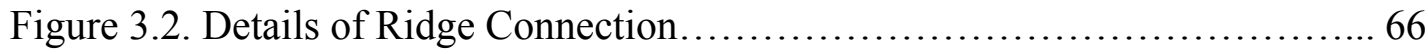

Figure 3.3. Wind Load Schematics for Use with (a) Eq. (1), (b) Eqs. (2)\&(3),

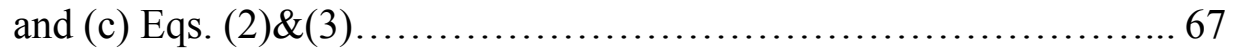

Figure 3.4. Strong Barrel Load Test: (a) Cross-section of Tested Specimen

(b) Positive External Pressure for Load Combinations 2 and 3,

(c) Negative External Pressure for Load Combination 1,

(d) Load Test Schematic.... .68

Figure 3.5. Moment-Deflection Response Curves for Strong Barrel Tests:

(a) Positive Pressure, and (b) Negative Pressure.

Figure 3.6. Roof-to-Wall Connection Detail.................................. 70

Figure 3.7. Roof-to-Wall Connection Test Setup................................ 71

Figure 3.8. Panel-to-Panel Connection Detail.................................. 72

Figure 3.9. Panel-to-Panel Connection Test Setup............................ 72

Figure 3.10. Ridge Design Schematic........................................... 72 
Figure 3.11. Ridge Connection Tests with Shear Connections Made of (a) FRP,

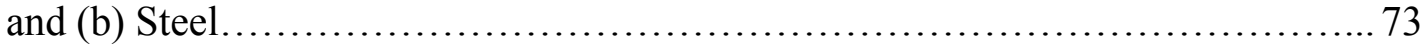

Figure 3.12. Ridge Failure (a) FRP, and (b) Steel.............................. 74

Figure 3.13. Moment-Deflection Demand Curves for Ridge Tests with FRP and Steel Plates..................................................... 75

Figure 4.1 New Panel System (a) View of the panel shape; (b) Panel reinforcement; (c) Test panel section................................100

Figure 4.2 Roof to Wall Connection Detail..................................... 100

Figure 4.3 Panel to Panel Connection......................................... 101

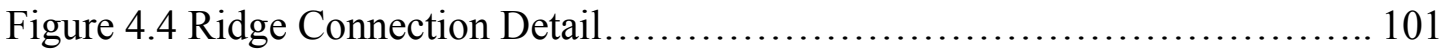

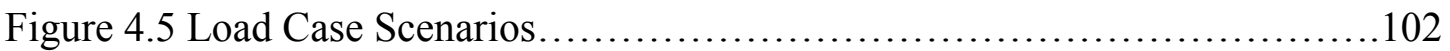

Figure 4.6 Strong Barrel Section and Testing Panels............................ 102

Figure 4.7 Load Application Device Can Apply both Positive and Negative Pressure............................................................ 103

Figure 4.8 Full-Scale Test Setup (a) Load application; (b) Isometric view............104

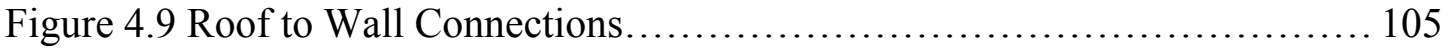

Figure 4.10. Instrumentation Schematic for the Full-Scale Test.................... 106 


\section{INTRODUCTION}

\subsection{Problem Statement}

Roofs, specifically residential roofs, exist for two main reasons: privacy and separation of environments. Roofs have come through many different phases and have used different materials, but are traditionally based on the needs and aesthetics of the local environment. Considering just the clay and concrete roof tile, clay tiles can be dated in North America as appearing 400-500 years ago (MCA, 2014) while concrete tiles are dated within the last 100 years (Unicrete, 2012). Their purpose has been strictly for aesthetic purposes.

Much research has been done towards fixing the tiles to the roof's structural system. Mortar has been used, a labor intensive method, and a has been shown to provide good strength (Huang, et al, 2009), although at times has led to weakness along the ridge and eave, especially with clay tiles (Building Code Compliance Office, 2006). Mechanical fasteners have been shown to fail along the edge progressing upward (Building Code Compliance Office, 2006); however, the connection of the roof tile to the sheathing underlayment is only part of the problem.

Underlayment failure can also cause premature failure of the roofing system. Once wind can get under the underlayment, the roof tile is just dead weight and will not be able to hold the roof surface in place. Once the underlayment is compromised, the sheathing can be damaged by wind driven rain, wind pressure, and wind borne debris.

The sheathing serves as a membrane on which to apply the weathering and aesthetic finishes. The sheathing also serves the important structural purpose of bracing 
the trusses. Once the sheathing is compromised, not only can the property contents be damaged, but the structure becomes highly compromised due to two reasons. First of all, the trusses, the main stiffness of the roof structure, lose their stability. This will inevitably cause them to reduce their load bearing ability, if they are not lost completely. The trusses also serve to provide lateral support to the wall. Therefore, compromise of the roof can lead to structural compromise in the entire structure (Prescott and Compton, 2014). Secondly, the loss of the sheathing leads to heightened internal pressure. This internal pressure further endangers the rest of the structure. So, it can be seen that even though the roof tiles and underlayment are not structural, i.e. a part of the main wind force resisting system, their failure can lead to overall structural failure. This calls, then, for a holistic approach to residential roofing.

The problem with residential roofs is that all these building components need to be relied upon to ensure safety in the context of the dwelling. It has been shown that when these component and cladding elements are held on tighter, it can lead to structural failure (Cochran and Levitan, 1994). There is a balance that must be struck, but it forces the designer to play with probability of losing the structure or allowing the cladding to become dislodged from the structure and endanger surrounding structures due to wind borne debris. It is needed, therefore, to determine a manner in which to fix the components and cladding to, and indeed become part of the main wind force resisting system.

While research continues to propose new ways to strap the roof to the walls, the problem of the weakness of the roof is not solved. Even if there is not major structural failure, the compromise of the components and cladding will lead to high post-disaster 
costs (Lee and Rosowsky, 2005). Furthermore, merely holding on the roof trusses does not ensure the safety of the occupants. The roof needs to be considered as an entire element, the sum of the parts, where the failure leads to detrimental factors to the entire structure.

If a system could be devised that incorporates all roof features into one complete system, then this devised system can allow the designer to focus on preserving the entire structure. Roof to wall connections actually save the structure and contents if the roofs to wall connections are actually holding on the aesthetic cladding portions as well as the structure. If the water membrane could be placed beneath the structure, then strength protects against property loss and not just the protection of the occupants. The structure then becomes the first defense against water loss, wind borne debris, and other dangers to the structure.

A system has been devised and termed to be Supertile, as it is indeed roof tile in shape; although, the shape is now incorporated into the structure. However, the system entails, not only stiffness, but also connections to actually connect this Suptertile to the walls in such a way that the occupants can be assured that they are indeed safe. Testing has shown that this structural system is able to bear the loads of a typical geographical location that experiences extreme wind force events and also provides strength at the connections.

\subsection{Research Objectives}

The research can then be divided into the following objectives to determine the strength of the novel roofing system: 
1) Create a structural shape that is both aesthetically pleasing and also lends itself to allowing structural reinforcement to be placed into the shape created.

2) Demonstrate that such a system can be both constructible and provide energy efficiency options.

3) Develop flexural strength that is compatible with the stiffness provided by conventional roof trusses.

4) Develop connections, namely roof to wall, panel to panel, and ridge, that create a system that is able to pass the load to the walls and, ultimately, the foundation through the walls.

5) Use the results of the testing to create design or example tables that allow designers to use the results to efficiently consider structures in different geographical regions.

6) Bring the components together in a full-scale test to demonstrate that the panels and connections work together to provide a strong system.

7) Show how the results and tables developed can be used for different structures and geographical regions.

\subsection{Research Methodology}

The research methodology first seeks to use innovative materials that provide sufficient strength while enabling a high level of maintenance efficiency and constructibility. Towards that end, a system is developed that replaces trusses with an embedded beam in the roof panels themselves. This beam is designed to take all loads on the structure as a truss would be designed to do. This beam is designed to fit into the 
natural wave of a barrel roof tile shape. In this way, the embedded beam is not seen from the top surface and has the versatility to be spaced throughout the tile wave shape as needed depending on the design.

The Supertile panel features two main areas: the strong barrel, embedded beam region; and the inter- barrel region (i.e. the area in between the strong barrel sections). As stated earlier, the purpose of the embedded beam is to carry the load and provide stiffness to the system as the trusses do in a conventional roofing system. Using reinforced concrete, as opposed to wood trusses, allows the system to stay thin and free up attic space for the use of the residents (Bricoe, et al, 2010). The purpose of the inter-barrel region is to create a membrane to transfer the load laterally and provide puncture resistance to the system.

The first test level of testing is flexural testing that confirms the design of the strong barrel region. Obtaining a moment for the system allows other members of the system to be designed and creates a baseline of strength, with which the designer can then alter the design parameters as needed. The next step is to create connections for the system. Three connections are evident from a structural perspective: roof to wall connections, panel to panel connection, and a ridge connection. These need to be designed and tested. Obtaining this data is important to creating design tables that allow the designer the ability to quickly solve problems for this system using experimentally verified data.

The connection tests are designed to address specific parameters for each connection. A parametric design allows the designer to choose the design specific to the structure and wind design needs of the local geographical region. As such, the roof to 
wall connection, for instance, can be spaced at an appropriate spacing distance for the structure and region. This allows the Supertile system to be used in many different loading situations in various geographical wind design regions.

Once the individual components are tested, a full-scale test can be created and carried out that tests the system. This data will yield the results needed to confirm the results of the individual tests and demonstrate the system's ability. Using the data from the full-scale test, results can be produced that demonstrate how the panels would be installed in different regions based upon national standards, such as ASCE 7 (ASCE7$10)$.

\subsection{Organization of Dissertation}

The dissertation is setup to follow the course of the study as presented in the sections above. This chapter serves as an introduction both to the problem, presented in this research, and the solution, the novel panel system, Supertile. Chapter 2 follows with the conceptual development of the system. Three features are important to the system: strength, constructibility, and energy efficiency. While the structural results demonstrate the capability of the system, the feasibility and responsibility are presented in the constructibility and energy efficiency. Chapter 3 presents the design paper for the system components. The tests of the individual components of the system and results of the tests will be presented. The paper will end with design tables being formulated that allow the designer to appropriately use the technology produced. Chapter 4 presents the full-scale test, both its setup and results. The purpose of this chapter is to present the full-scale test and to provide a basis for using this novel roofing system in different geographical situations with different structures. The final chapter summarizes the results and 
demonstrates the novelty and scientific contributions of this dissertation. Future research will be documented that provides a direction to take the results produced throughout this study and use them to move the concept forward from an innovative roofing design concept to manufacturing, constructing, and maintaining the Supertile roofing system. 


\section{References}

MCA (2014) "History of Clay Tile" MCA, Superior Clay Roof Tile. <http://www.mcatile.com/history.htm>

Unicrete (2012) "Roof Tiles-History" Unicrete Products Ltd. $<$ http://www.unicrete.com/history.php $>$

Huang, P., Mirmiran, A, Chowdhury, A. G. Abishdid, C, and Wang, T. (2009) "Performance of Roof Tiles under Simulated Hurricane Impact." American Society of Civil Engineers, Journal of Architectural Engineering, March, 2009.

Building Code Compliance Office (2006) "Post Hurricane Wilma Progress Assessment." Miami-Dade County, April.

Prescott, C. L. and Compton, D. L. (2014) "Raise the Roof: A Look at How Your Roof Supports Your Walls and Other Uncommon Knowledge." $15^{\text {th }}$ Annual Windstorm Conference, Orlando, Florida, January 27-30, 2014.

Cochran, L. and Levitan, M. (1994) "Lessons from Hurricane Andrew.” Architectural Science Review, 37, pp. 115-121.

Lee, K. H. and Rosowsky, D. V. (2005) "Fragility Assessment for Roof Sheathing Failure in High Wind Regions.” Engineering Structures, 27, pp. 857-868.

Briscoe, C.R., Mantell, S.C., Davidson, J.H., and Okazaki, T. (2010) "Design Procedures for Web Core Sandwich Panels for Residual Roofs." Journal of Sandwich Structures and Materials, 13, 23-58.

ASCE 7 (2010). “Chapters 26: Wind Load: General Requirements.” American Society of Civil Engineers, 241-258.

ASCE 7 (2010). "Chapter 27: Wind Loads on Buildings_-MWFRS." American Society of Civil Engineers, 259-295. 


\section{THE USE OF ARCHITECTURAL FEATURES FOR HURRICANE MITIGATION IN CONCRETE SUPERTILES}

\subsection{Introduction and Background}

\subsubsection{Tile Roofs}

In their study of Hurricane Andrew effects in Louisiana Cochran and Levitan (1994) noted that there is a trade-off between designing components and cladding to fail in strong winds, thereby reducing the wind load on the structure, and creating resistant cladding connections, thus allowing stronger wind loadings to act on the structure. They noted that larger panel sections performed well, as the wind effects become reduced owing to the spatial non-uniformity of the wind load, and that failures were much more common among roofing than among wall components. It was found that in Hurricane Andrew roof failure was a predominant type of damage, likely caused primarily by windborne debris (Smith, 1992).

In conventional construction tile roofs are problematic for two reasons. First, when fastened with mechanical fasteners, they produce breaks in the roofs water barrier. Water intrusion results in damage to building contents - one of the most significant sources of losses in windstorms -- and creates maintenance issues for the wood elements underneath the underlayment.

Second, roof tiles can be displaced from roofs. Not only does this lead to further damage to the roof, but tiles can become wind-borne debris and endanger surrounding structures. 


\subsubsection{Novel Roofing System}

Roof tiles are advantageous from an aesthetics point of view. Also, they contribute to the structure's requisite stiffness. Their shape allows for convenient mutual connection. By proper design combined tiles can become Supertiles providing stiffness that may replace the stiffness and diaphragm action provided by the roof trusses and the plywood sheathing, which is typically $15.9 \mathrm{~mm}$ (5/8 in) thick.

It is in principle possible to replace the truss by a reinforced concrete beam, the top of which is designed to accommodate a barrel roofing tile. If the beam is cast into the roofing tile, then it acts jointly with the tile. A reinforcing mesh provided within the beam-tile system can supply resistance to puncturing. The Supertile thus created will eliminate the sheathing, trusses, and tiles, while freeing up attic space (Briscoe, et al, 2010). Detailing the panel leads to a watertight barrier and creates superior insulation capability.

In this work a novel roofing system will be presented that allows an architectural element traditionally associated with tiles to play a role in the overall design of the windresistant structure. The system must meet strength, constructability, and energy efficiency requirements. These features will first be considered briefly when presenting the conceptual design of the system. Each feature will then be considered individually.

\subsection{Novel System Features}

The system is developed primarily for strength. Its cost benefits must be assessed by accounting for the system's ability to reduce potential post-disaster losses. The energy efficacy of the system will be assured by specific features to be discussed subsequently. 


\subsubsection{Structural Development}

Titan America Structures and Construction Testing Laboratory has developed a system that could be used for residential and other construction. An initial design concept is shown in Fig. 2.1. The shape was determined on the basis of structural strength and architectural aesthetics considerations. The general shape of the section was designed to take on the form of a tile roof, while providing the requisite moment of inertia. The initial design concept was to form a panel that would span from truss to truss while allowing wider truss spacing to reduce costs. Fiber-reinforced polymer (FRP) was used to resist both negative and positive pressure. An internal FRP reinforced concrete rib was originally proposed as shown in Fig. 2.1. The FRP used was CFRP, C-Grid, C50 1.8 x 1.6 (Chomarat, 2010). The concrete strength at the time of testing was approximately 34.5 $\mathrm{MPa}(5,000 \mathrm{psi})$.

Flexural testing was conducted in both the strong and the weak principal axes to determine the appropriate span length and the distance between trusses. Furthermore, the specimens needed to be tested for both positive (towards the roof) and negative (away from the roof) pressures.

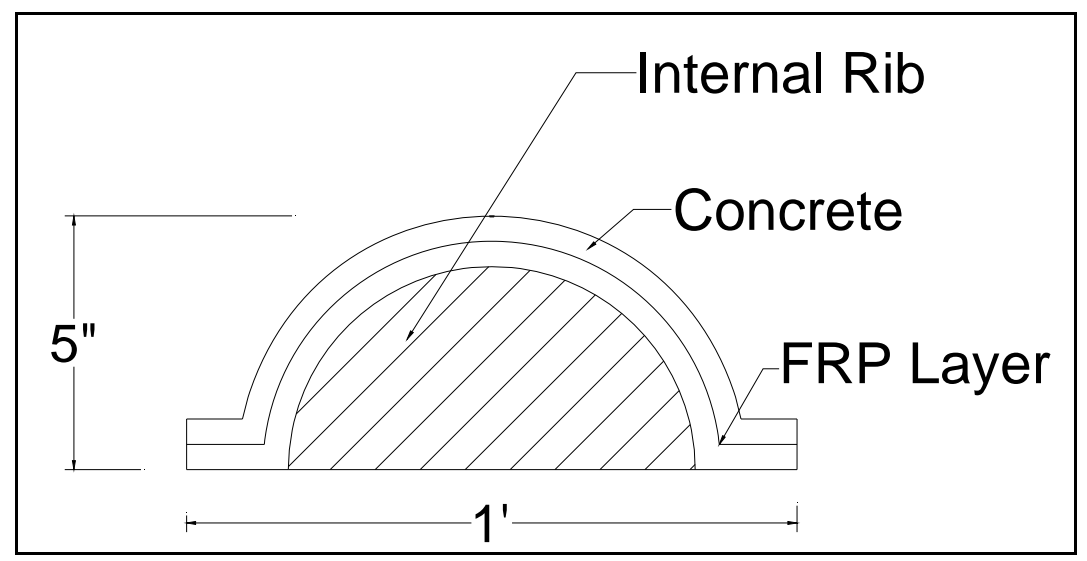

Fig. 2.1 Initial Design Concept 
The testing of the specimens was conducted on a Tinius Olsen Universal Testing Machine as is shown in Figs. 2.2 and 2.3. The load and crosshead movement, which translates approximately as the midspan deflection, were recorded and documented. The crosshead movement was due to deflection in the specimen and seating changes at the supports and load application area.

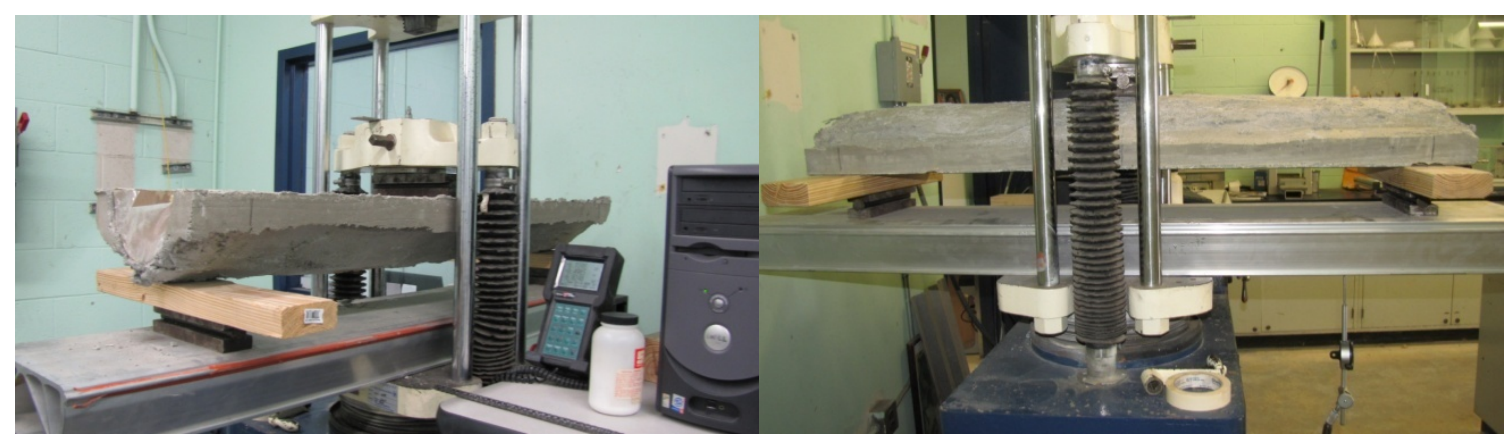

Fig. 2.2 Test Setup for Suction (left) and Pressure (right)

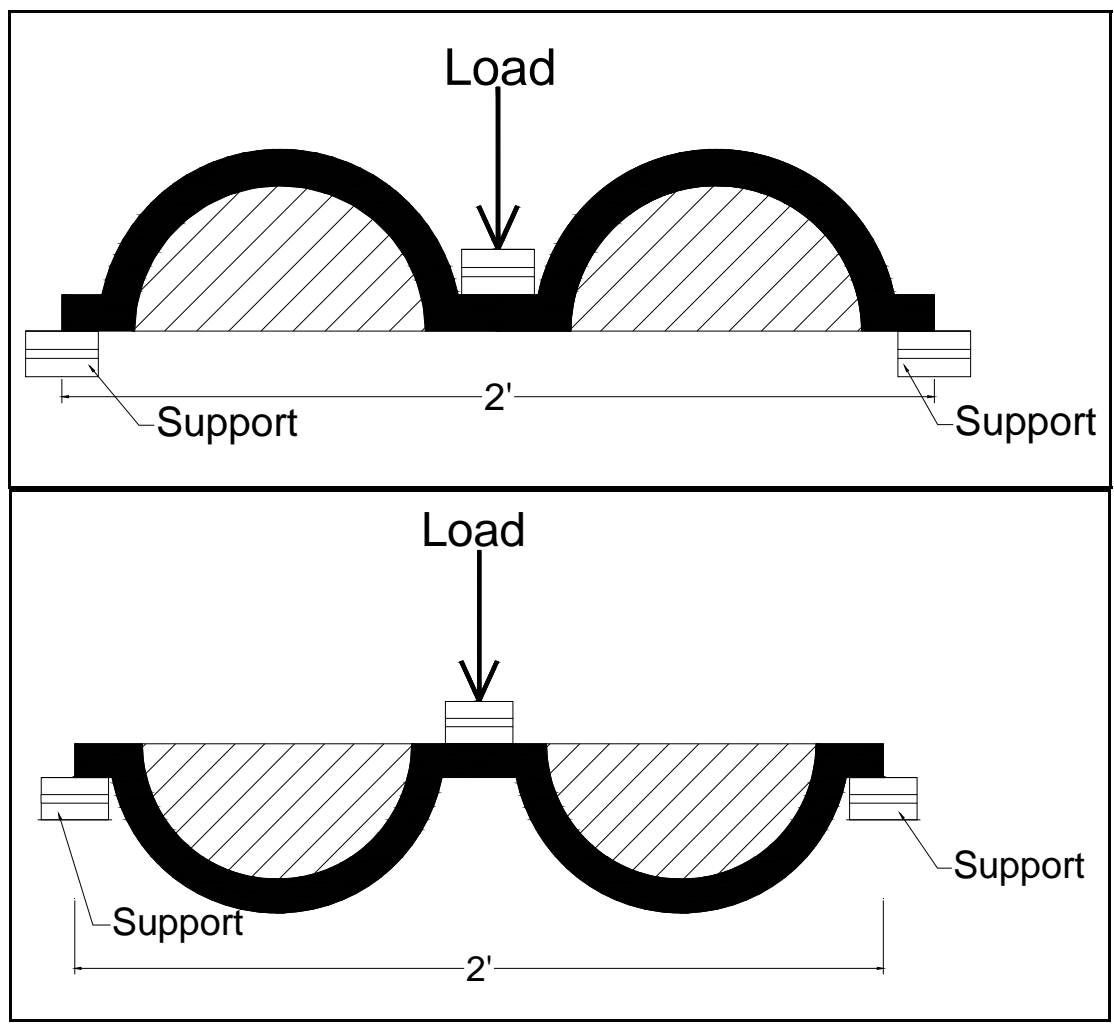

Fig. 2.3 Weak Direction 


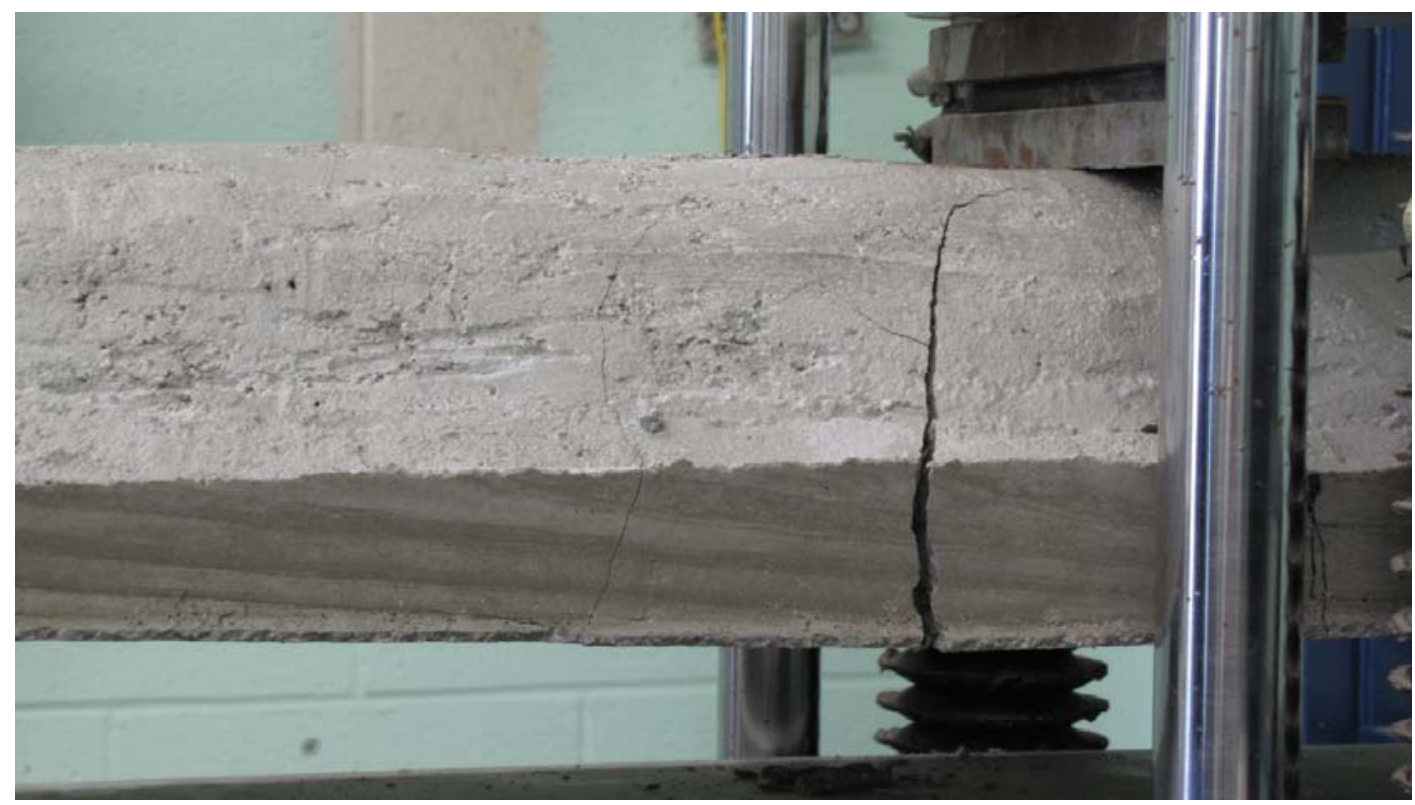

\section{Fig. 2.4 Typical Flexural Cracking in Specimens}

At least two tests for both the weak and strong directions were carried out for both positive and negative pressures. The crosshead movement testing was conducted at $0.0423 \mathrm{~mm} / \mathrm{sec}(0.1 \mathrm{in} / \mathrm{min})$. Testing was stopped after a significant load drop of at least $50 \%$. Typical flexural cracking, which developed before the maximum load, is shown in Fig. 2.4.

\subsubsection{Initial Results}

Cracking in the specimens and seating deflections, tested for both positive and negative pressures, is reflected in the load drops of Figs. 2.5 and 2.6. It can be noted from the change in slope of the moment-deflection curves of Fig. 2.5 that there was an issue with seating. Also, for specimen construction reasons, specimen 1 did not have as high a capacity as the other two specimens. This is likely due to the fact that FRP reinforcement did not follow the curve of the specimen well and underscores the need for better placement of the FRP for concrete casting. 


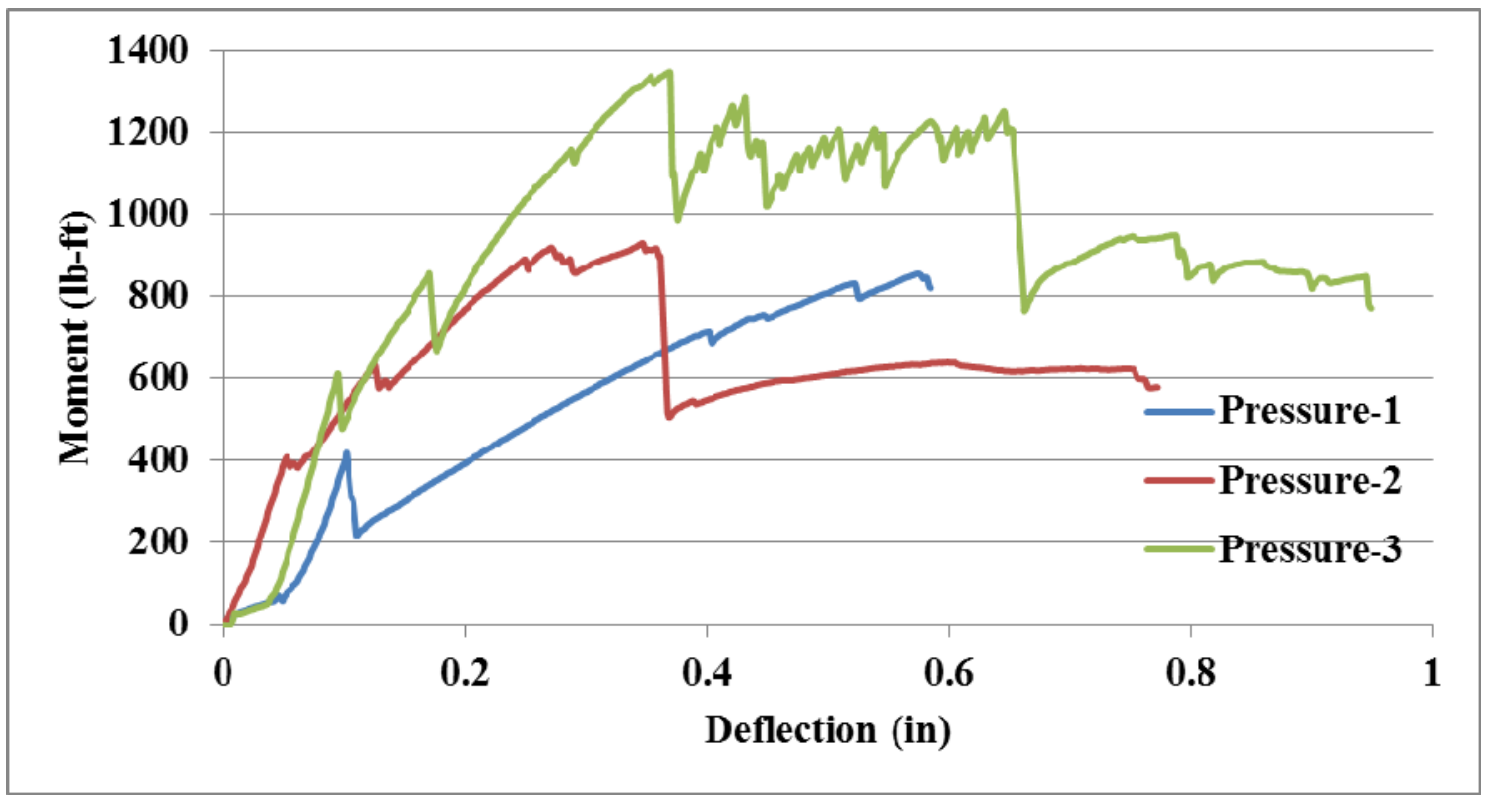

Fig. 2.5 Strong Direction Pressure (Positive pressure)

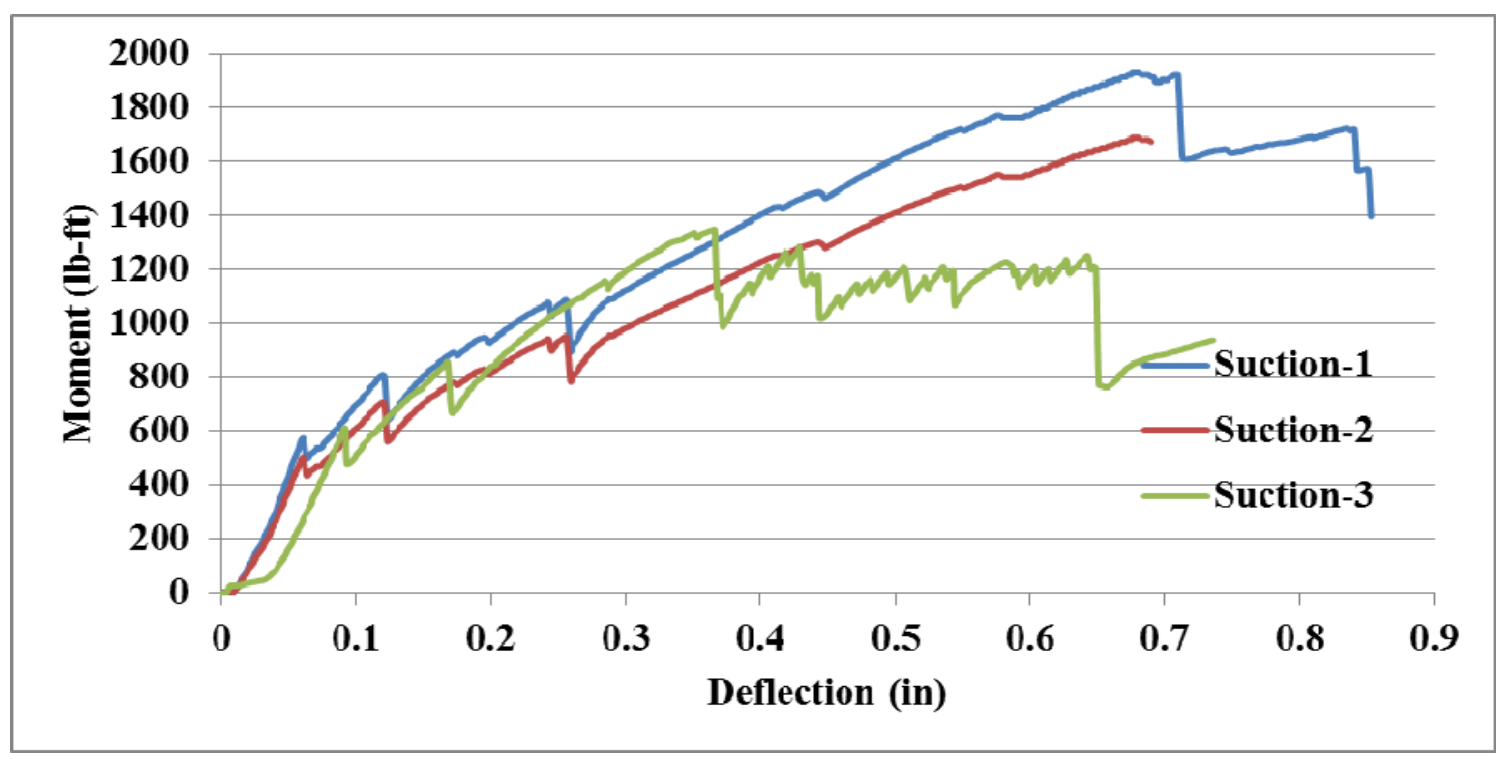

Fig. 2.6 Suction (Negative Pressure)

The specimens tested for suction were regular in their behavior and demonstrated similar stiffness. Fig. 2.6 shows the moment-deflection curves for the suction direction. It should be noted from Figs. 2.5 and 2.6 that the specimens' capacities were nor sufficient to allow spans from the wall to the ridge in a typical home. 
Figures 2.7 and 2.8 show the moment-deflection curves for the weak direction of the specimens tested in the positive pressure direction and negative pressure direction, respectively. They both demonstrate good behavior as the capacity needed is much lower in the weak direction. Capacities of about $0.26 \mathrm{kN} / \mathrm{m}(18 \mathrm{lb} / \mathrm{ft})$ in the downward direction and $0.29 \mathrm{kN} / \mathrm{m}(20 \mathrm{lb} / \mathrm{ft})$ in the upward (uplift) direction were observed.

The capacities observed in the tests are too small for south Florida. They are relatively low because the FRP placement was hard to control between the ridges because of the stiffness of the mesh.

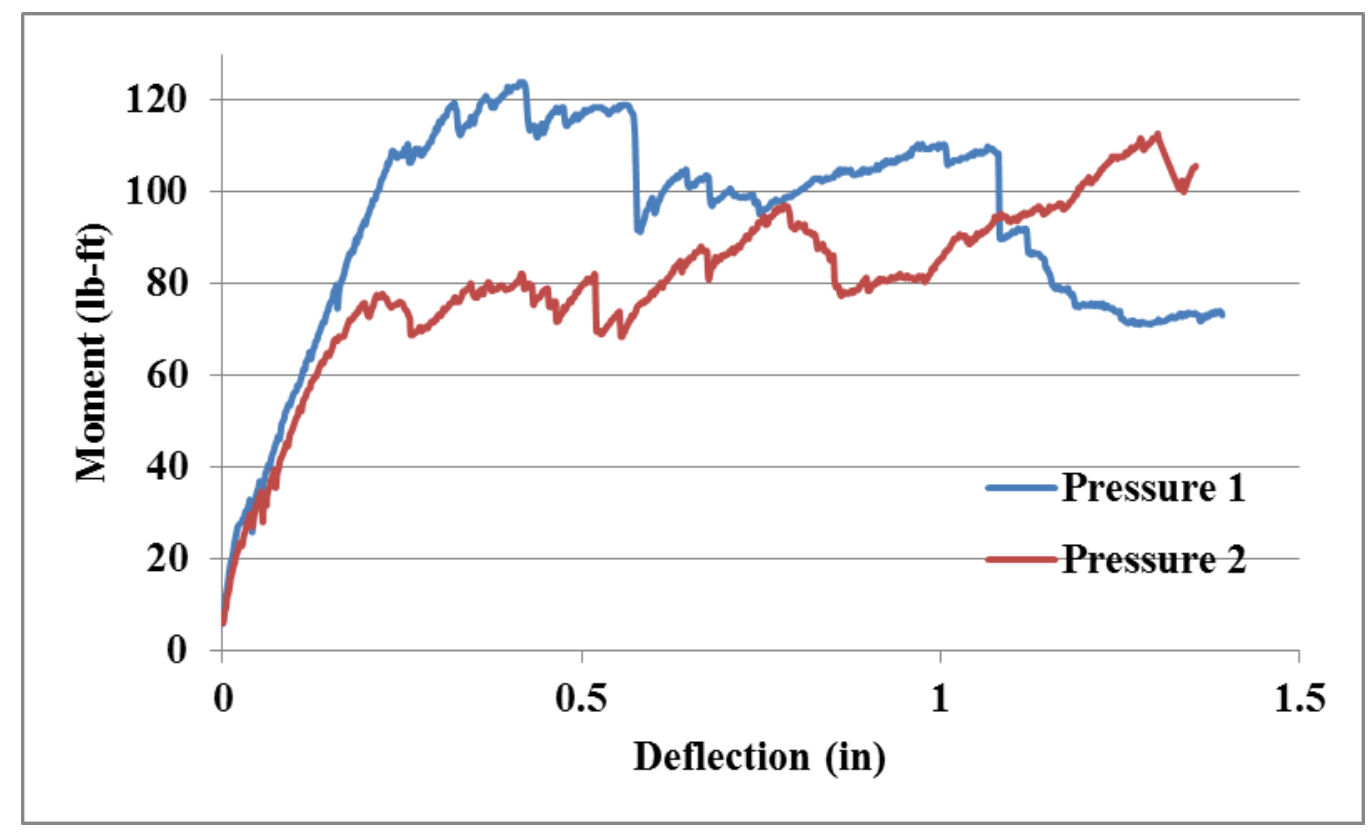

Fig. 2.7 Moment-deflection Curve for Weak Direction Specimens Tested for Pressure 


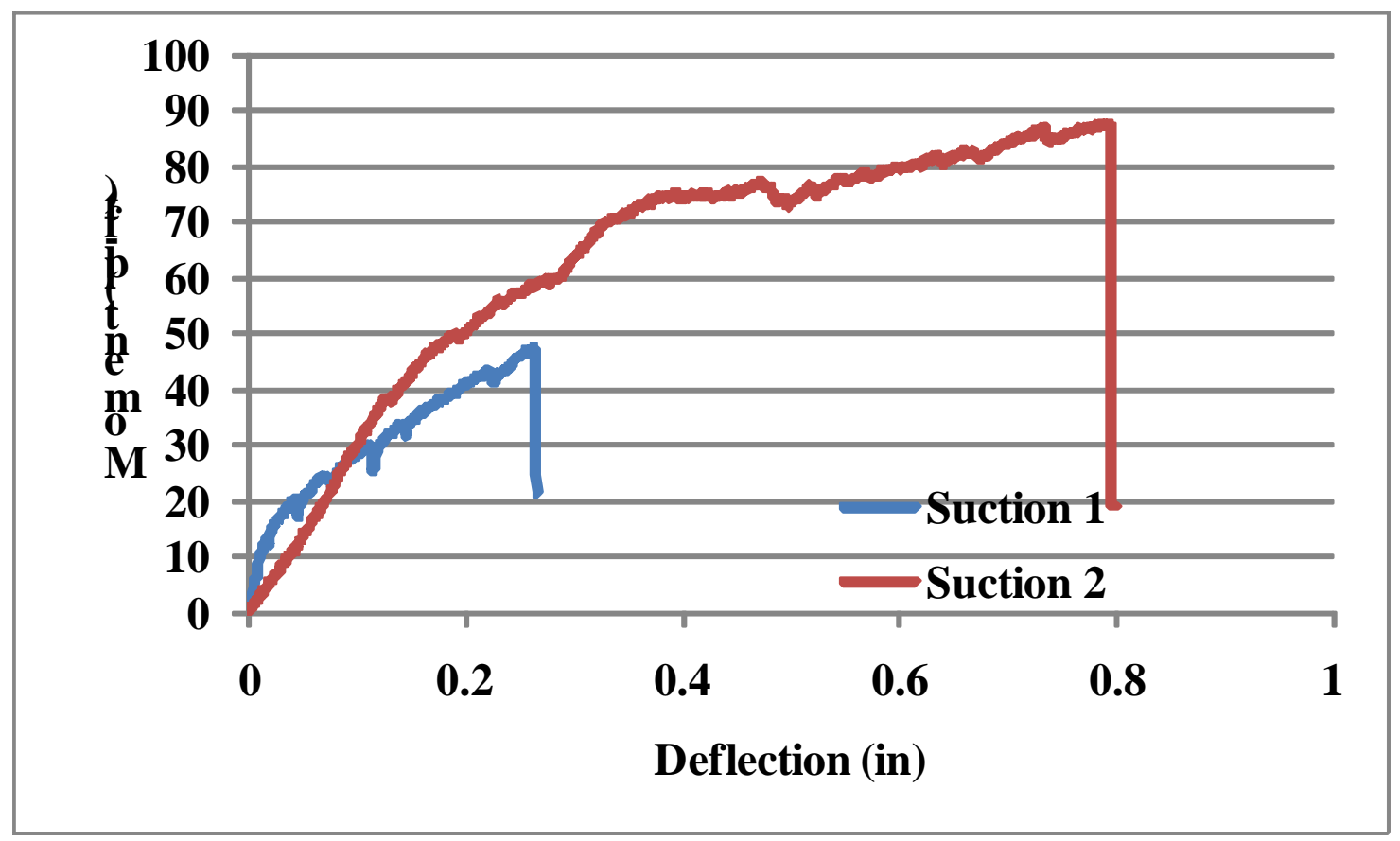

Fig. 2.8 Moment-deflection Curve for Weak Direction Specimens Tested for Suction

Based upon these finding these following recommendations can be made from the initial development stage just described:

- Placement of FRP

The FRP tie-down points need to be such that the required depth is achieved. A more flexible CFRP (carbon fiber-reinforced polymer) could be used in lieu of the C50 grid used in this study. Glass fiber-reinforced polymer (GFRP) should also be considered due to its higher flexibility.

- Shape Mitigation

To make a higher capacity section in the strong direction, different shapes should be analyzed to find a section that can span the whole length from the wall to the ridge. This is important to achieve, since construction joints could result in roof leaks. 
- Constructibility

A construction procedure that is more time efficient is needed. Elimination of the concrete ribs will lead to better, faster construction. The concrete mix, which can require lower slump depending on the mold used, can cause problems in the tight sections. The procedure used did not always result in the aesthetically most satisfying aspect.

\subsubsection{Aesthetic Development}

Research during the aesthetic development phase centered on finding a solution for the placement of the FRP to yield a better result, creating a construction process that yielded a more aesthetic section and using new products in the concrete design to yield a lighter specimen that would be easier constructed. The use of Sonotubes, which were used in the initial development to create the roof curve, was abandoned in favor of a foam mold that would create the desired shape. By using the foam mold, a surface was created that made it easier to tie the FRP into the mold. Tie-wire was used to tie the FRP to the foam molds and hold it in place for casting the concrete. This method was much quicker than the method used in the initial development stage.

The concrete design was also modified by using an integrated color in the concrete to enhance the aesthetics. Also, lightweight aggregates in the mix would reduce the panels' weight. However, this would require stronger vibration. An example of these new specimens can be seen in Fig. 2.9.

The specimens were tested using a Shore Western actuator in Titan America Structures and Construction Testing Laboratory. Load was applied by a moving piston powered by a hydraulic motor. Specimens were placed on concrete blocks that acted as supports as shown in Fig. 2.10. Testing was completed when the load dropped 
significantly. A foam panel was placed upon the specimen in an attempt to distribute the point load from the actuator to the panel in a way that is closer to the area load that wind produces. Deflection was measured using string potentiometers and load was measured with a load cell. A specimen undergoing testing can be seen in Fig. 2.11.

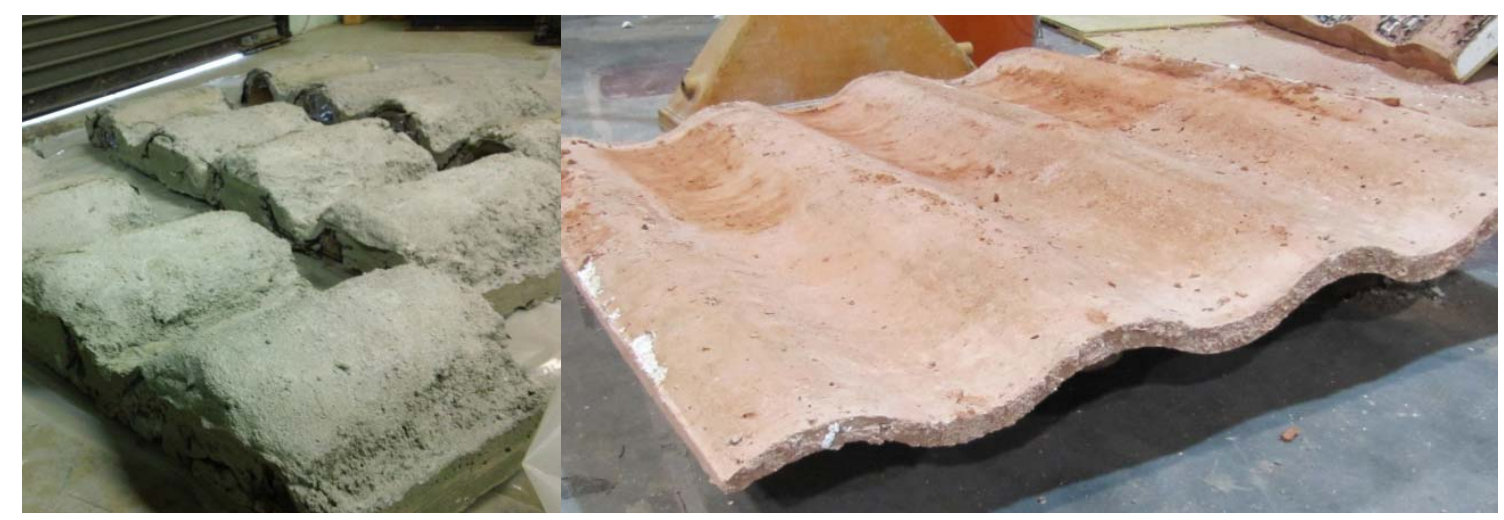

Fig. 2.9 Initial Roof Panels (left) and Foam Shaped Roof Panels (right)

\subsubsection{Results and Discussion}

Two specimens were created and tested. One specimen was somewhat deformed because it did not hold its shape in the mold. This specimen was used to evaluate the test setup. The results of the first test will not be presented here since the specimen did not have realistic dimensions.

The construction method used in the aesthetic development stage was highly superior to the one used initially. It produced a stronger and a much more aesthetically pleasing specimen. Fig. 2.9 shows the aesthetic comparison between the specimens created for the two stages. It can clearly be seen that the aesthetics were greatly improved not only by the color, but also by the texture. 


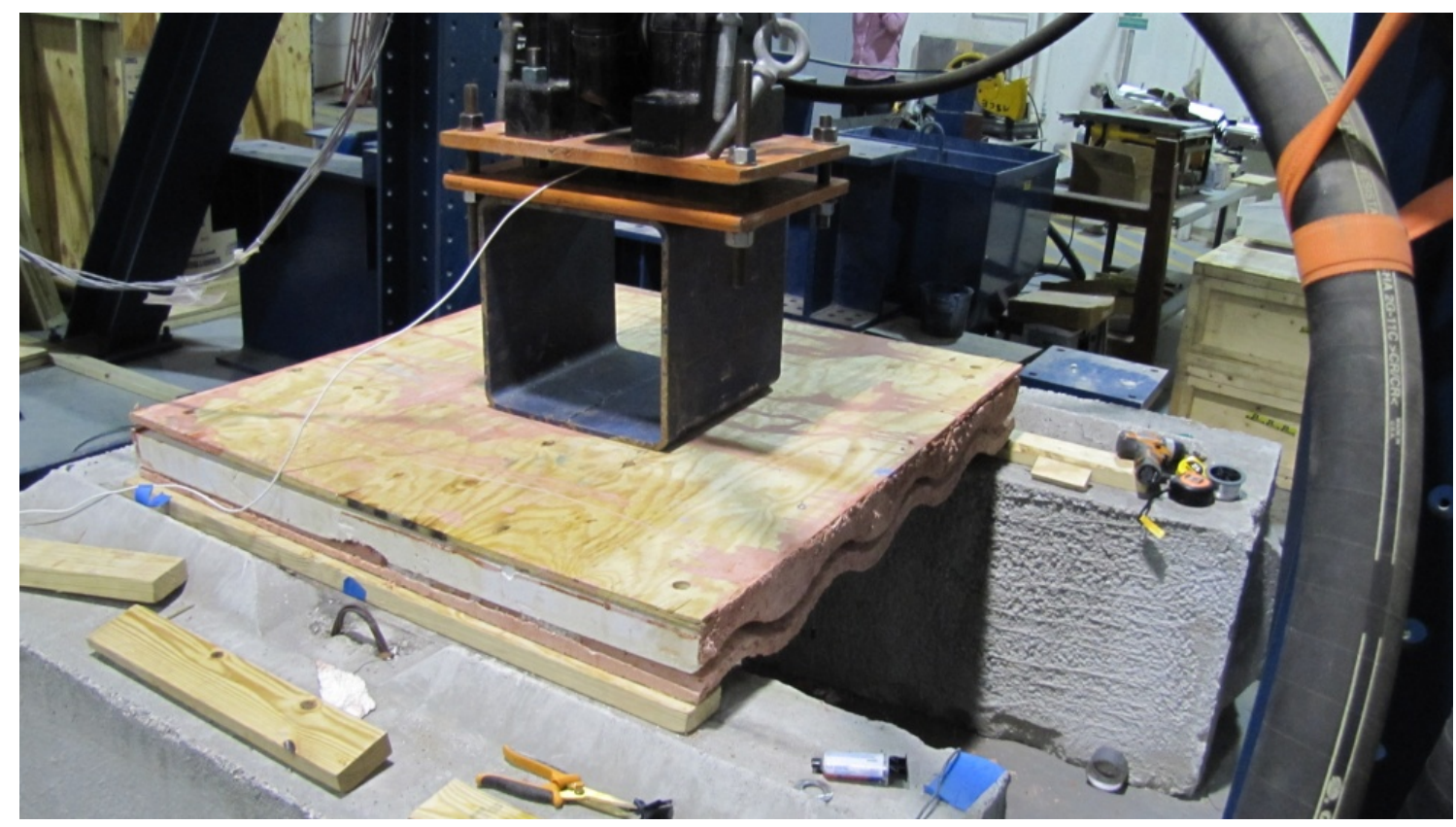

Fig. 2.10 Aesthetically Improvement Test

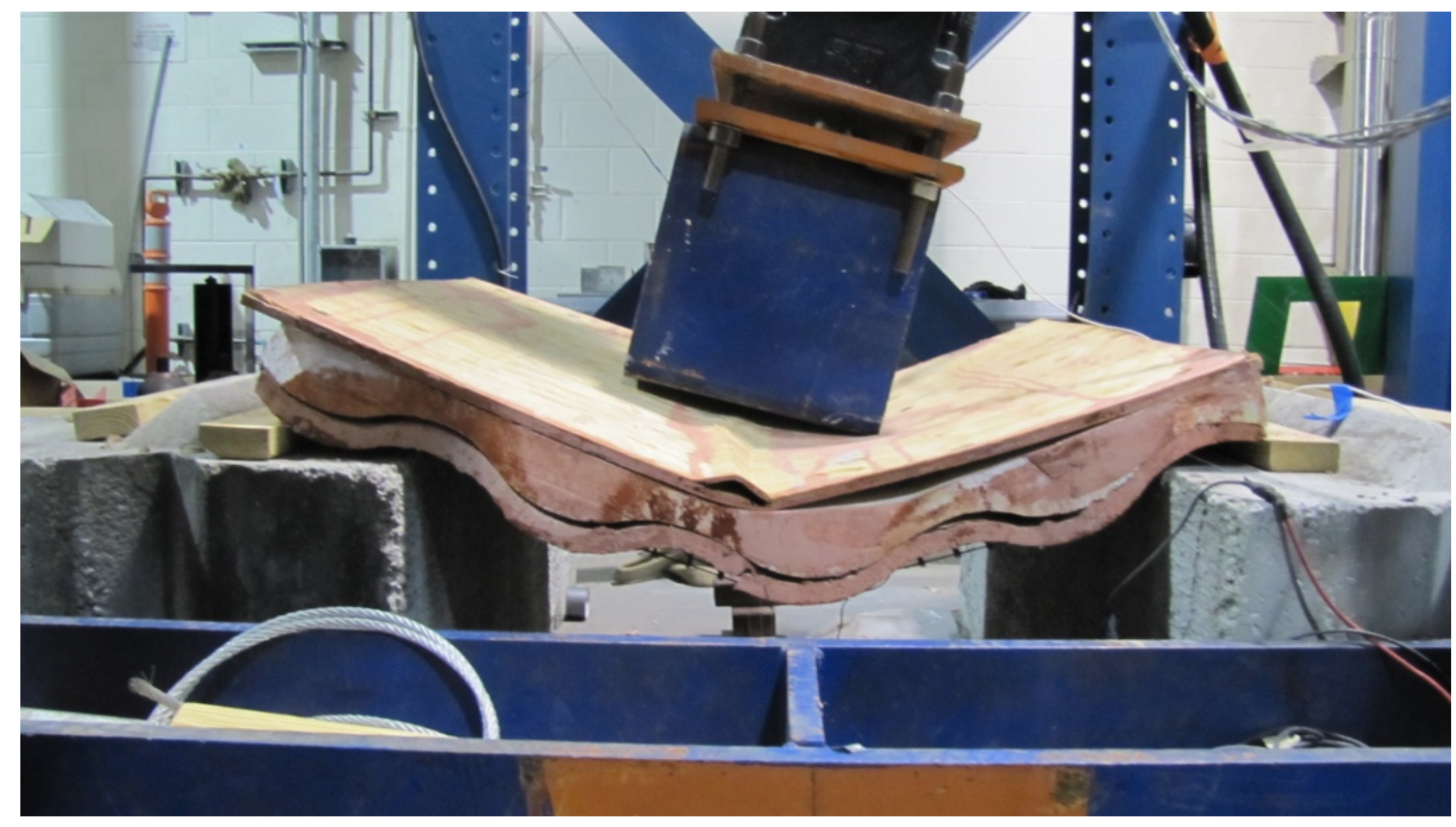

Fig.2.11 Deflected and Failed Specimen

The second specimen demonstrated good load bearing capability and very good ductility. There is a marked improvement both in capacity and ductility with respect to the results of the specimens produced initially. Fig. 2.12 shows the moment vs. 
displacement curves for the two phases together, and demonstrates that the better construction technique improved the load bearing capacity of the panel.

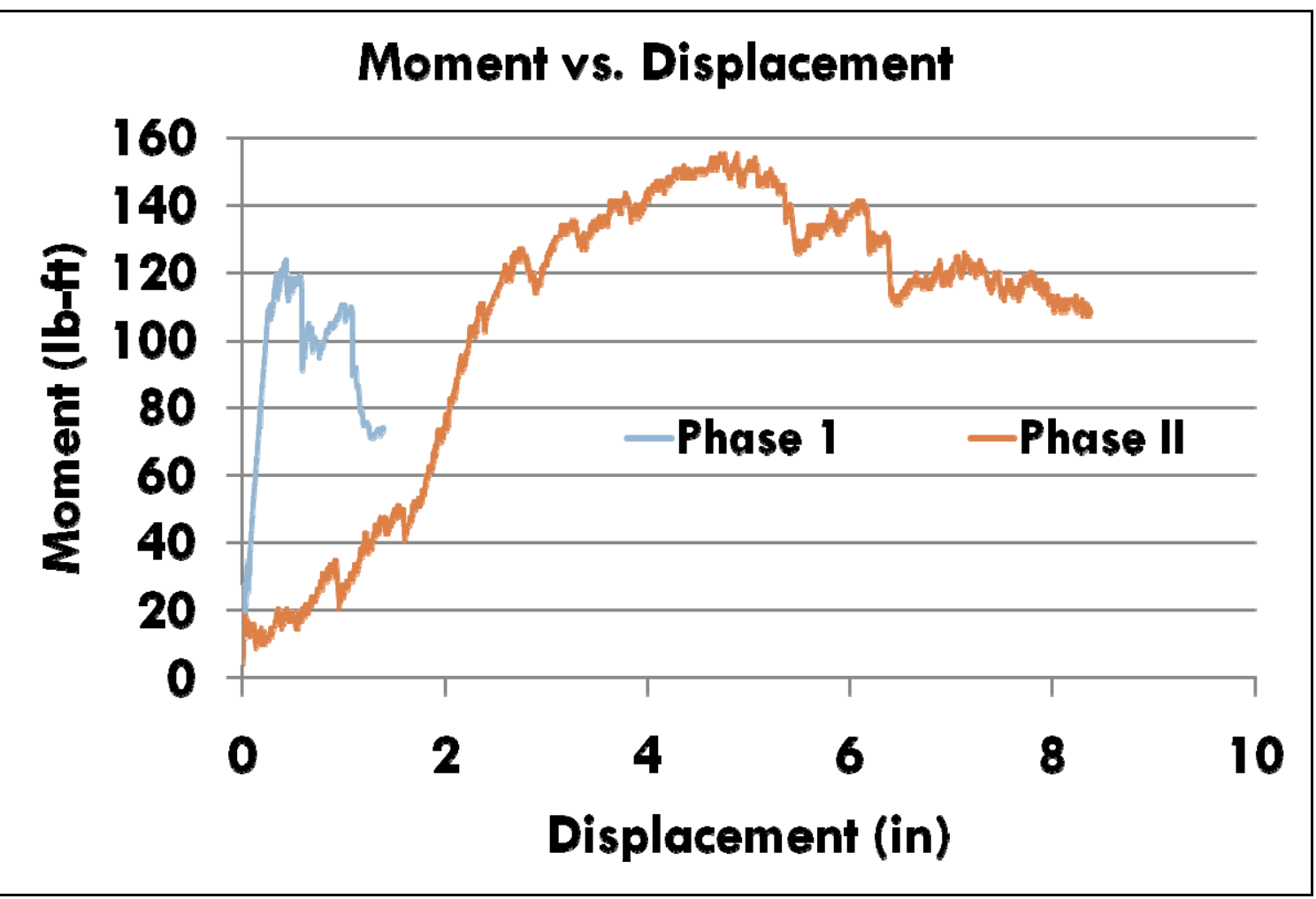

Fig. 2.12 Moment vs. Displacement for the Two Phases (Initial Development [Phase

\section{I]; Aesthetic Development [Phase II])}

However, there was still concern over the construction problem that created voids inside of the molds due to a lack of strong vibration. A regular concrete vibrator cannot be placed inside the molds because it would melt the foam and FRP and possibly overheat. All subsequent castings have been done with a cement and water mixture ensuring that there would be no significant voids. Wallbrators from Lite Form Technologies (Wallbrator TM, 2010) were used to ensure a vibration process that would yield a better specimen. These changes would help to ensure specimens that could attain 
their full capacity. Concrete mix optimization can be done as a part of the general optimization that occurs in the manufacturing stage.

To summarize, progress was achieved in the development of concrete roof panels for hurricane mitigation. The construction was improved by using foams molds to hold the form of the panel and hold the FRP in place. The aesthetics were improved by using the molds and including a colored dye in the concrete mix. The strength was increased by having the construction method hold the FRP in place. With these improvements, it became clear that a system could be created, not just to span in between trusses, but that would eliminate trusses altogether. System development was therefore pursued by using an embedded beam to replace the trusses.

\subsubsection{Strength}

Disasters have historically prompted change to building codes and caused reexamination of the strength of the structure. That is to say, we best realize the deficiencies of a system when it fails. The resulting changes have primarily revolved around strengthening the structure's features in their individual role in the overall structure. That is, roof to wall connections are analyzed and changes effected accordingly. Separately, roof sheathing is connected in different ways using connectors. Roof tiles are connected by using various products or mechanical fasteners.

It is typically more productive to consider the structure holistically. New designs and innovative products should be developed that are not only constructed differently, but also create better load paths for structures. The answer to better structures is not a larger section or stronger connectors, but a better idea. 
For instance, the shape of a roofing tile provides a good shape to achieve favorable moments of inertia. The creation of a continuous structure allows the diaphragm to also provide stiffness and to contribute to aesthetics. The weakness of typical roofing construction comes from the weakness of the connections, especially the roof to wall connections. However, in the system being proposed here, connections do not have to be located at the trusses, but can be placed at any point along the length of the wall, and as frequently as necessary. And these connections do not need to be made between wood elements, but can be built into the walls, so that a mechanical connection can hold the roofing panel to walls and provide continuity between the roof and the walls. Also, the tile connections are eliminated and the concrete surface is aesthetically satisfying while not endangering surrounding structures in high wind situations.

\subsubsection{Cost}

The cost of the roof panel can be measured both in terms of material costs and of the benefits that a strong Supertile roofing system can bring. First, the roofing system being proposed is not a system that is put in place of the roofing tile. Rather, it replaces the conventional roof while preserving its aesthetic character. It is anticipated that the initial costs would be higher for the proposed system than for the conventional system. However, conventional roofs are very labor intensive. As such, many contractors become involved in the placement of conventional roofs and much time is involved on-site with the placement of the trusses, the sheathing, and then the installation of the underlayment and aesthetic finish. On the other hand, the proposed roofing system can be mass produced and installed in a relatively short period of time without being labor intensive. 
In addition, insurance benefits are expected, as most claims are associated with roof damage. This benefit, and the benefit due to the structure being safer, is one of the greatest reasons in favor of a new system. The costs of strong wind events are well documented, and a reduction of these costs to individual owners and to society is an important consideration. An initial cost comparison is presented later.

\subsubsection{Energy Efficiency}

Energy efficiency is an important aspect of any residential roofing member. Typically, the insulation of a residential structure fits between roofing members such as trusses. This system though creates energy gaps that allow heat to infiltrate the roofing system. One of the major problems with residential construction insulation is that it is performed inconsistently and depends largely on the person installing the insulation. (Harley, 2005) There are other factors that play a role in the effectiveness of residential construction's insulation. Because the insulation is installed between the rafters, the Rvalue is hard to calculate, as the value cannot merely be averaged.

The system being presented here removes all wood framing and allows the insulation to be placed directly onto the roof surface from underneath. By either placing foam boards or spray on insulation, a continuous insulation layer is created. With further development, the foam can even be used as a sort of stay-in-place form, first establishing the shape of the structure, then providing the needed energy efficiency. Once again, the multi-purpose of roofing aspects leads to a credible, sustainable design.

The American Society of Heating, Refrigerating and Air-Conditioning Engineers (ASHRAE) provides guidance as to the R-value that is suitable for non-residential structures. ASHRAE 189.1P recommends an R-value of 25 (ASHRAE, 2011). The North 
American Insulation Manufacturers Association (NAIMA) provides recommendations for residential structures (NAIMA, 2014). While typical residential construction may have difficulty in meeting such a standard, the system being proposed here can provide the needed R-value without having thermal bridging losses.

\subsection{Strength}

Strength is created by using the architectural shape of the roof tile. The wave of the tile allows for beams to be embedded inside of the shape of the wave. This embedded beam is large enough to allow for reinforcement to be placed inside of the wave without affecting the aesthetics. The beam can be spaced and repeated as needed per the design requirements. The following section details the process that enables the shape of a tile to create a system of waves that allows for the concept of the embedded beam.

\subsubsection{Design}

The design for the panel system starts with the shape of a roofing tile, such as the one shown in Fig. 2.13. The shape can change based on local architectural styles. However, the shape shown is a good representation as it reproduces the repetitive wave tile pattern seen in many roofs. As the wave progresses, different portions can be filled in to form embedded beams, or strong barrel sections. The spacing or occurrence rate of these embedded sections can vary based on particular needs and design parameters. 


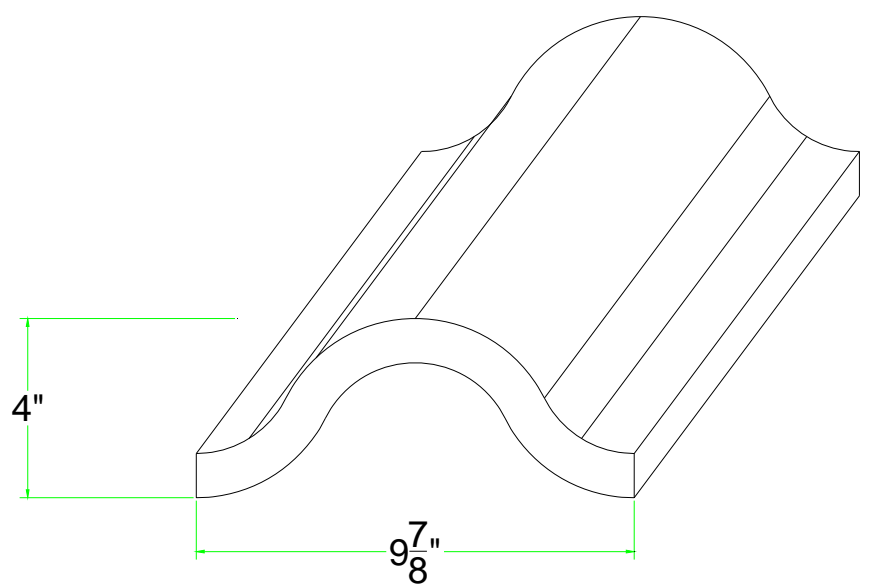

(a)

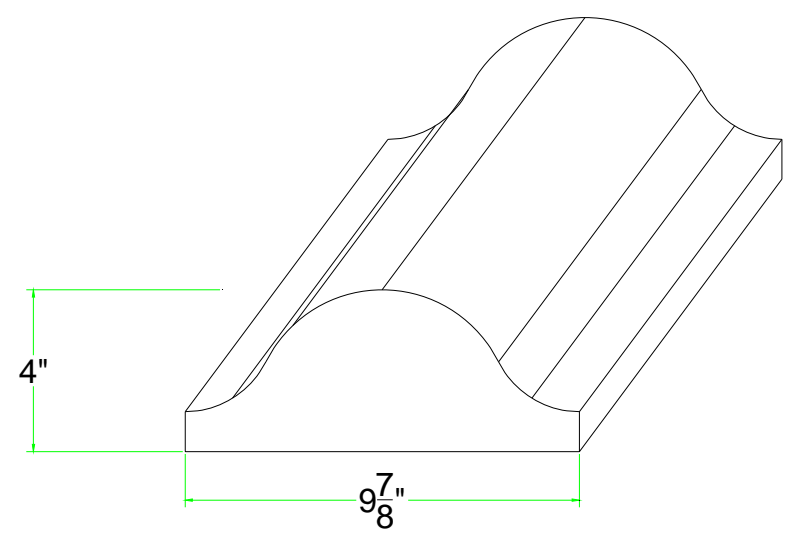

(b)

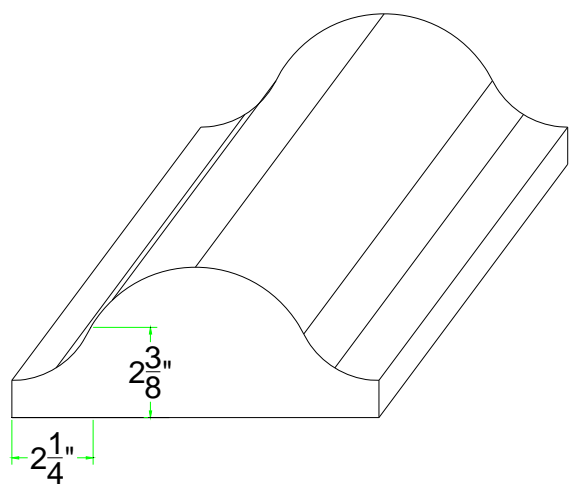

(c)

Fig. 2.13 Converting a Tile Shape into an Embedded Beam Size: (a) demonstrates the tile shape; (b) demonstrates the tile shape fill-in for an embedded beam; (c) shows that the shape can be broken into finite sections for design purposes. 
The total width of the section is just less than $254 \mathrm{~mm}$ (10 in.). The shape was divided into small portions, with a width of $6.4 \mathrm{~mm}(0.25 \mathrm{in}$.$) and the height of the$ element measured at this point, such as is seen in Fig. 2.13(c), where $60.3 \mathrm{~mm}(2-3 / 8$ in.) is measured at $108 \mathrm{~mm}(4-1 / 4 \mathrm{in}$.$) . All of these data points are used to find the height for$ each element over the total length of the section, as is shown in Table 2.1. Using curve setting, either manually or by use of conventional software, curves can be superimposed on the resulting graph of the data points found by use of the measurements described above. The resulting curve is shown as a graph in Fig. 2.14. Using the curves, the areas under the curves can be integrated, so that Whitney stress block analysis (Wight and McGregor, 2009) can be used and information found from the graph such as a stress curve.

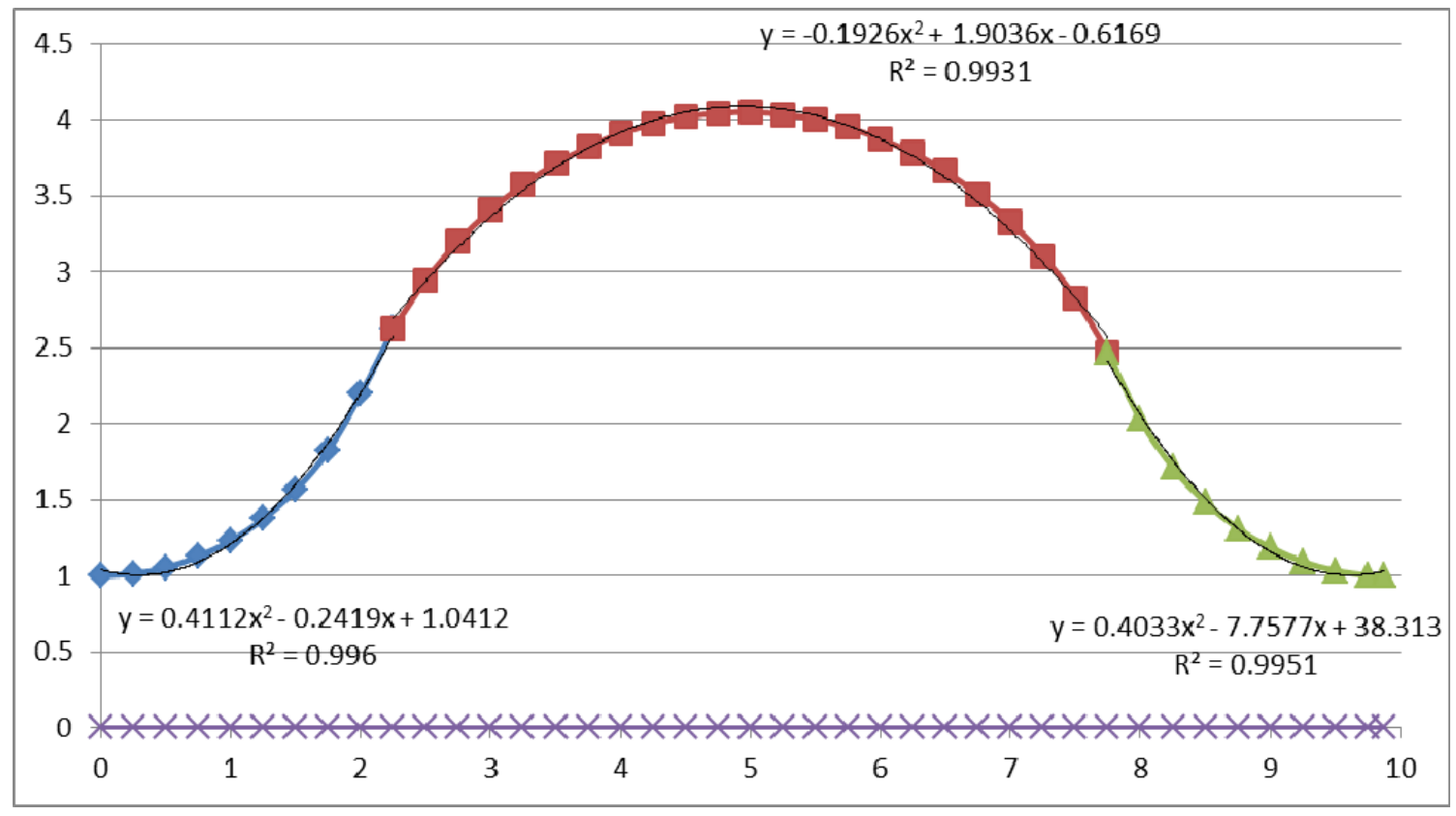

Fig. 2.14 Showing the Tile Shape as a Graph for Structural Analysis 


\section{Table 2.1 Section Development for a Given Section}

\begin{tabular}{cc}
\hline \multicolumn{2}{c}{ Section Development } \\
\hline $\begin{array}{c}\text { Position on Section } \\
\text { (in.) }\end{array}$ & $\begin{array}{c}\text { Height Measured } \\
\text { (in.) }\end{array}$ \\
$\mathbf{0}$ & 1 \\
$\mathbf{0 . 5}$ & 1.05469 \\
$\mathbf{1}$ & 1.23047 \\
$\mathbf{1 . 5}$ & 1.56641 \\
$\mathbf{2}$ & 2.19531 \\
$\mathbf{2 . 5}$ & 2.94531 \\
$\mathbf{3}$ & 3.40625 \\
$\mathbf{3 . 5}$ & 3.71094 \\
$\mathbf{4}$ & 3.91016 \\
$\mathbf{4 . 5}$ & 4.01953 \\
$\mathbf{5}$ & 4.05078 \\
$\mathbf{5 . 5}$ & 4.00391 \\
$\mathbf{6}$ & 3.875 \\
$\mathbf{6 . 5}$ & 3.66016 \\
$\mathbf{7}$ & 3.32813 \\
$\mathbf{7 . 5}$ & 2.82813 \\
$\mathbf{8}$ & 2.02734 \\
$\mathbf{8 . 5}$ & 1.48438 \\
$\mathbf{9}$ & 1.1875 \\
$\mathbf{9 . 5}$ & 1.03516 \\
$\mathbf{9 . 8 7 5}$ & 1 \\
\hline & \\
\hline
\end{tabular}

A section was designed as was described in the previous paragraphs, using glass fiber reinforced polymer (GFRP) as the main longitudinal reinforcement. GFRP has the added benefit of being lightweight and ductile. Carbon fiber-reinforced polymer (CFRP) mesh was used as the transverse reinforcement. While contributing to the flexural strength, the transverse reinforcement is in place to protect against puncture. We used Cbar \#4 bars as the GFRP component and C-grid as the CFRP component (Marshal Technologies, 1999). The resulting section was as shown in Fig. 2.15. It should be noted that FRP has a low glass transition temperature and insulation may be need around the 
reinforcement to protect against fire (Benichou, $\mathrm{N}$ et al, 2010). However, this was not considered in this study.

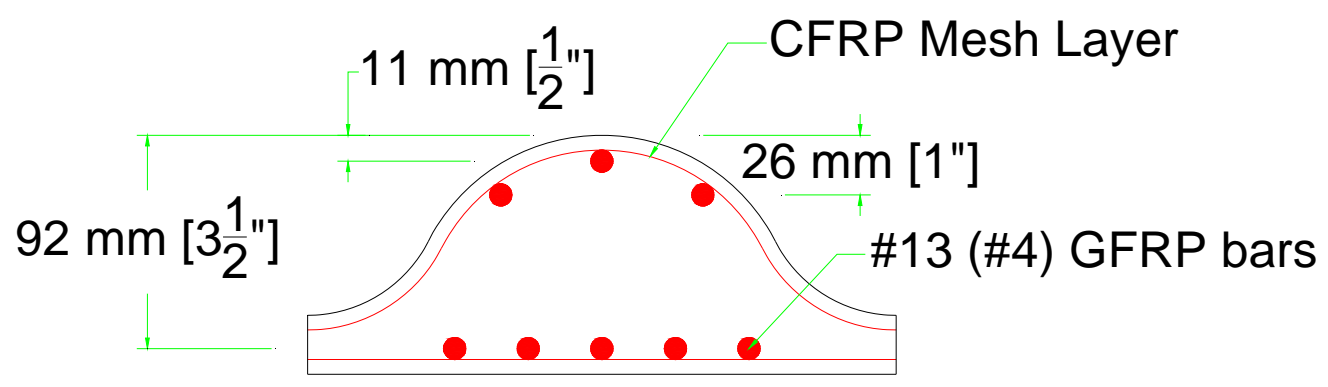

\section{Fig. 2.15 Strong Barrel Section}

The specimen must be capable to handle stress in both positive pressure and negative pressure scenarios. The uplift condition that pulls on the roof to wall connections is due to wind-induced suctions. As can be seen in Fig. 2.15, reinforcement is provided for bending in both directions.

\subsubsection{Testing}

The system was tested to check that it had enough bending capacity for a span of at least $4.57-6.10 \mathrm{~m}(94.515-20 \mathrm{ft})$, i.e., the span from wall to ridge in a typical residential home. The test was carried out as shown in Fig. 2.16. An actuator system with a reaction frame tied down to a structurally strong floor was used to apply the load.

The load was measured using a load cell placed in series with the actuator's ram. The deflection was measured with the actuator's LVDT and a string potentiometer placed at the midspan of the specimen. As the specimen was simply supported, the maximum moment and the maximum deflection occur at midspan. The loading was applied under displacement-controlled conditions until there was a drop in the magnitude of the load. 
Four specimens were tested to verify the flexural capacity of the section. Two specimens were loaded for positive pressure conditions and two for negative pressure conditions. The demand is lower for the negative pressure case since the dead load is applied in the direction of the positive pressure. The dead load is beneficial insofar as it is opposed to the uplift. This is the case to a far lesser extent for conventional roofing tiles.

The system was structurally sound for both the positive and negative loading conditions. The mode of failure was compression-controlled flexure for both positively loaded specimens. Under negative pressure, one specimen failed in compressioncontrolled flexure while the second specimen failed in shear. The failure modes are shown in Fig. 2.17. The maximum moment experienced by both specimens is shown by the moment-deflection curves of Fig. 2.19 b. This maximum moment is induced by the combined dead load, live load, and wind load. Building codes should be used to determine the required moment capacity.

As an example, the Florida Building Code load combinations for load and resistance factor design are (FBC 2010):

Load Combination 1: $0.9 D+1.0 \mathrm{~W} \quad$ (using wind uplift)

Load Combination 2: $1.2 D+0.5 L_{R}+1.0 \mathrm{~W}$ (using wind downward pressure)

Load Combination 3: $1.2 D+1.6 L_{R}+0.5 W$ (using wind downward pressure) 

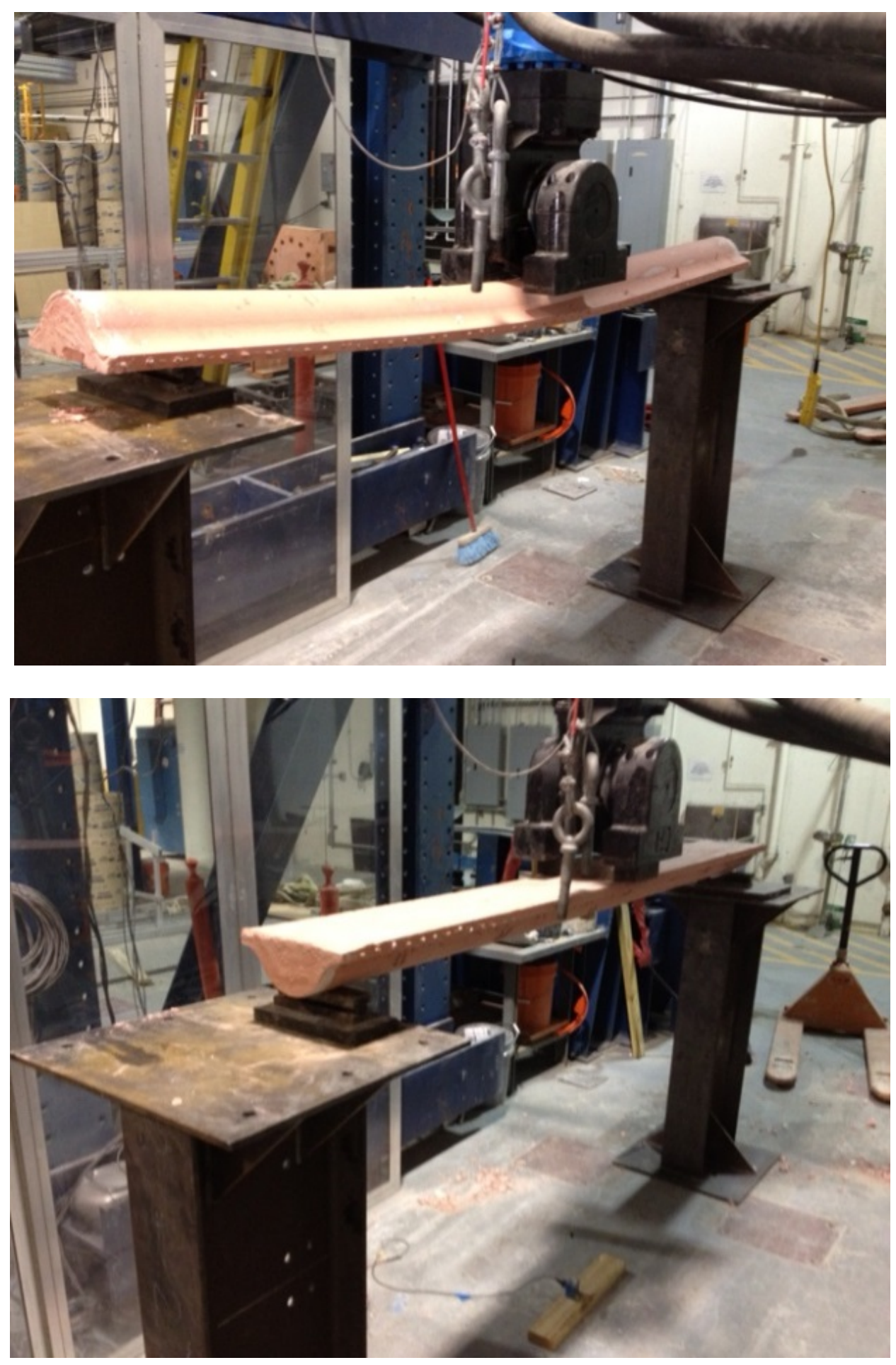

Fig. 2.16 Strong Barrel Load Test (Positive pressure, left; negative pressure, right) 


\subsubsection{Results}

Based upon the weight of the specimen, the live load from the code, and different combinations from the ASCE 7 Standard (ASCE 7, 2010), the maximum effects can be determined for any given region.

To use the Florida Building Code as an example, the roof live load is taken to be $958 \mathrm{~Pa}\left(20 \mathrm{lb} / \mathrm{ft}^{2}\right)$. The dead load depends upon the weight of the concrete. The concrete produced in our experiment was a combination of water, cement, and concrete dye. The water to cement ratio was about 0.5 . Due to the fact that aggregates were not used in the mix, high early strength was possible. This resulted in a weight of about $6,129 \mathrm{~Pa}$ (123 $\left.\mathrm{lb} / \mathrm{ft}^{2}\right)$ and a compressive strength at testing of about $55.85 \mathrm{MPa}(8,100 \mathrm{psi})$. The wind load can be determined for three cases. In all cases, the wind speed being considered was $121 \mathrm{~m} / \mathrm{s}$ (175 mph), a representative wind speed according to ASCE 7-10 for the high velocity wind zone of Miami-Dade county.

\subsubsection{Loading Conditions Considered}

\subsubsection{Maximum Uplift}

In Equation 1 positive internal pressure is used, based on an internal pressure coefficient of 0.55 for partially enclosed structures, according to ASCE 7. The span considered is $5029 \mathrm{~mm}$ (16.5 ft.) (from wall to the ridge, representative for a typical residence). The results, as they relate to this mode of loading, will be discussed in depth in subsequent chapters.

\subsubsection{Imbalanced Loading}

The second loading scenario corresponds to loading in which the windward and leeward panel experience positive and negative pressure, respectively. The internal 
pressure coefficient is -0.55 . The results, as they relate to this mode of loading, will be discussed in depth in subsequent chapters.
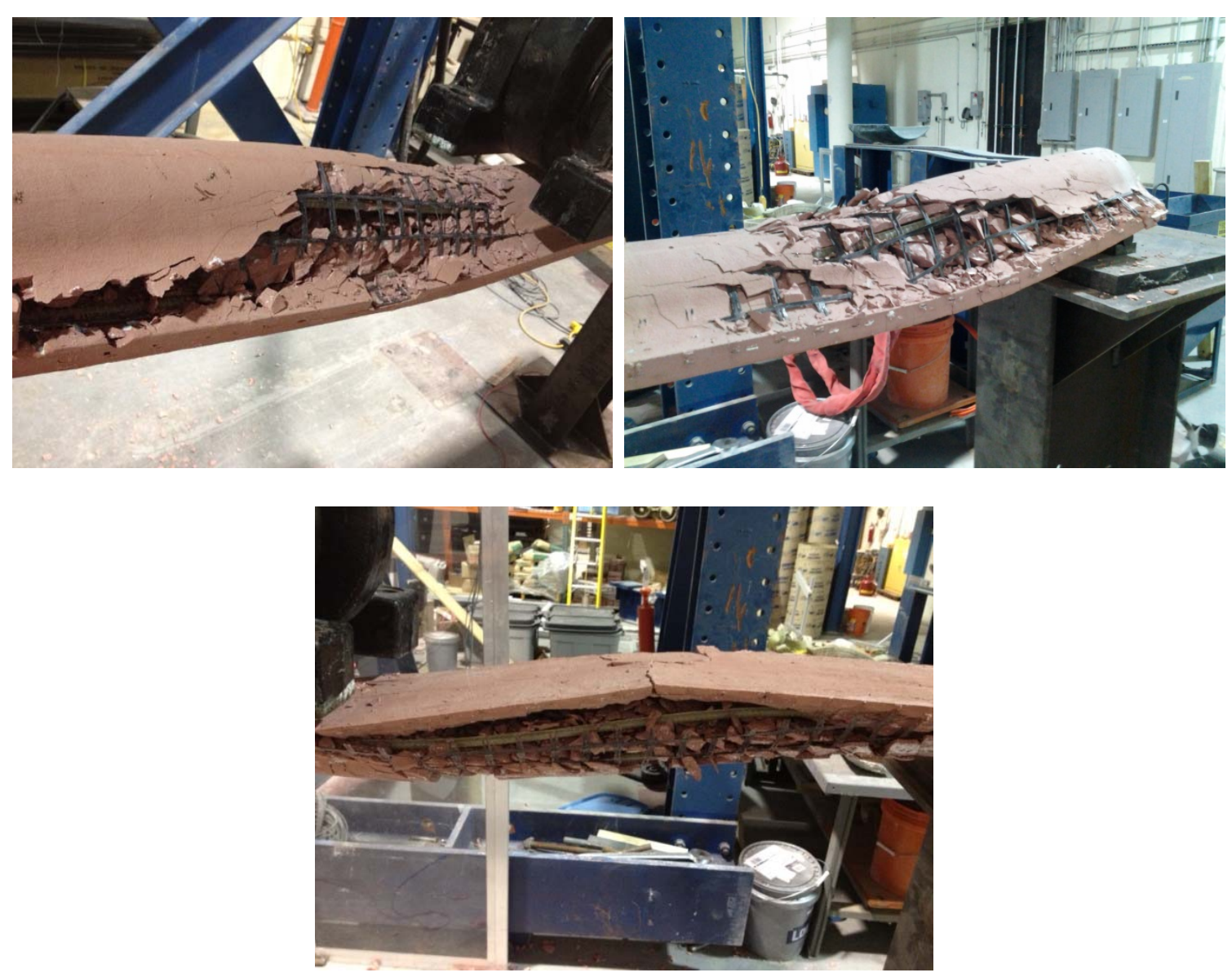

Fig. 2.17 Specimen Failure Modes

\subsubsection{Maximum Positive Pressure}

Finally, the loading scenario is considered that corresponds to maximum positive pressure for each panel and negative internal pressure. The goal of this scenario is to determine the maximum positive value for the leeward panel. Together these five scenarios present the loading conditions for the tested specimens. The results, as they relate to this mode of loading, will be discussed in depth in subsequent chapters. 


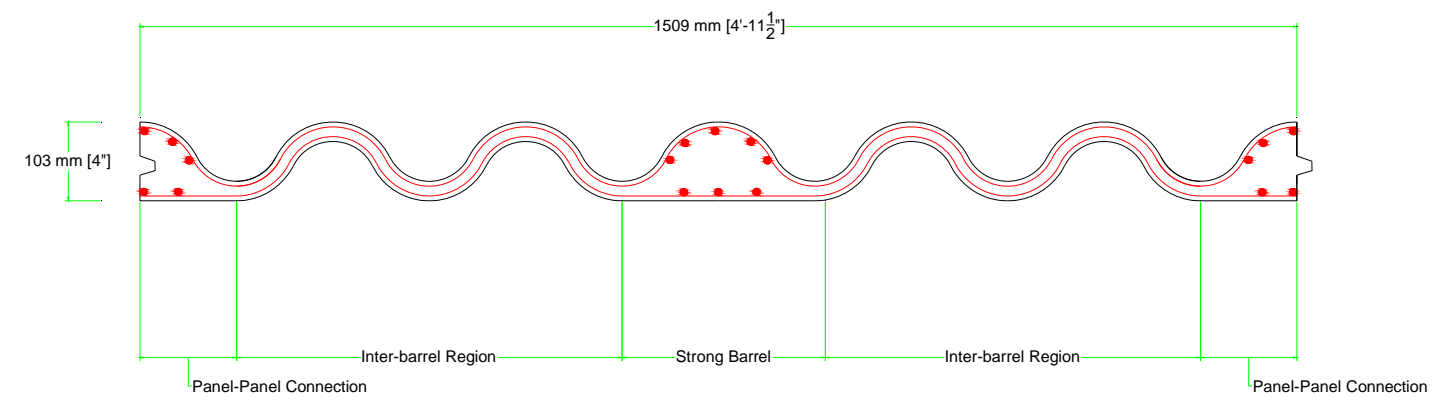

Fig. 2.18 Example of the Tributary Loading Applied to Each Strong Barrel Section 2.4 Constructability and Insurance Benefits

Constructability refers here to a fast and easy method to construct a residential roof, while using only bone contractor. The benefits that come from intangible cost reduction will result from insurance benefits that would help to allay any initial costs and create a shorter payback period.

\subsubsection{Constructability}

The constructability of the Supertile system allows for quicker construction due to the fact that only one contractor is necessary. The product arrives on-site as one entity, and the roof can be completed in one day. The construction sequence is described next. Figure 2.20 describes the anticipated construction sequence. Figure 2.20 (a) shows that the first panel is supported by one wall and shored in place. The crane then retrieves the opposite panel. For quicker construction, two cranes may be utilized. Once the first panel is in place, the bottom ridge plate is secured to the bottom of the panel. Then the second panel is put in place and secured to the opposite wall and to the bottom ridge plate. This construction step is illustrated in Fig. 2.20 (b). The shoring must stay in place until the 
top ridge piece is attached. Fig. 2.20 (c) demonstrates the completed construction. It is anticipated that the construction of the entire roof could take place in one day.
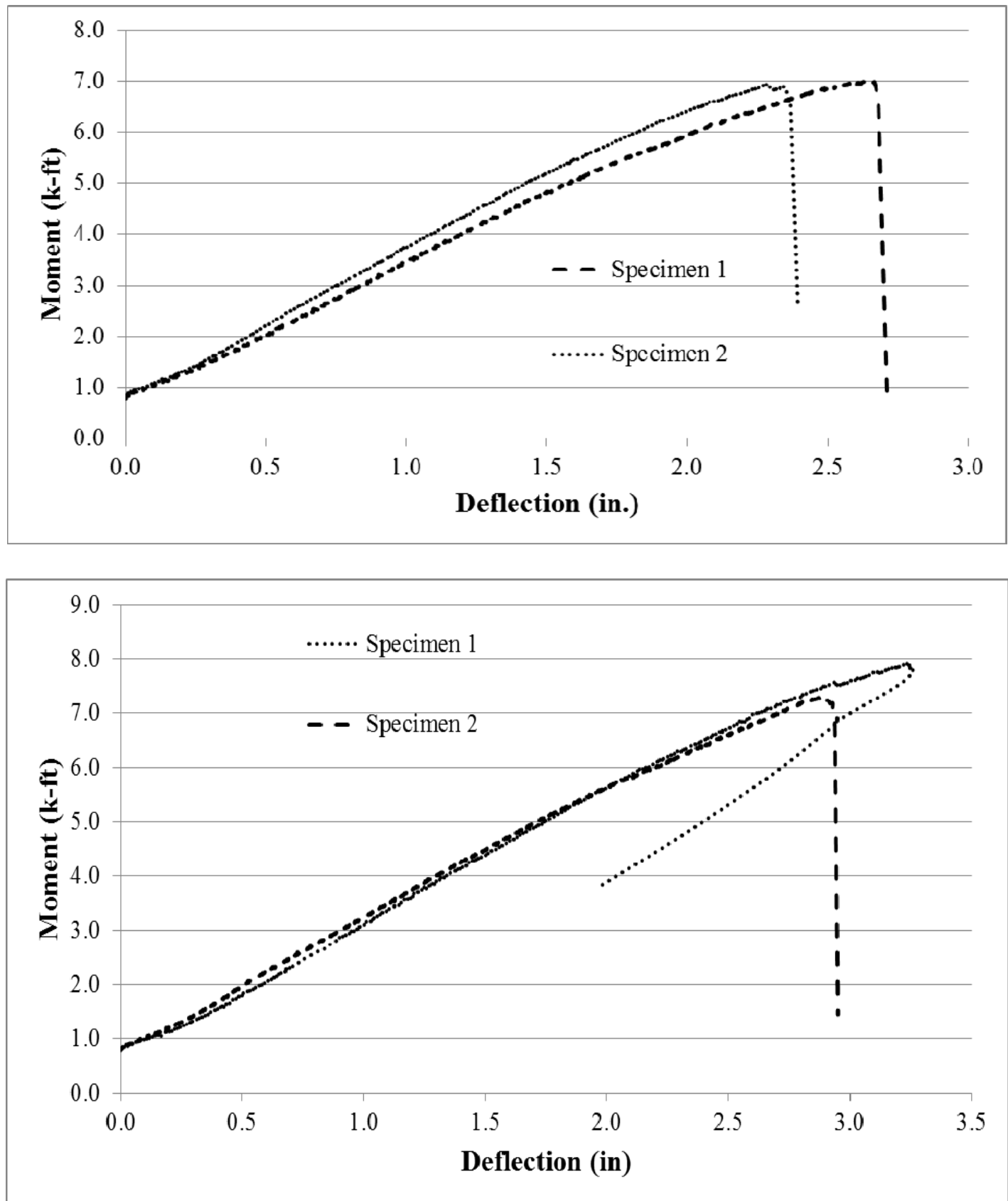

Figure 2.19 Strong Barrel Testing Moment-Deflection Curves (Top, positive pressure; bottom, negative pressure) 

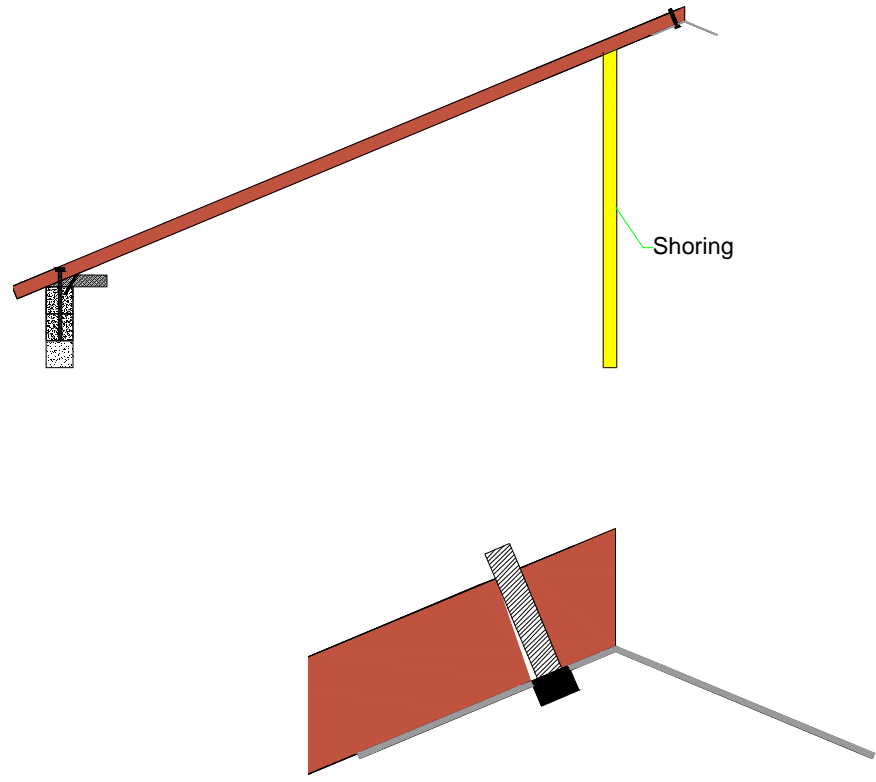

Fig. 2.20 Construction Sequence of the Supertile System, Step 1
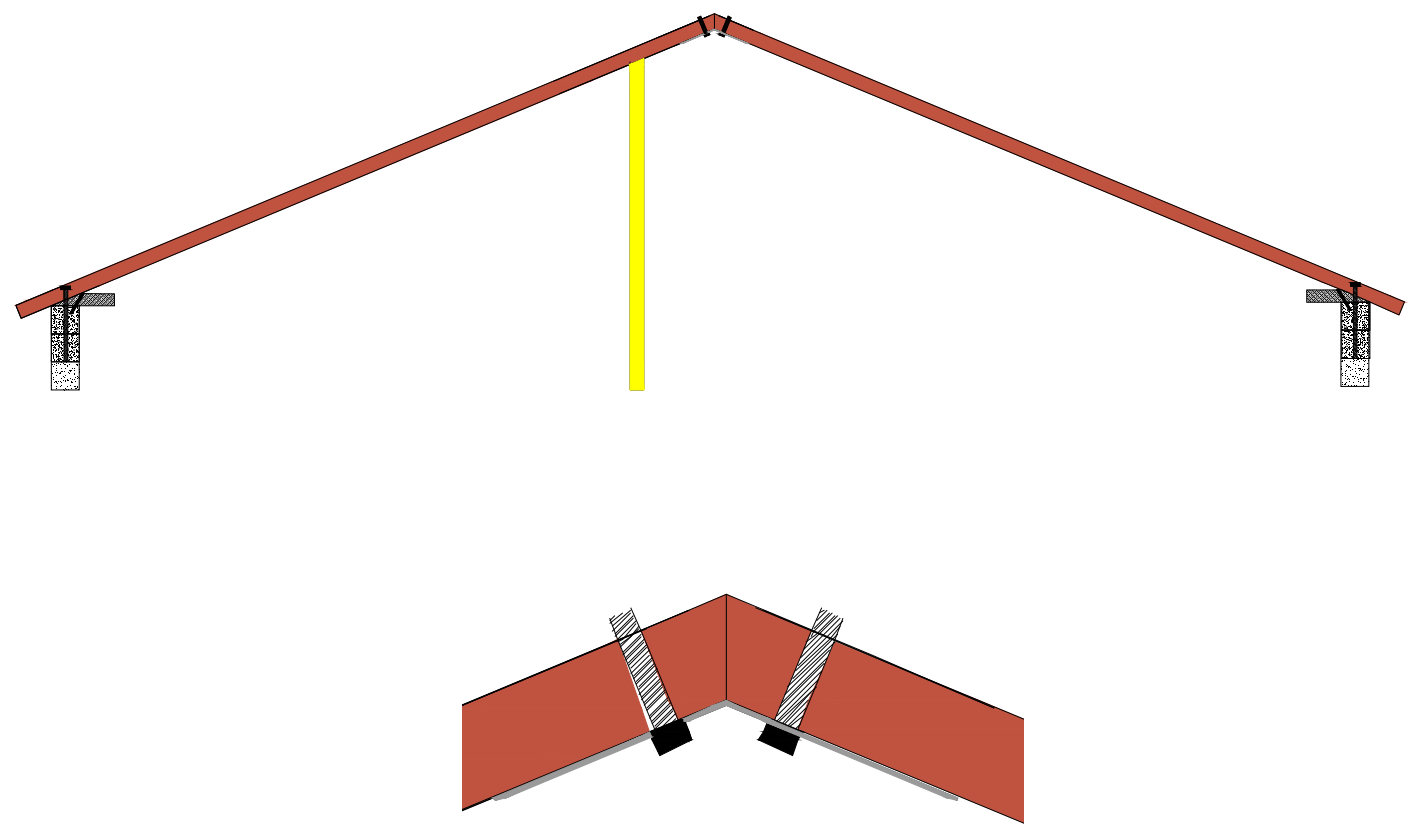

Fig. 2.21 Construction Sequence of the Supertile System, Step 2 

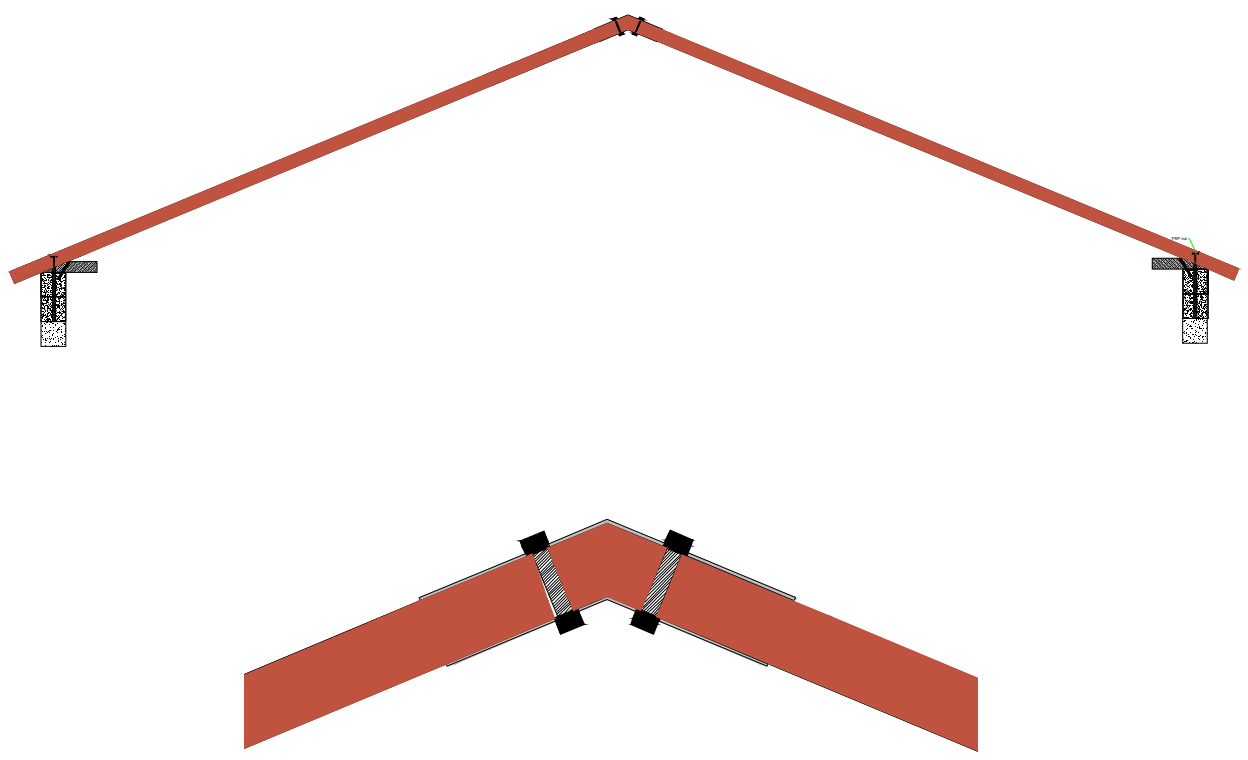

Fig. 2.22 Construction Sequence of the Supertile System, Step 3

\subsubsection{Intangible Cost Reduction}

Statistics are needed to determine if the payback period will be short enough to entice residents to invest in a system for which initial costs are higher than for conventional construction. The proposed system has the advantages of increased strength, in addition to performing better from a water intrusion viewpoint if properly detailed. The strength of the structure means lower property loss costs after a major wind event. The fact that the attic elements, conventionally composed of wood, are eliminated entails savings in insurance costs (Lafarge, 2014). Both of these are reasons to consider the Supertile system. The total economic benefits, though, of the proposed system need to be determined by detailed cost analyses. 


\subsection{Energy Efficiency}

Energy efficiency revolves around the idea of, "using less energy to provide the same service." (EETD, 2014). The purpose of the roof is then to accomplish this task by effectively separating the interior environment from the exterior. Conventionally, this is done by using insulation. Typical roof materials are not highly insulating. Other materials such as fiberglass batts are used between the roof rafters to produce a layer that is resistive to heat movement across that layer. In cold environments, this is done to keep the produced heat inside of the residence, and in warm environments, to stop heat from passing from the exterior into the interior portions of the residence, requiring the use of energy to regulate the interior environment. Energy efficient roofs provide an effective layer to reduce the amount of energy needs from mechanical devices such as airconditioning systems.

\subsubsection{Insulation Options}

Insulation is needed in residential roofs to separate the interior environment from the outside environment. Three options are being considered to achieve the energy efficiency needed for a residential home. The choice made by individual homeowners can be driven by the local climatic needs and the desired interior aesthetics. These options will be considered next.

\subsubsection{Spray-On Insulation}

Spray-on insulation is effective because it forms not only a full barrier to air flow, but also a water barrier. The area under the roof could then be finished to the owner's specifications. It is important that proper ventilation is provided to ensure that the lifespan of the roof is adequate as a lack of ventilation can cause heat to build-up against the 
roofing surface and reduce the service life. This method applies an environmental barrier with good R-value. The problem with this method that it requires a fire barrier to be in place (US Dept. of Energy, 2012), although the use of precast concrete may allow dispensing with a fire barrier. Spray-on insulation is depicted in Fig. 2.21.
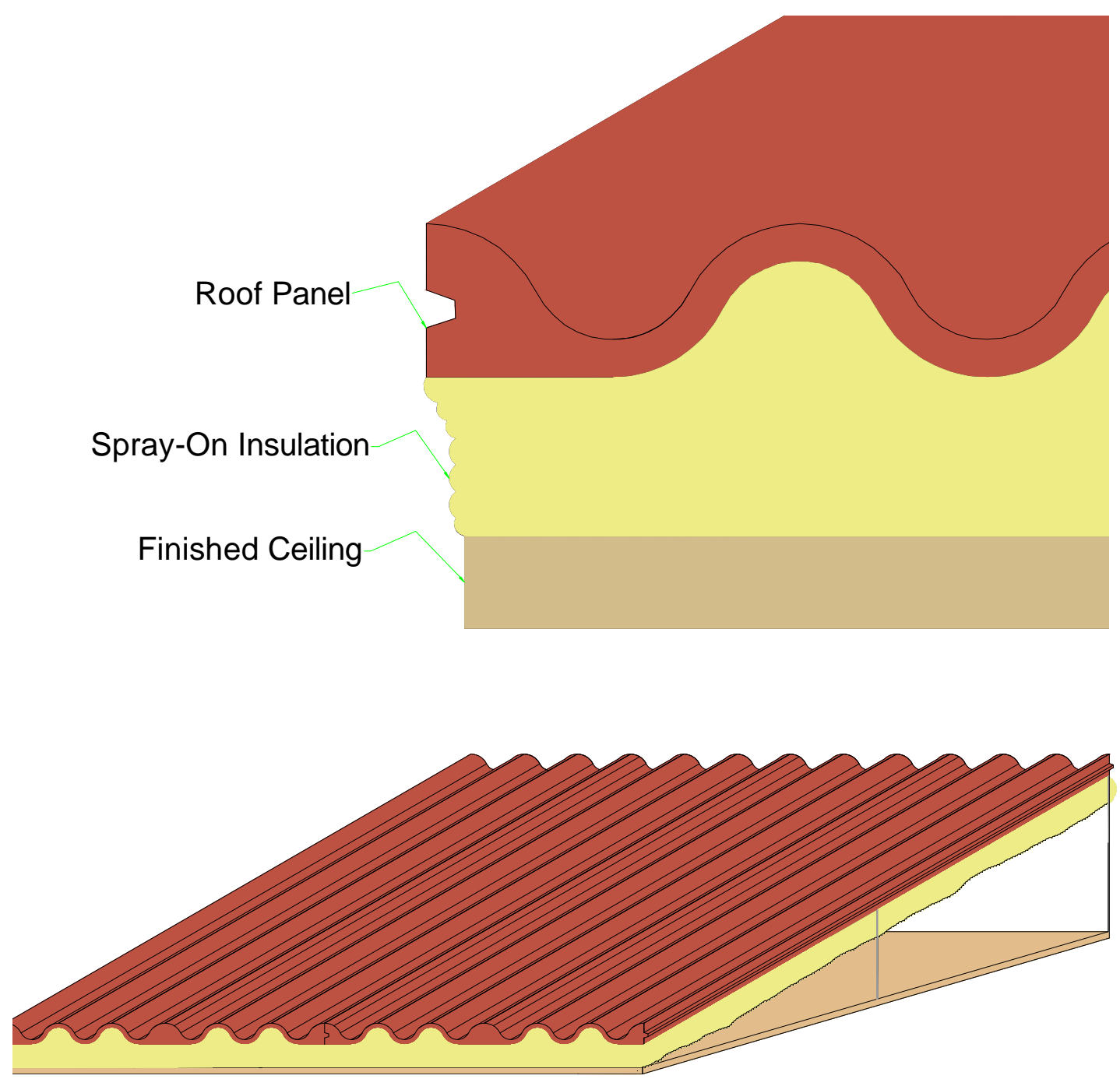

Figure 2.23 Spray-On Insulation Schematic 


\subsubsection{Insulated Concrete Formwork}

Insulated concrete forms can be fabricated to fit on the bottom side of the precast concrete panel, In the specimens made in the laboratory, foam panels were fixed to the reinforcement before casting to hold the form and reinforcement in place. The foam was removed before testing; however, this method could allow fixing the insulating form to the bottom side of the concrete. This method also provides a high R-value while reducing the costs of labor.

The panels would have a higher initial cost; however, it would pay itself back over time in insurance and energy savings (US Dept. of Energy, 2012). More research needs to be conducted towards a determination of the procedure for fixing the form to the panel to ensure that there is no slippage between the layers during wind events. This type of insulation is depicted in Fig. 2.22.

\subsubsection{Conventional Batt Insulation}

The typical batt insulation is effective, even though it is not typically fixed or adhered to the surface. In addition, the R-value is not as high as the values that the other methods have the potential to produce. The underside would also necessitate the addition of a ceiling to create an aesthetically pleasing surface. This type of insulation is depicted in Fig 2.23.

\subsection{Initial Development Conclusions}

A novel roofing system has been devised and a concept was developed that employs architectural shape to build structural strength. This is accomplished through using a precast concrete panel acting as a rigid diaphragm. This rigid diaphragm is strengthened through the use of the embedded beams to provide the stiffness needed to 
resist dead, live, and wind loading. The embedded beam was designed and tested to demonstrate the viability of the concept just described.

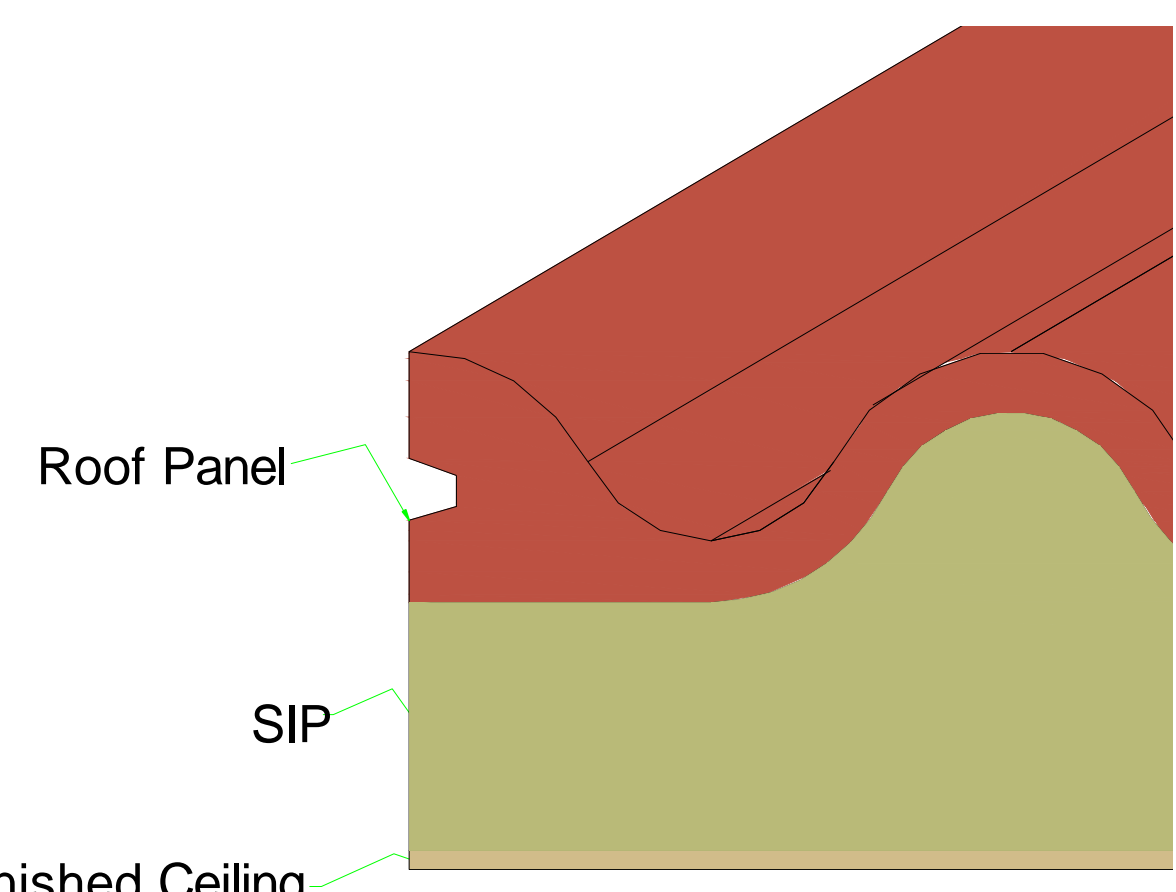

\section{Finished Ceiling}

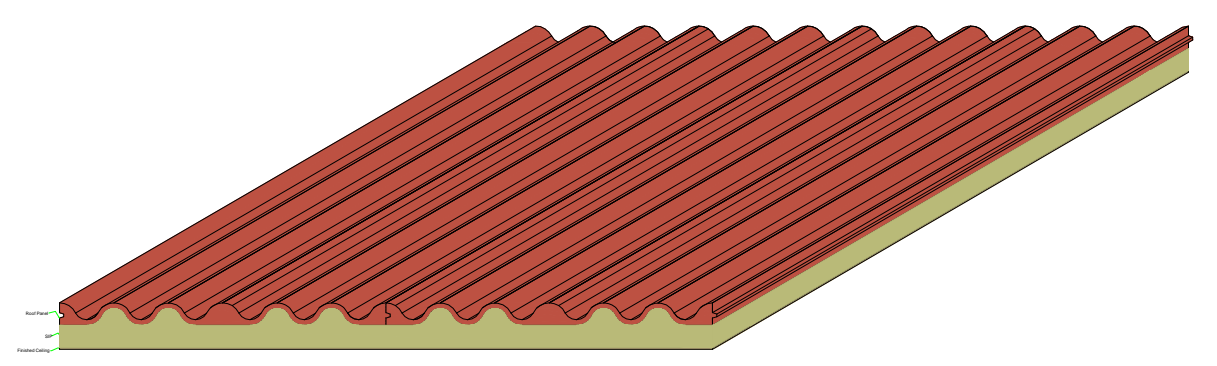

Figure 2.24 Insulated Concrete Form Schematic 

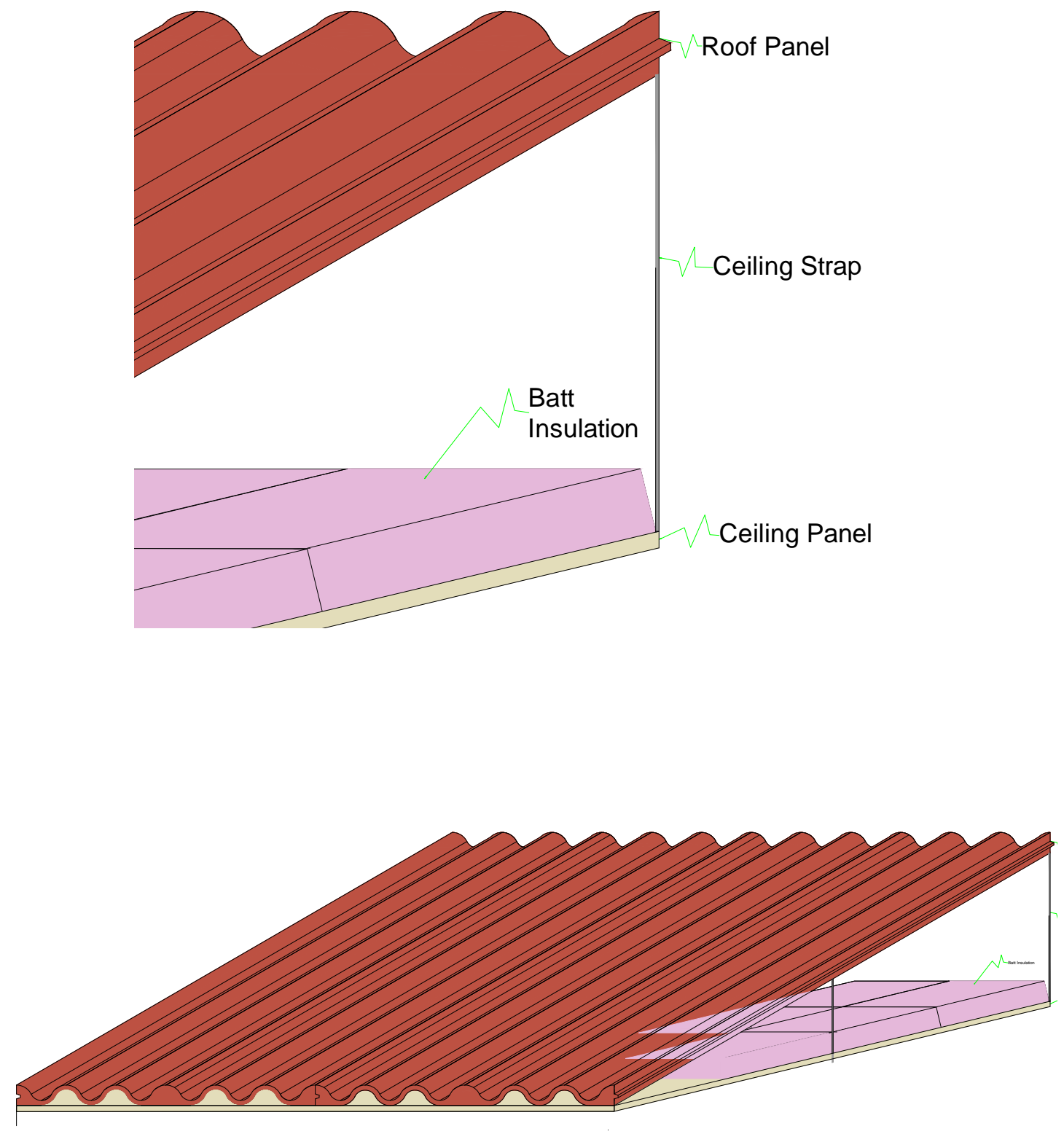

Figure 2.25 False Ceiling with Batt Insulation Schematic

Four specimens were produced that were reinforced with glass fiber-reinforced polymer reinforcement to provide stiffness and a carbon fiber-reinforced polymer to provide longitudinal reinforcement to tie the panel together by continuing out of the embedded beam and into the next embedded beam. Two of the four beams were tested 
under positive pressure, and two were tested under negative pressure. It was found that the specimens had good strength and ductility properties.

Other factors that will determine the practical usefulness of the proposed panels are cost effectiveness and energy efficiency. Related to both are considerations of manufacturing, constructibility, maintenance, and insurance costs.

The panel system lends itself to achieving high energy efficiency. One possibility is to place the insulation as a stay-in-place layer. This layer will improve constructability as it reduces the number of steps in the construction procedure.

Based upon the results of this study, additional components of the system need to be created and tested. The connections are important elements in the panel system. As was stated earlier, the connections are a major problem in conventional roofing, whereas they can contribute to achieving superior performance in concrete Supertile panels. 


\section{References}

Smith, T. L. (1992) "Hurricane Andrew: A Preliminary Assessment," Professional Roofing-A National Roofing Contractors Association.

Cochran, L. and Levitan M. (1994) "Lessons from Hurricane Andrew." Architectural Science Review, 37, pp. 115-121.

Briscoe, C.R., Mantell, S.C., Davidson, J.H., and Okazaki, T. (2010) "Design Procedures for Web Core Sandwich Panels for Residual Roofs." Journal of Sandwich Structures and Materials, 13, 23-58.

Chomarat (2010) "Technical Data Sheet - C50-1.8 x 1.6." Chomarat.com http://www.chomarat.com/wp-content/uploads/2011/06/C50-1.8x1.6.pdf>

Wallbrator TM (2010) "Wallbrator: Compact Concrete Consolidation Attachment." Liteform.com < http://liteform.com/wallbrator/>

Harley, B. (2005) “Insulation Inspections for Home Energy Ratings.” Home Energy, Jan./Feb. 2005.

ASHRAE (2011) "Standard 189.1 Standard for the Design of High-Performance, Green Buildings, Except Low-Rise Residential Buildings." American Society of Heating, Refrigerating and Air-Conditioning Engineers.

NAIMA (2014) "How Much Insulation Should Be Installed." North American Insulation Manufacturers Association. $<$ http://www.naima.org/insulation-knowledgebase/residential-home-insulation/how-much-insulation-should-be-installed.html>

Wight, J. K. and MacGregor, J. G. (2009) "Reinforced Concrete: Mechanics \& Design." Pearson Education, Inc.. Upper Saddle River, New Jersey.

Marshall Composites Systems, LLC (1999) "C-bar-Product Guide Specification." Marshallcomposites.com < http://www.marshallcomposite.com/c_bar_specs.pdf $>$

Benichou, N., Kodur, V. K. R. , Green, M. F., and Bisby, L. A. (2010) "Fire Performance of Fibre-Reinforced Polymer Systems Used for the Repair of Concrete Buildings." Construction Technology Update No. 74, National Research Council of Canada, Institute for Research in Construction.

Florida Building Code (FBC) (2010). "Chapter 15: Roof Assemblies and Rooftop Structures." Florida Code. 15.1.

ASCE 7 (2010). "Chapters 26: Wind Load: General Requirements." American Society of Civil Engineers, 241-258. 
ASCE 7 (2010). "Chapter 27: Wind Loads on Buildings-MWFRS.” American Society of Civil Engineers, 259-295.

Lafarge (2014) “Total Precast Advantages.” Lafarge < http://www.lafargena.com/wps/portal/na/en/3_E_2_7-Total_Precast_Construction_Advantages $>$

EETD (2014) "What Is Energy Efficiency" Environmental Energy Technologies Division, E.O. Lawrence Berkeley National Laboratory. $<$ http://eetd.lbl.gov/ee/ee-1.html $>$

US Dept. of Energy (2012) "Types of Insulation." Energy.gov $<$ http://energy.gov/energysaver/articles/types-insulation> 


\title{
3. DESIGN, DEVELOPMENT AND TESTING OF A COMPOSITE ROOFING SYSTEM
}

\author{
Brandon Mintz, Arindam Gan Chowdhury, Amir Mirmiran, Nakin Suksawang, and \\ Ramtin Kargarmoakhar
}

\section{Submitted to ASCE Journal of Composites for Construction}

\begin{abstract}
Roofing is one of the most vulnerable parts of the building envelope in a residential structure, often damaged during extreme wind events such as hurricanes or tornadoes. Conventional roofing systems in residential buildings mostly consist of separate Main Wind Force Resisting System (MWFRS) and Components and Cladding (C\&C). High wind uplift forces often cause partial or full destruction of one or more of these elements, leading to water intrusion and losses of interior contents. This study focuses on the design, development and testing of a new composite roofing system that integrates the functionalities of MWFRS and $\mathrm{C} \& \mathrm{C}$. The new system is comprised of lightweight concrete panels reinforced with fiber reinforced polymer mesh and rods. The architectural shape of a conventional residential roof with high profile tiles was adopted for the composite roof panels to help provide the requisite structural stiffness and strength of the MWFRS, while maintaining similar C\&C aesthetics and avoiding failure of individual tiles which often become wind-borne debris. The panel system was subjected to a battery of tests under equivalent wind loads. In addition, three connections for the system were designed and validated through testing. The panel to wall connection provided ample continuity of the vertical load path, the panel to panel connection was found adequate for shear transfer, and the ridge connection allowed for load transfer between the windward and leeward sides of the roof. Tests demonstrated viability and
\end{abstract}


superiority of the new system as an alternative to conventional roofs, making it ideal for residential buildings in hurricane zones and tornado alleys.

KEYWORDS: Precast concrete panels; Fiber-reinforced polymers (FRP); Residential roofing; Tiles; Wind mitigation.

\subsection{Introduction}

Roofing is one of the most vulnerable parts of the building envelope in a residential structure, often damaged during extreme wind events such as hurricanes and tornadoes. Posthurricane disaster surveys highlight roof damage as a major hurricane impact (NAHB 1993). A review of historical storms shows that an estimated $80 \%$ of losses from Category 4 Hurricane Hugo in 1989 (Bright 2010) may be attributed to roofing failure (Cook 1991). Substantial roof damage may cause exterior walls to lose lateral support, leading to building collapse (Manning and Nichols 1991). Most failures in Hurricane Andrew were due to negative pressures on roofs under high winds, and subsequent increases in the internal pressure after the building envelopes were compromised (Ayscue 1996). Windstorm induced roof damage may also lead to water intrusion and losses to interior contents (Visscher and Kopp 2007). Therefore, reducing roof damage due to wind effects is one of the most important challenges for designers, contractors, owners, insurers, and building code officials.

Conventional roofs are comprised of several elements, described generally as the Main Wind Force Resisting System (MWFRS) and Components and Cladding (C\&C). Both MWFRS and C\&C are designed based on wind provisions of American Society of Civil Engineers 7-10 Standard (ASCE 2010). The MWFRS, providing structural resistance, may be viewed as being comprised of structural sheathing connected to the 
trusses that are attached to the walls. The $\mathrm{C} \& \mathrm{C}$, forming the building roof envelope and providing aesthetics and resistance to water intrusion, includes roof covering (tiles or shingles) and secondary water barriers such as felt underlayment attached to the sheathing. The numerous connections between these various elements often (1) create the weak $\operatorname{link}(\mathrm{s})$ in the chain and/or (2) increase the risk of poor workmanship (e.g., missing fasteners, inadequate spacing, etc.), leading to damage initiation and progressive collapse. For example, roof coverings (tiles or shingles) often fail due to bond rupture (e.g., detachment of foam, mortar, or sealant), tear, or nail pull out even in hurricanes with wind speeds less than the design wind speed, as in Hurricane Wilma (MDC-BCCO 2006, Li 2012). Roof sheathing failure due to inadequate connections leads to water intrusion (van de Lindt 2009 and 2010). Inadequate roof-to-wall connections lead to discontinuous load paths and building failure (Cheng 2004, Chowdhury et al. 2013). Despite enhancement of building codes in hurricane prone regions, roof damage, often initiated by wind uplift induced $\mathrm{C} \& \mathrm{C}$ failures, continues to pose a major problem during hurricanes.

Limited research has been aimed at developing a new roofing system that addresses these concerns while incorporating building aesthetics. Peter et al. (2010) proposed an economical roofing system with precast concrete beams, both for construction cost reduction and energy efficiency. However, little research has focused on developing an alternative roofing system that is aesthetically attractive, structurally strong, and economically feasible. This study integrates MWFRS and C\&C in a new precast composite roofing system, which is structurally sound while intrinsically aesthetic. The paper presents the panel design concept, flexural tests to validate the 
design, and connection tests to confirm the overall system performance. Three connection types are considered: roof panel to wall, panel to panel, and the ridge. Test results demonstrated the capacity of the system and its ability to withstand various load combinations. Sample design tables are also developed for different load conditions and geographical regions.

\subsection{Design Concept}

The proposed composite roof panel system, named Supertile, reproduces the general shape of a conventional residential tiled roof, effectively employing the shape to provide the required stiffness and strength. The new system represents an integration of the functionalities of MWFRS and C\&C, thus eliminating the conventional procedure of attaching the C\&C to the MWFRS, which often leads to failures discussed earlier. The Supertile roof panels can be prefabricated as a monolithic system in a quality-controlled factory environment, thus reducing (1) the number of smaller inter-connected MWFRS and $\mathrm{C} \& \mathrm{C}$ elements in conventional roofs (e.g., sheathing, underlayment, and roof tiles), (2) the risk of inter-component connection failures and water intrusions, and (3) the chances of poor on-site workmanship (e.g., missing nails and screws, inadequate connector spacing, improper fastener penetration depths, and/or misaligned fastener penetration). The design also includes appropriate roof panel-to-wall, panel-to-panel, and ridge connections. Moreover, the system eliminates roof trusses and reduces construction costs by spanning from the walls to the ridge. This allows for either higher ceilings by leaving the attic space open (Briscoe et al. 2010), or an uninterrupted and usable attic space by providing a false ceiling. Use of non-corrosive reinforcement in the panels helps eliminate corrosion issues in humid regions. 
The new roof consists of lightweight concrete panels reinforced with glass fiber reinforced polymer (GFRP) rods as primary reinforcement and a carbon fiber reinforced polymer (CFRP) grid as a secondary mesh to improve the impact resistance of the panels. Figure 3.1 (a) shows a schematic of the panel section. The aesthetic barrel shape of the panel is intrinsic to its design, as it enhances its moment of inertia due to the high curvature profile, rather than being an add-on C\&C element that may be compromised in hurricanes and adds no strength. The panel consists of strong barrel sections acting as embedded beams to effectively replace the roof trusses, while integrated into the natural contours of the tile shape as shown in Fig. 3.1 (a). The FRP rods in each barrel section are designed to take the loads for the tributary area between the barrels. Figure 3.1 (b) shows a photo of a portion of a Supertile panel. Figure 3.2 shows the conceptual ridge connection with the two inclined panels sandwiched between top and bottom steel plates and FRP or steel bolts. The on-site construction sequence is envisioned as follows: (a) the roof panels are hoisted, with one end placed on and connected to external walls, and the other end shored in place, (b) the bottom steel plate is connected along the ridge using bolts and nuts, (c) the opposite panel is placed on its external wall and fitted and bolted to the bottom ridge plate, and (d) the top plate of the ridge is secured before shoring is removed. The entire process is expected to take less than a day for a typical residential house, as compared to the current laborious and time-consuming roofs with trusses, sheathing, and tiles.

\subsection{Loading Demand and Panel Design}

Loading for the new roofing system was based on the Florida Building Code (FBC 2010) high velocity hurricane zones specifications applicable to the South Florida hurricane prone Miami-Dade and Broward counties. The load calculations and 
assumptions made in this study, however, can be easily adapted for any other geographical region. Accordingly, both the panel width and the spacing of strong barrel sections can be adjusted to accommodate the loading.

Design loads also depend on the building configuration. For this study, a three story residential building configuration was selected with a mean roof height of $9.1 \mathrm{~m}$, a roof slope of 5:12, and a $10 \mathrm{~m} \times 20 \mathrm{~m}$ footprint. The design span of the roof panel is greatly impacted by its dead load, which controls the positive moment. To minimize the dead load, the concrete mix was apportioned with 0.55 water-to-cement ratio (by weight) for a seven-day compressive strength of $34.5 \mathrm{MPa}$ and a unit weight of $15 \mathrm{~N} / \mathrm{m}^{3}$. The live load was taken as $0.96 \mathrm{KPa}$ (FBC 2010). The wind load design in FBC (2010) follows ASCE 7-10, based on several factors including location, terrain exposure, and building height. The 3-sec gust basic wind speed for a Category II building located in Miami-Dade County is $78 \mathrm{~m} / \mathrm{s}$ (for Exposure $\mathrm{C}$ and $10 \mathrm{~m}$ height). Table 3.1 lists design parameters as specified by the ASCE 7-10 requirements to estimate the wind speed at $9.1 \mathrm{~m}$ mean roof height of the building considered here. When considering the aerodynamic net pressure on the roof panel, three critical cases should be examined for system design (see Fig. $3.3)$ :

1) Windward Roof: Maximum negative external pressure (upward) with positive internal pressure (acting towards the bottom surface);

2) Windward Roof: Maximum positive external pressure (downward) with negative internal pressure (acting away from bottom surface); and

3) Leeward Roof: Maximum negative external pressure with positive internal pressure. 
The pressure coefficients are listed in Table 3.2 for each of the above cases depicted in Fig. 3.3. These cases, considering both positive (downward) wind pressure and negative (uplift) wind pressure, must be considered in the load combinations, as given in FBC (2010), as follows:

Load Combination 1: $0.9 \mathrm{D}+1.0 \mathrm{~W}$

Load Combination 2: $1.2 \mathrm{D}+0.5 \mathrm{~L}_{R}+1.0 \mathrm{~W}$

Load Combination 3: $1.2 D+1.6 L_{R}+0.5 W$

These loading cases were used to select test parameters for the roof panel and the connections, as described in the next section. A preliminary analysis was carried out to determine the most critical load combination for the prototype building roof. Table 3.2 presents the maximum and minimum values of the moments induced by the design wind loads in the windward and leeward roof panels.

A sectional analysis was carried out using Whitney's stress block (Wight and MacGregor 2009) to validate the initial design parameters and the sectional capacity. While the ridge may partially restrain the rotation of the panels, it was conservatively assumed to act as a hinge for the preliminary design. The panel section was divided into subsections to represent the shape of the barrel section with a curve fit used to determine the stress block. The compressive strength of FRP was neglected in the analysis. Flexural test results were later used to calibrate the analysis.

\subsection{Flexural Testing of a Strong Barrel Section}

The test panel used for flexural testing was made with a strong barrel in the middle and a half barrel at each end [see Fig. 3.4 (a), (b), (c)]. Two identical specimens, 
each with a span length of $2.26 \mathrm{~m}$, were tested for downward loading (positive external pressure) and upward loading (negative external pressure and positive internal pressure) cases, as shown in Fig. 3.4 (b) and (c). The GFRP rods, called C-bar, were produced by Marshall Composites Technologies (1999). The transverse CFRP mesh, called C-grid, was produced by Chomarat (2010). The properties of both materials are listed in Table 3.3. Figure 3.4 (a) shows the reinforcement schematic for the tested specimens for both positive and negative pressure. The load was applied using a hydraulic actuator equipped with a load cell. Deflections were monitored both by the movement of the actuator head and a string potentiometer at the midspan, as demonstrated in Fig. 3.4 (d). The two specimens tested in positive bending failed in shear and compression-controlled flexure, whereas both specimens tested in negative bending failed in compression-controlled flexure. Figure 3.5 shows the moment-deflection response curves for both sets of specimens. The maximum strength capacity is shown in Fig. 3.5. Based upon the maximum moment (demand) in Table 3.2, it can be observed that the specimens satisfied the required capacities. The barrels showed a higher reserve capacity under negative pressure, implying that the positive pressure represents the more critical load combination. If the maximum deflection is limited to the span length divided by 240 (e.g., FBC, 2010), the corresponding limit on the bending moments under positive and negative pressures can be obtained from Fig. 3.5. Deflections need to be further investigated in full-scale tests to assure conformity with requirements specified in various building codes.

Based on the strength test results discussed above, Table 3.4 provides maximum span lengths of the proposed composite roof system as applicable to 5:12 gable roof 
buildings with various mean roof heights $(h)$ in five hurricane-prone regions along the east coast and the Gulf of Mexico. The analysis was based on the corresponding 3-sec gust design wind speeds (in $\mathrm{m} / \mathrm{s}$ ) at $10 \mathrm{~m}$ above ground for open terrain exposure in each region, as per ASCE 7-10. Table 3.4 shows that for a single story residential house ( $h=$ $3.1 \mathrm{~m}$ ) located in terrain with open exposure in Miami, Florida, the maximum span length will be $5.38 \mathrm{~m}$. For a similar house in Bar Harbor, Maine, the maximum span length will be $5.83 \mathrm{~m}$. For a four-story gable roof building, the spans will be slightly reduced, as shown.

\subsection{Connections}

\subsubsection{Roof Panel to Wall Connections}

The roof panel to wall connections are designed to resist uplift as well as in-plane and out-of-plane shear forces. A connection was designed to allow for adequate load transfer between the roof panels and the wall. An anchor may be installed in the wall using two different methods: (a) casting an anchor bolt into the masonry block wall, which is ideal for new construction and ensures a good bond, or (b) installing an anchor sleeve with a threaded rod screwed into the sleeve, which is more appropriate for retrofitting of existing buildings and replacing of the roof. Through-holes need to be installed in the panels, or holes drilled to allow either the threaded rod or the anchor bolt to pass through. Figure 3.6 shows the proposed connection detail, with the embedded rod option. Assuming conservatively that both panels are in the uplift condition, the wall loading can be estimated as: 


$$
P_{\text {wall }}=\frac{w L}{2}
$$

where $P_{\text {wall }}=$ load per unit length of the wall, $w=$ total loading per unit area from a given load combination, and $L=$ span length from the wall to the ridge.

Figure 3.7 shows the test setup to determine the required spacing of the panel-towall connections. The connection test was performed using a $16 \mathrm{~mm}$ FRP threaded rod embedded into a cast concrete block simulating the wall. The wall section was a block of concrete having a dimension approximately representative of two typical masonry blocks. A hydraulic jack was attached to the rod and placed on the wall section with a donutshaped load cell above. A wooden wedge was placed in between the panel and the load cell to ensure adequate bearing pressure throughout the test and minimize the potential for local failure. The roof panel, consisting of a $460 \mathrm{~mm}$ long piece of a strong barrel section, was placed onto the load cell and an FRP nut secured the panel to the wall. For connection testing, the average compressive strength of the concrete panel was over 69 MPa to ensure that failure occurred in the connection. Two identical specimens were tested, yielding similar results. Failure occurred with shearing of the nuts off the bolts at an average axial load of $14.2 \mathrm{kN}$. The test results were divided by a safety factor of four to obtain the reduced capacity used for design purposes. The spacing was then determined, considered against each load combination to find the one with the maximum effect, from that reduced capacity and the loading demand was determined by using Equation (4). Accordingly, Table 3.5 provides maximum spacing of the panel-to-wall anchors for the proposed roofing system for different geographical regions and building 
heights, the assumed roof slope being 5:12. The table clearly shows that the spacing should not exceed $242 \mathrm{~mm}$ for the most critical case considered.

\subsubsection{Panel to Panel Connections}

The panel-to-panel connections are needed not only for load transfer. The joints should also prevent water intrusion and the resistance to water intrusion will be tested in future using full scale specimens. The design of the tongue-in-groove connection, shown in Fig. 3.8, is based on the shear strength of concrete as provided in ACI 318 (2013):

$$
V_{c}=2 \sqrt{f_{c}^{\prime}} b d
$$

where $f_{c}^{\prime}=28$-day compressive strength of concrete; $b=$ unit of length being considered (e.g., $1 \mathrm{~m}$ ); and $d=$ tongue portion of the connection, which was $25.4 \mathrm{~mm}$ in this study.

The panel-to-panel connections are designed to transfer the shear between adjacent panels. Such shear may occur due to the non-uniform wind induced pressure on adjacent panels (e.g. wind blowing parallel to the roof ridge will induce higher uplift pressure on the panels closer to the gable end and the magnitude of pressure will be reduced on panels farther away from the gable end). The shear force must be resisted by the concrete tongue. Figure 3.9 shows the schematic for testing such a panel-to-panel connection. Three specimens were tested.

The maximum loads achieved before shear failure for the three tests were 2.56 $\mathrm{kN}, 2.98 \mathrm{kN}$, and $2.68 \mathrm{kN}$, respectively; the average shear capacity is thus $2.74 \mathrm{kN}$. The assumption for the tests is that the panel to panel connection might have to resist the entire load associated with pressure non-uniformities, as was discussed earlier. As was confirmed in the testing, shear is the mode of failure for the connection, 
Different thicknesses of the tongue could be determined for various loadings. However, creating a form for each different tongue thickness would be labor intensive. Instead, for any given building in any given region, the connection can be checked by comparing the shear stress due to the load yielded by the analysis to the shear capacity of the tongue.

\subsubsection{Ridge Connection}

The ridge connection is designed to sandwich the joining windward and leeward panels of the roof and has two functions: to serve as a load transfer mechanism and to facilitate the staged construction of the roof. The top and bottom steel plates are secured to the roof panels using bolts as shown in Fig. 3.2. Alternatively, a through-hole could be made in the panels to allow the threaded rods to be placed while placing the panels, making the on-site construction even more flexible. The required load for the ridge can be estimated by considering the load per unit length that is transferred in shear to the panel on the opposite side, as

$$
V=\frac{w L}{2 b_{s}}
$$

where $w=$ total line loading per unit length from a given load combination, based on the design wind speed; $L=$ span length from e wall to the ridge; and $b_{s}=$ width of the tributary area. Figure 3.10 shows a schematic that illustrates these parameters. The capacity of the ridge connection, determined in the testing, is then reduced by an appropriate capacity reduction factor consistent with code requirements. The design of the connection must satisfy the requirement that the reduced capacity is higher than the demand, V. 
The purpose of the ridge connection test was to validate the connection mechanism and find the spacing for the shear connectors (see Fig. 3.11). The test also helped determine the load bearing capacity of the ridge and check that premature failure would not occur due to shearing off of the bolts. Two types of materials were used for the ridge connection: GFRP and steel, shown in Fig. 3.11. The benefit of using GFRP is that it is lightweight and does not corrode; however, the lower shear strength and rigidity of the plates may lead to premature failure of the plates in shear and larger deflections. Steel is beneficial due to its high shear capacity and rigidity. It would however need to be galvanized to prevent corrosion, which can increase the overall cost of the ridge connection. Both test specimens, using steel and GFRP, are shown in Fig. 3.11.

Test panels were constructed for the roof panel portion of the test. The GFRP plates and the steel plates were $4.8 \mathrm{~mm}$ thick. The specimen was pushed downward until failure occurred. It was assumed that the span length, measured from the base of one panel to the base of the other, remained constant. As can be seen from Fig. 3.11, steel or wood sections were tied down at the edges of the panels to prevent the supports from moving outwards. Assuming simple supports, the steel ridge demonstrated good capacity. The GFRP connection resulted in excessive deflections of the ridge. Figure 3.12 presents the condition of both ridge systems after failure. Figure 3.13 shows that the steel ridge gave the connection more capacity. It is therefore recommended that hot dipped galvanized steel be used for the ridge section in high wind velocity areas and for longer spans. The tests provided the data needed to estimate the load transferring ability of the ridge. The ridge connection results were used to develop Table 3.6, which lists the requisite spacing of the shear connectors as a function of roof height and wind velocity. 
For example, it is shown in Table 3.6 that the shear connector spacing would be $261 \mathrm{~mm}$ in Miami, Florida for a mean roof height of $6.10 \mathrm{~m}$. For a similar structure in Bar Harbor, Maine the spacing would be $610 \mathrm{~mm}$.

\subsection{Economic Considerations}

To adequately predict the cost over the life of a product, the initial costs, as well as on-site construction, maintenance, and repair costs need to be considered. Based on the design described, a preliminary estimate of the cost is shown in Table 3.7, while a similar estimate shows the cost of conventional roofing-see Table 3.8, in which the underlayment and sheathing costs were obtained from roofing providers. The cost of construction for framing and trusses can be estimated to be over $\$ 170$ per square meter (Taylor, 2014). It is, therefore, anticipated that the cost of the composite system would be competitive. This is especially true when incentives such as insurance benefits and post disaster costs are figured into the total cost. Further data can lend more insight into the system's life costs.

\subsection{Conclusions}

A new composite roof system, integrating the functionalities of MWFRS and C\&C, has been developed and tested for its flexural capacity. Test results show the resistance exceeded the demand for the span length considered in this study. The flexural panel tests, simulating bending of the panel with supports at the wall and the ridge demonstrated the capacity of the panels to perform as required. It was shown that the span length can attain $5 \mathrm{~m}$, even in the most extreme of wind events. A systems level test at full scale is planned to fully determine the deflection of the system. 
Three types of connection have been developed, tested, and found to have adequate capacity. Testing each connection to failure demonstrated the ability of the system to carry loads indicative of those caused during extreme wind events. The roof panel to wall connection allowed for a continuous load path from the roof to the walls and provided adequate capacity. A spacing of approximately $240 \mathrm{~mm}$ for the roof panel to wall connectors was deemed to be appropriate for the most extreme wind loading case considered. Panel-to-panel connections were of the tongue in groove type. The ridge connection was tested with both a GFRP and steel ridge. While the GFRP ridge does not experience corrosion, its capacity was limited and it experienced large deflections. The steel ridge demonstrated capacity almost 2-3 times the capacity of the GFRP ridge and is a very good option when galvanized. Sample design tables were presented to show how a designer may select the required spacing as a function of building configuration and design loads. The preliminary cost analysis showed the new system is a viable alternative to traditional roofing systems and has the potential to transform residential roof design and construction.

As future work, a full-scale system level test would provide more information on constructability and system capacity. This test will use four panels, two on the windward side and two on the leeward side of the structure, thereby providing a holistic method to test the panels and connections.

\section{Acknowledgements}

Support for this study was provided by the International Hurricane Research Center (IHRC) at Florida International University (FIU) through the Center of Excellence in

Hurricane Damage Mitigation and Product Development. All experiments were 
conducted at the Titan America Structures and Construction Testing Laboratory at FIU. The authors would like to thank Dr. Emil Simiu for his valuable comments and suggestions. Juan Cesin and Andres Urrego are acknowledged for assisting with the tests. The opinions expressed are those of the writers alone and do not necessarily reflect the views of the sponsors. 


\section{References}

ACI 318 (2013). Building code requirements for structural concrete. American Concrete Institute, Farmington Hills, MI.

ASCE 7 (2010). Minimum design loads for buildings and other structures. American Society of Civil Engineers (ASCE), Washington, DC.

Ayscue, J. (1996). "Hurricane damage to residential structures: risk and mitigation." Natural Hazards Research Working Paper \#94, The Johns Hopkins University.

Bright, R. (2010) "NWS Charleston, SC-Hurricane Hugo." National Weather Service, February 16, 2010. < http://www.erh.noaa.gov/chs/events/hugo.shtml>

Briscoe, C. R., Mantell, S. C., Davidson, J. H., and Okazaki, T. (2010) "Design procedures for web core sandwich panels for residual roofs." Journal of Sandwich Structures and Materials, 13, 23-58.

Cheng, J. (2004) "Testing and analysis of the toe-nailed connection in the residential roof-to-wall system.” Forest Products Journal, 54 (4), 58-65.

Chomarat (2010) "Technical data sheet-C50-1.8 x 1.6." Chomarat.com < http://www.chomarat.com/wp-content/uploads/2011/06/C50-1.8x1.6.pdf>

Chowdhury, A. G., Canino, I., Mirmiran, A., Suksawang, N., and Baheru, T. (2013) "Wind-loading effects on roof-to-wall connections of timber residential buildings." ASCE-Journal of Engineering Mechanics, 1-10.

Cook, R. (1991) "Lessons learned by a roof consultant." Hurricane Hugo One Year Later, Proceedings of a Symposium and Public Forum, Sill, B. L. and P. R. Sparks, eds. American Society of Civil Engineers, 144-152.

Florida Building Code (FBC) (2010). "Chapter 15: Roof assemblies and rooftop structures.” Florida Code. 15.1.

Li, R. (2012). "Effects of architectural features of air-permeable roof cladding materials on wind-induced uplift loading." ProQuest ETD Collection for FIU. Paper AAI3541803.

Manning, B. R., and Nichols G.G. (1991) "Hugo lessons learned." Hurricane Hugo one year later. In: Sill B.A., Sparks P.R., eds. New York: American Society of Civil Engineers.

Marshall Composites Systems, LLC (1999) "C-bar-Product guide specification." Marshallcomposites.com <http://www.marshallcomposite.com/c_bar_specs.pdf $>$ 
MDC-BCCO. Post hurricane Wilma progress assessment. Miami-Dade County Building Code Compliance Office, Miami, FL, 2006:1-22.

NAHB (1993) "Assessment of damage to single-family homes caused by hurricane Andrew and Iniki." NAHB Research Center Report. Upper Marlboro (MD). Peter, J. A., Lakshmanan, N., Sivakumar, P., and Rajamane N. P. (2010) "A novel precast roofing scheme for affordable housing." The Indian Concrete Journal, January 2010, 34-39.

Taylor, H. (2014) "Cost of constructing a home." HousingEconomics.com, NAHB. van de Lindt, J. W., Dao, T. N. (2009)."Performance-based wind engineering for wood-frame buildings." Journal of structural engineering, 135(2), 169-177.

van de Lindt, J. W., Dao, T. N. (2010).”Construction quality issues in performance-based wind engineering: effect of missing fasteners." Wind and Structures, 13(3), 221234.

van de Lindt, J. W., Li, Y., Bulleit, W. M., Gupta, R., Morris, P. I. (2009).’The next step for AF\&PA/ASCE 16-95: performance-based design of wood structures." Journal of Structural Engineering, 135(6), 611-618.

Visscher, B. and Kopp, G.A. (2007). "Trajectories of roof sheathing panels under high winds." Journal of Wind Engineering and Industrial Aerodynamics, vol. 95, pp. 697-713.

Wight, J. K. and MacGregor, J. G. (2009) "Reinforced Concrete: Mechanics \& Design." Pearson Education, Inc.. Upper Saddle River, New Jersey. 
Table 3.1. Wind Pressure Calculation Data for Miami-Dade County Using ASCE 7-

10

\begin{tabular}{cccc}
\hline Description & $\begin{array}{c}\text { Wind Pressure (Exposure C) } \\
\text { Parameter Symbol }\end{array}$ & Value & Units \\
\hline Mean Roof Height & $\mathrm{h}$ & 9.1 & $\mathrm{~m}$ \\
\hline $\begin{array}{c}\text { Velocity Pressure Exposure } \\
\text { Coefficient }\end{array}$ & $\mathrm{K}_{\mathrm{z}}$ & 0.98 & - \\
\hline Topographical Factor & $\mathrm{K}_{\mathrm{zt}}$ & 1.0 & - \\
\hline Wind Directionality Factor & $\mathrm{K}_{\mathrm{d}}$ & 0.85 & - \\
\hline Basic Wind Speed & $\mathrm{V}$ & 78 & $\mathrm{~m} / \mathrm{s}$ \\
\hline Gust-Effect Factor & $\mathrm{G}$ & 0.85 & - \\
\hline
\end{tabular}

Table 3.2. Moments Induced by Design Wind Loads

\begin{tabular}{ccc}
\hline \multicolumn{3}{c}{ Windward Panel } \\
\hline Load Cases & Maximum Positive & Maximum Negative \\
$\mathbf{1}$ & $(\mathrm{kN}-\mathrm{kN})$ & -1.28 \\
$\mathbf{2}$ & $\mathrm{N} / \mathrm{A}$ & $\mathrm{N} / \mathrm{A}$ \\
$\mathbf{3}$ & 4.62 & $\mathrm{~N} / \mathrm{A}$ \\
\hline \multicolumn{4}{c}{} \\
\hline \multicolumn{4}{c}{ Leeward Panels } \\
$\mathbf{1}$ & 4.29 & Maximum Negative \\
$\mathbf{2}$ & Maximum Positive & $(\mathrm{kN}-\mathrm{m})$ \\
$\mathbf{3}$ & $(\mathrm{kN}-\mathrm{m})$ & -5.08 \\
$\mathrm{~N} / \mathrm{A}$ & $\mathrm{N} / \mathrm{A}$ \\
& 5.14 & -3.64 \\
\hline
\end{tabular}

Table 3.3. Properties of C-grid and C-bar

\begin{tabular}{cccc}
\hline Product & Manufacturer & Modulus of Elasticity & $\begin{array}{c}\text { Ultimate Strain in } \\
\text { Tension }\end{array}$ \\
\hline C-grid & Chomarat & $235 \mathrm{GPa}$ & $0.76 \%$ \\
C-bar & Marshall & $42 \mathrm{GPa}$ & $1.90 \%$ \\
& Composites & & \\
\hline
\end{tabular}


Table 3.4. Typical Span Lengths Based on Mean Roof Height and Wind Velocity

\begin{tabular}{ccccc}
\hline Wind Region (V in m/s) & \multicolumn{4}{c}{ Mean Roof Height (m) } \\
\hline & $\mathbf{3 . 0 5}$ & $\mathbf{6 . 1 0}$ & $\mathbf{9 . 1 4}$ & $\mathbf{1 2 . 1 9}$ \\
Bar Harbor, Maine (52) & 5.83 & 5.81 & 5.77 & 5.74 \\
Boston, Massachusetts (57) & 5.74 & 5.71 & 5.66 & 5.63 \\
Southampton, New York (62) & 5.66 & 5.62 & 5.57 & 5.53 \\
Galveston, Texas (67) & 5.55 & 5.52 & 5.46 & 5.41 \\
Miami, Florida (76) & 5.38 & 5.33 & 5.21 & 5.12 \\
Key West, Florida (80) & 5.26 & 5.17 & 5.03 & 4.94 \\
\hline
\end{tabular}

Note: Span length is in meters

Table 3.5. Typical Roof-to-Wall Connection Spacing Based on Mean Roof Height and Wind Velocity

\begin{tabular}{ccccc}
\hline Wind Region (V in m/s) & \multicolumn{4}{c}{ Mean Roof Height (m) } \\
\hline Bar Harbor, Maine (52) & 610 & 610 & 610 & 610 \\
Boston, Massachusetts (57) & 610 & 610 & 603 & 550 \\
Southampton, New York (62) & 595 & 545 & 481 & 443 \\
Galveston, Texas (67) & 465 & 429 & 384 & 356 \\
Miami, Florida (76) & 335 & 313 & 286 & 270 \\
Key West, Florida (80) & 294 & 278 & 256 & 242 \\
\hline
\end{tabular}

Note: Connection spacing is in millimeters

Table 3.6. Typical Ridge Shear Connector Spacing Based on Mean Roof Height and Wind Velocity

\begin{tabular}{ccccc}
\hline Wind Region (V in m/s) & \multicolumn{5}{c}{ Mean Roof Height (m) } \\
\hline & $\mathbf{3 . 0 5}$ & $\mathbf{6 . 1 0}$ & $\mathbf{9 . 1 4}$ & $\mathbf{1 2 . 1 9}$ \\
Bar Harbor, Maine (52) & 610 & 610 & 610 & 610 \\
Boston, Massachusetts (57) & 610 & 578 & 502 & 458 \\
Southampton, New York (62) & 496 & 454 & 401 & 369 \\
Galveston, Texas (67) & 387 & 358 & 320 & 297 \\
Miami, Florida (76) & 279 & 261 & 238 & 225 \\
Key West, Florida (80) & 245 & 232 & 213 & 202 \\
\hline
\end{tabular}

Note: Connection spacing is in millimeters 
Table 3.7. Construction Costs for the New Roofing System

\begin{tabular}{ccccc}
\hline Item & Product & Company & \multicolumn{2}{c}{ Cost } \\
\hline Concrete & N/A & N/A & $\$ 0.22$ & $\mathrm{~m}^{2}$ \\
GFRP Rods & C-Bar & $\begin{array}{c}\text { Marshall Composites } \\
\text { Technologies }\end{array}$ & $\$ 23.14$ & $\mathrm{~m}^{2}$ \\
CFRP Mesh & C-grid & Chomarat & $\$ 34.01$ & $\mathrm{~m}^{2}$ \\
Underlayment & N/A & N/A & $\$ 1.18$ & $\mathrm{~m}^{2}$ \\
& & Material Total & $\$ \mathbf{5 8 . 5 5}$ & $\mathrm{m}^{2}$ \\
\hline
\end{tabular}

Table 3.8. Construction Costs for Conventional Tile Roofing System

\begin{tabular}{|c|c|c|}
\hline Item & \multicolumn{2}{|c|}{ Cost } \\
\hline Trusses (Taylor, 2014) & $\$ 22.50$ & $\mathrm{~m}^{2}$ \\
\hline Sheathing (Market value) & $\$ 15.07$ & $\mathrm{~m}^{2}$ \\
\hline Underlayment (Market value) & $\$ 1.18$ & $\mathrm{~m}^{2}$ \\
\hline Concrete Tiles (Taylor, 2014) & $\$ 32.72$ & $\mathrm{~m}^{2}$ \\
\hline Material Total & $\$ 71.47$ & $\mathrm{~m}^{2}$ \\
\hline
\end{tabular}




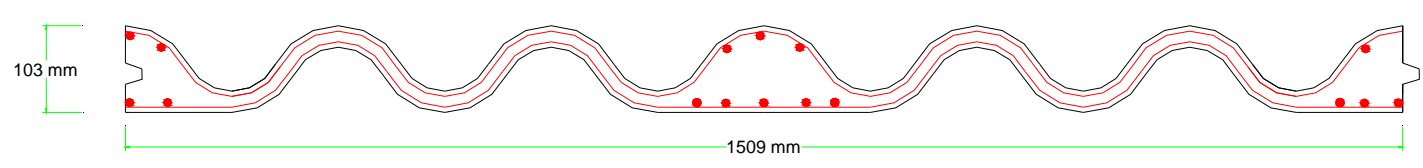

(a)

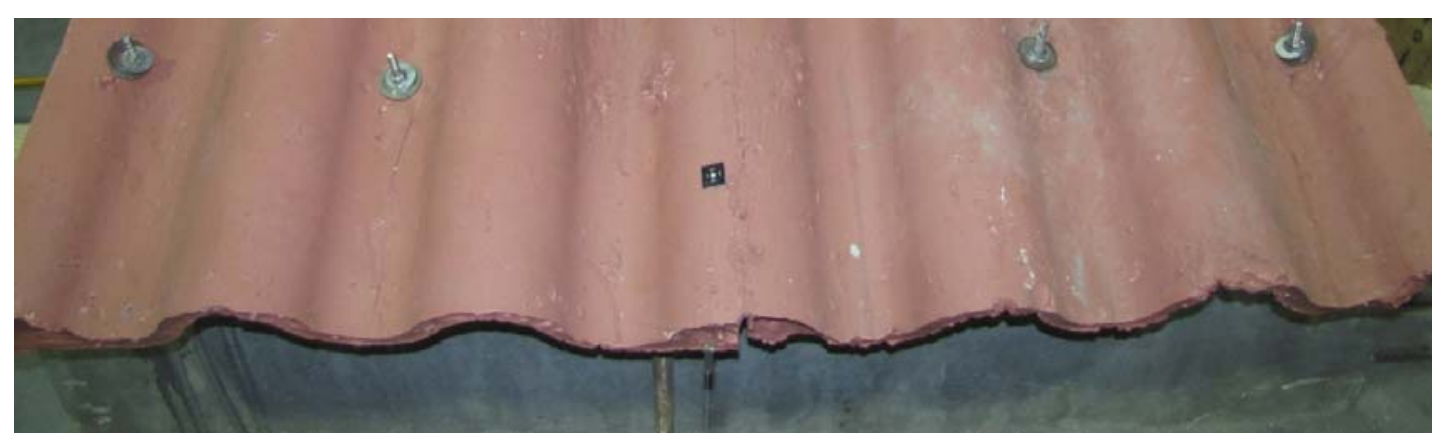

(b)

Figure 3.1. Details of the Composite Supertile Panel Section: (a) Reinforcement Details; (b) Panel Connection Details

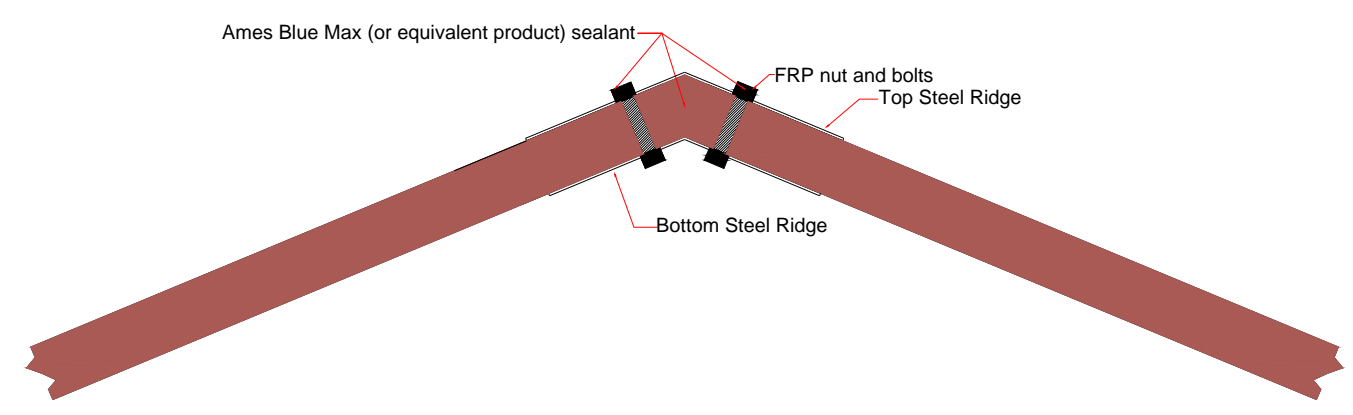

Figure 3.2. Details of Ridge Connection 


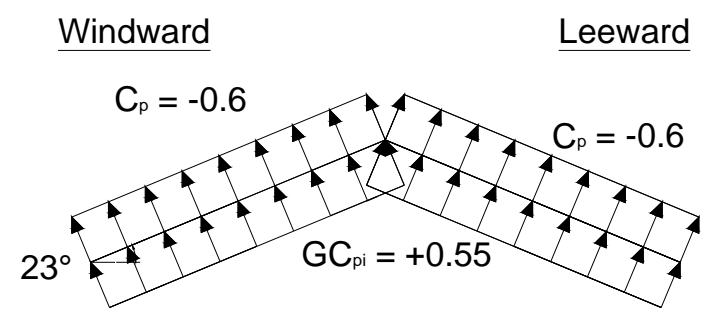

(a) For use with Eq. (1)

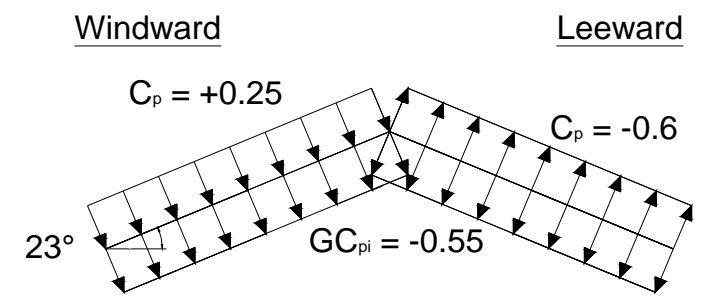

(b) For use with Eq. (2)and (3)

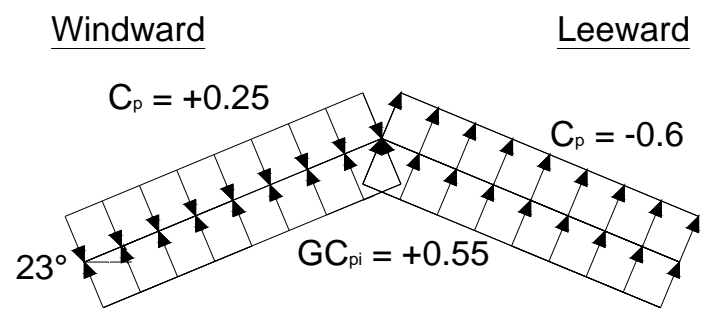

(c) For use with Eq. (2) and (3)

Figure 3.3. Wind Load Schematics for Use with (a) Eq. (1), (b) Eqs. (2)\&(3), and (c) Eqs. (2)\&(3) 


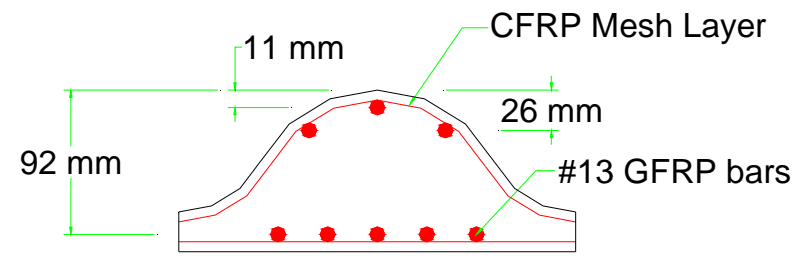

(a)

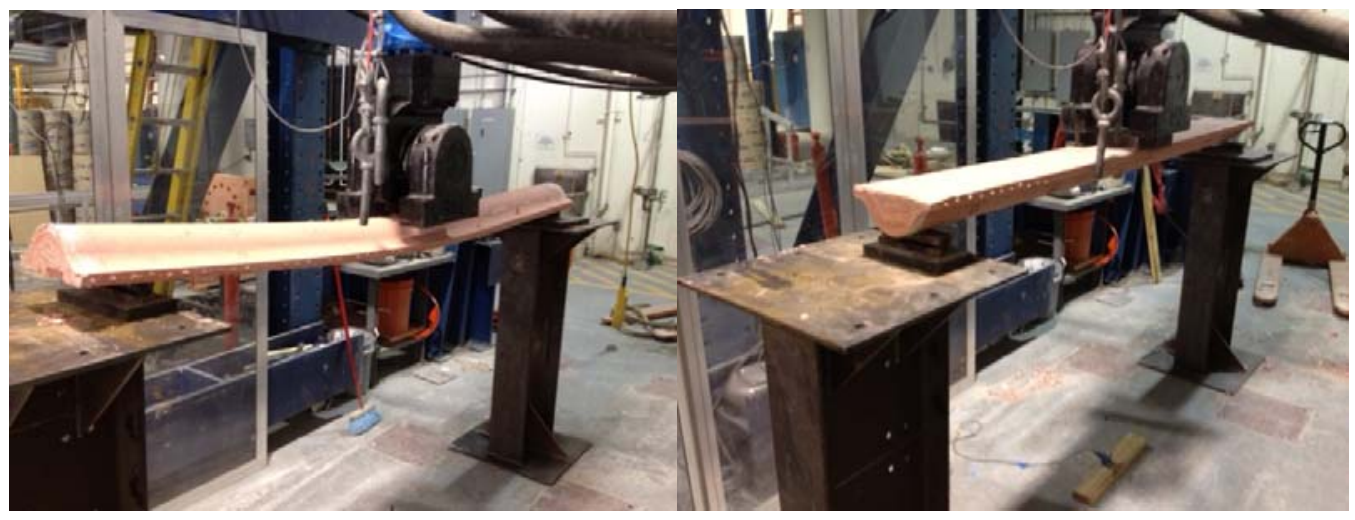

(b)

(c)

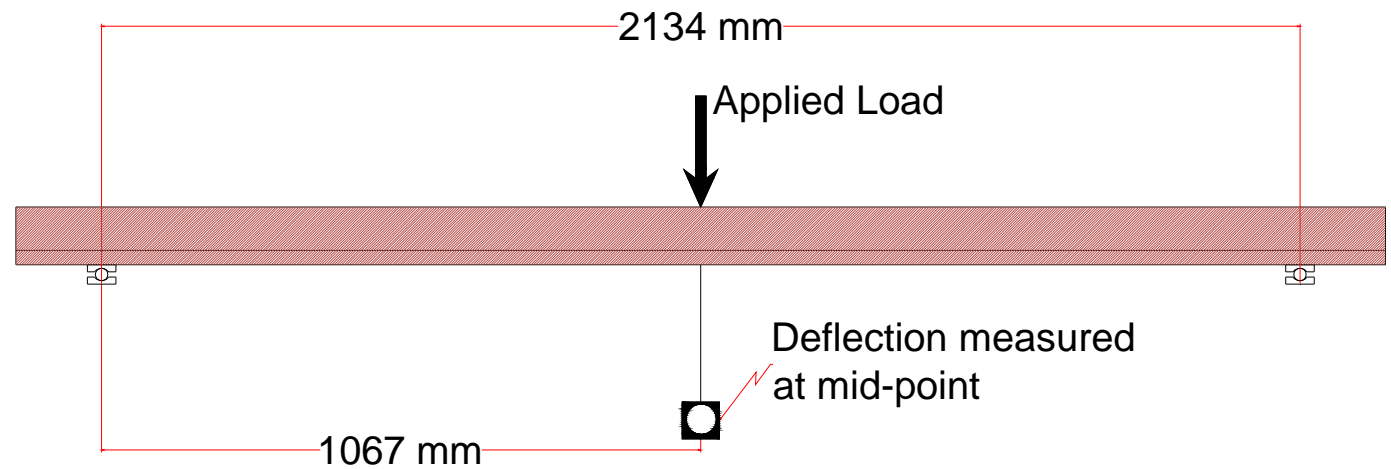

(d)

Figure 3.4. Strong Barrel Load Test: (a) Cross-section of Tested Specimen (b) Positive External Pressure for Load Combinations 2 and 3, (c) Negative External Pressure for Load Combination 1, (d) Load Test Schematic 


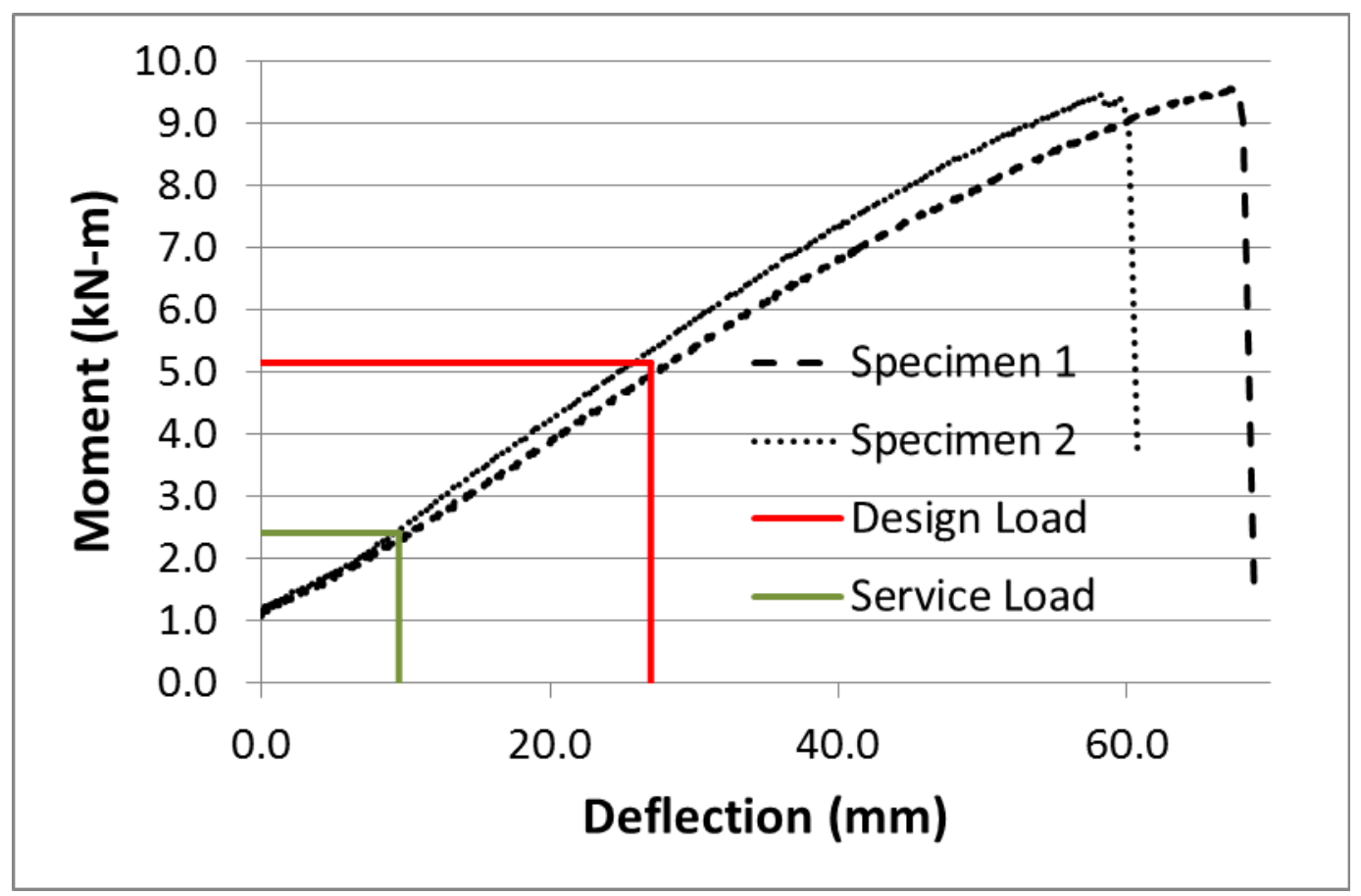

(a)

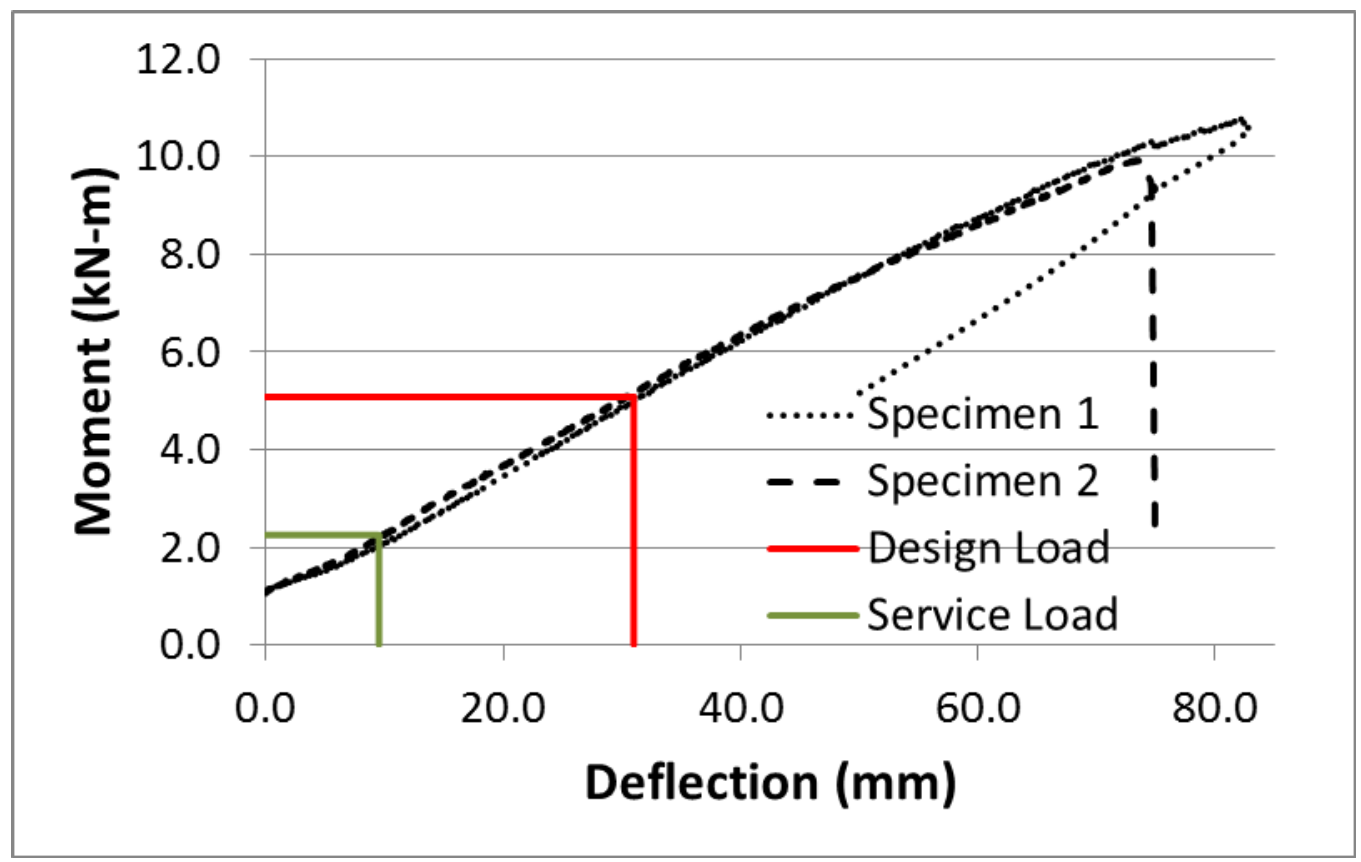

(b)

Figure 3.5. Moment-Deflection Response Curves for Strong Barrel Tests: (a) Positive Pressure, and (b) Negative Pressure 


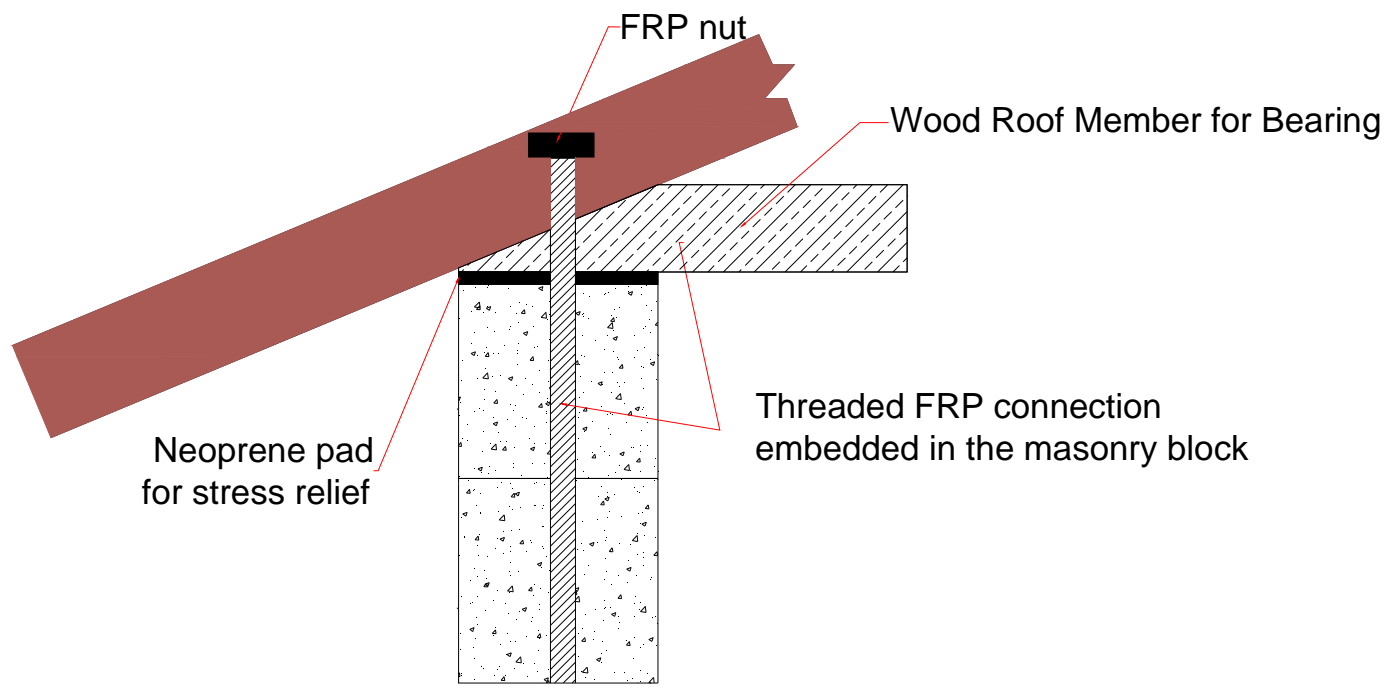

Figure 3.6. Roof-to-Wall Connection Detail 


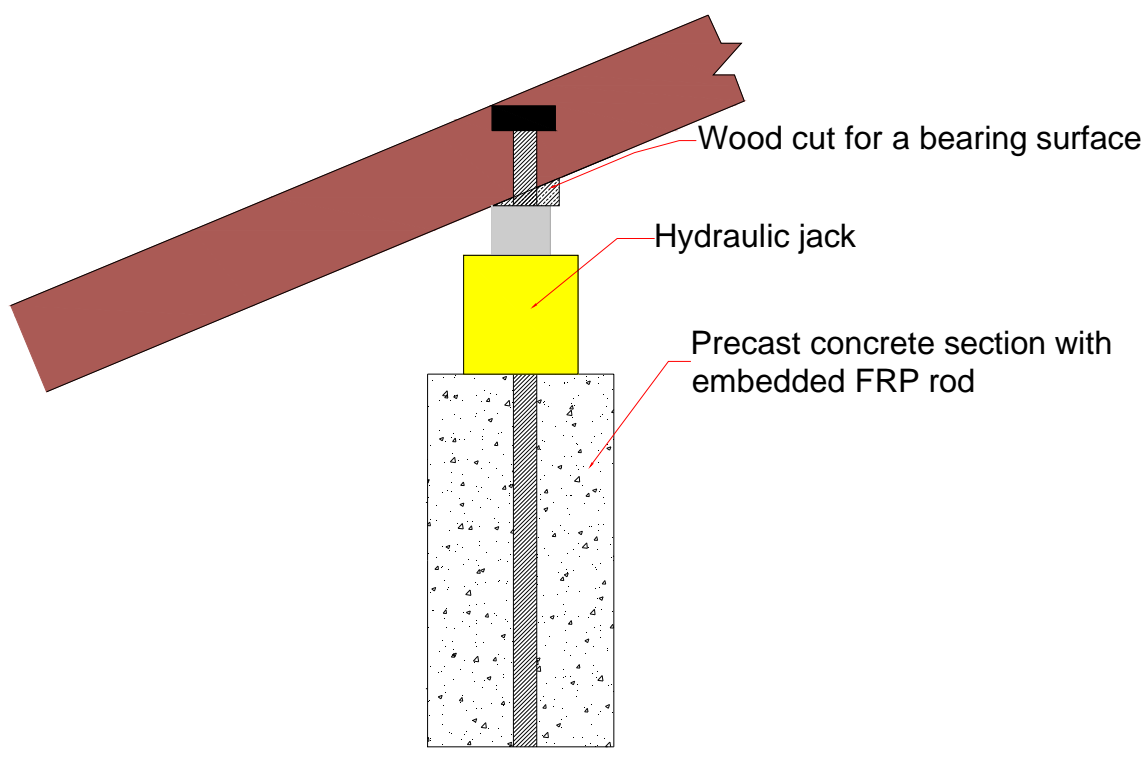

(a)

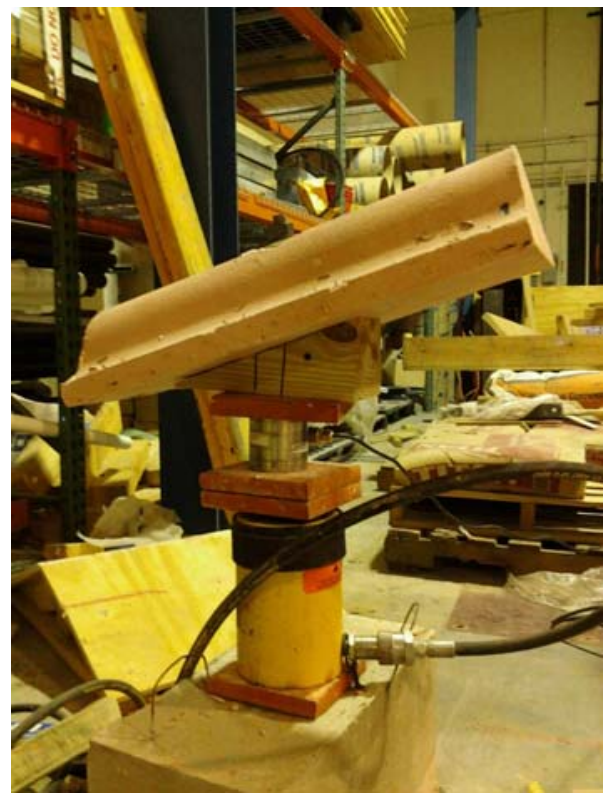

(b)

Figure 3.7. Roof-to-Wall Connection Test Setup (a) Schematic, and (b) Photograph 


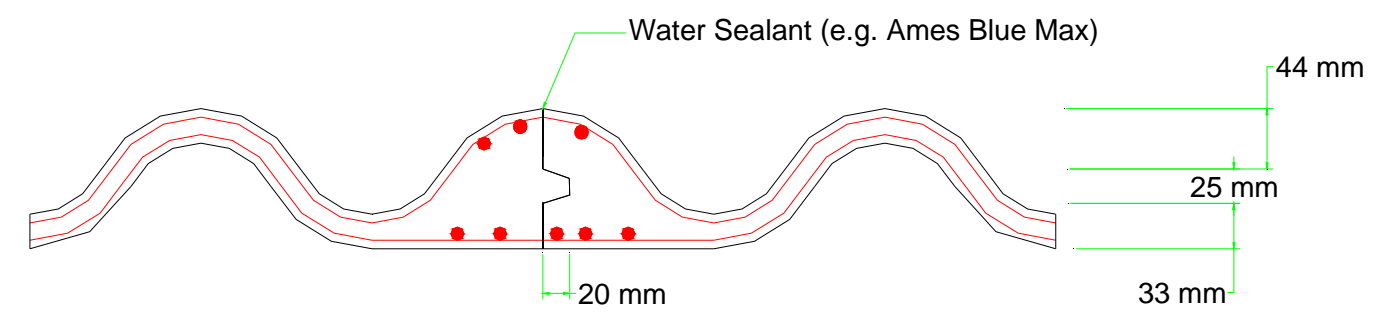

Figure 3.8. Panel-to-Panel Connection Detail

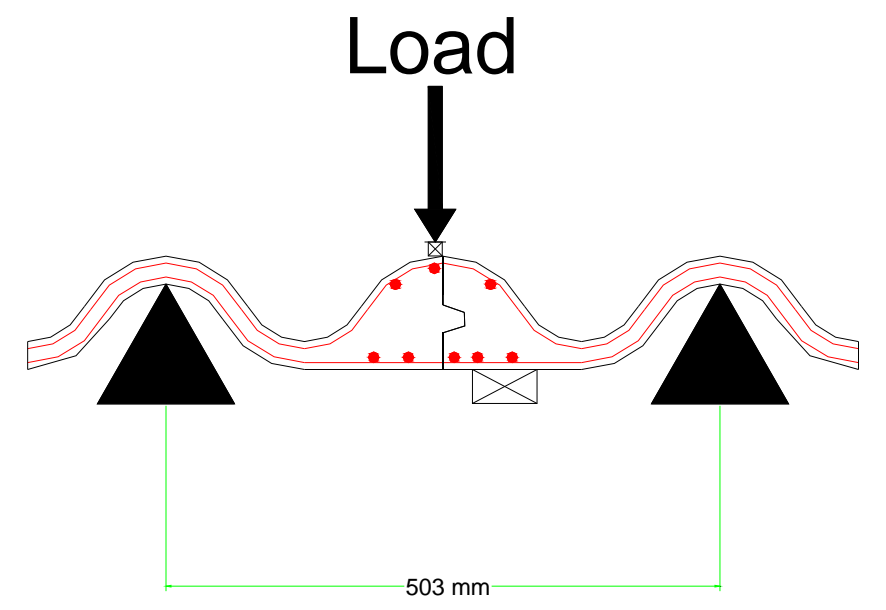

Figure 3.9. Panel-to-Panel Connection Test Setup

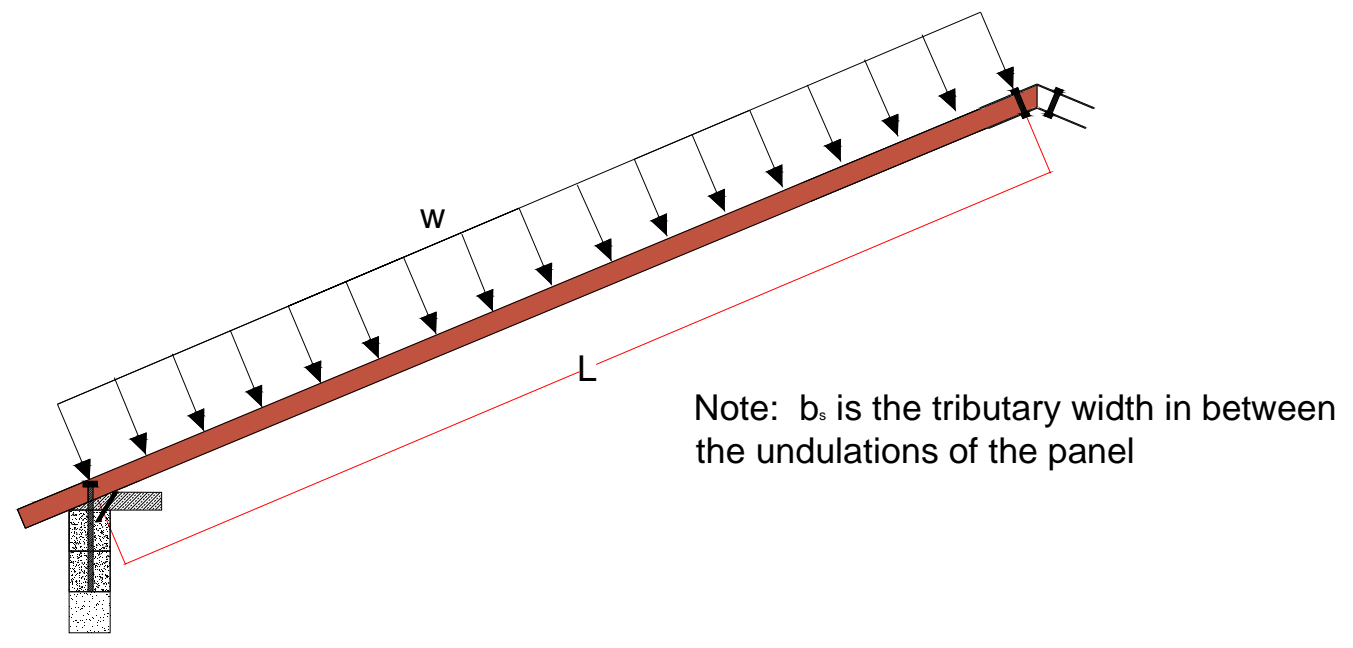

Figure 3.10. Ridge Design Schematic 


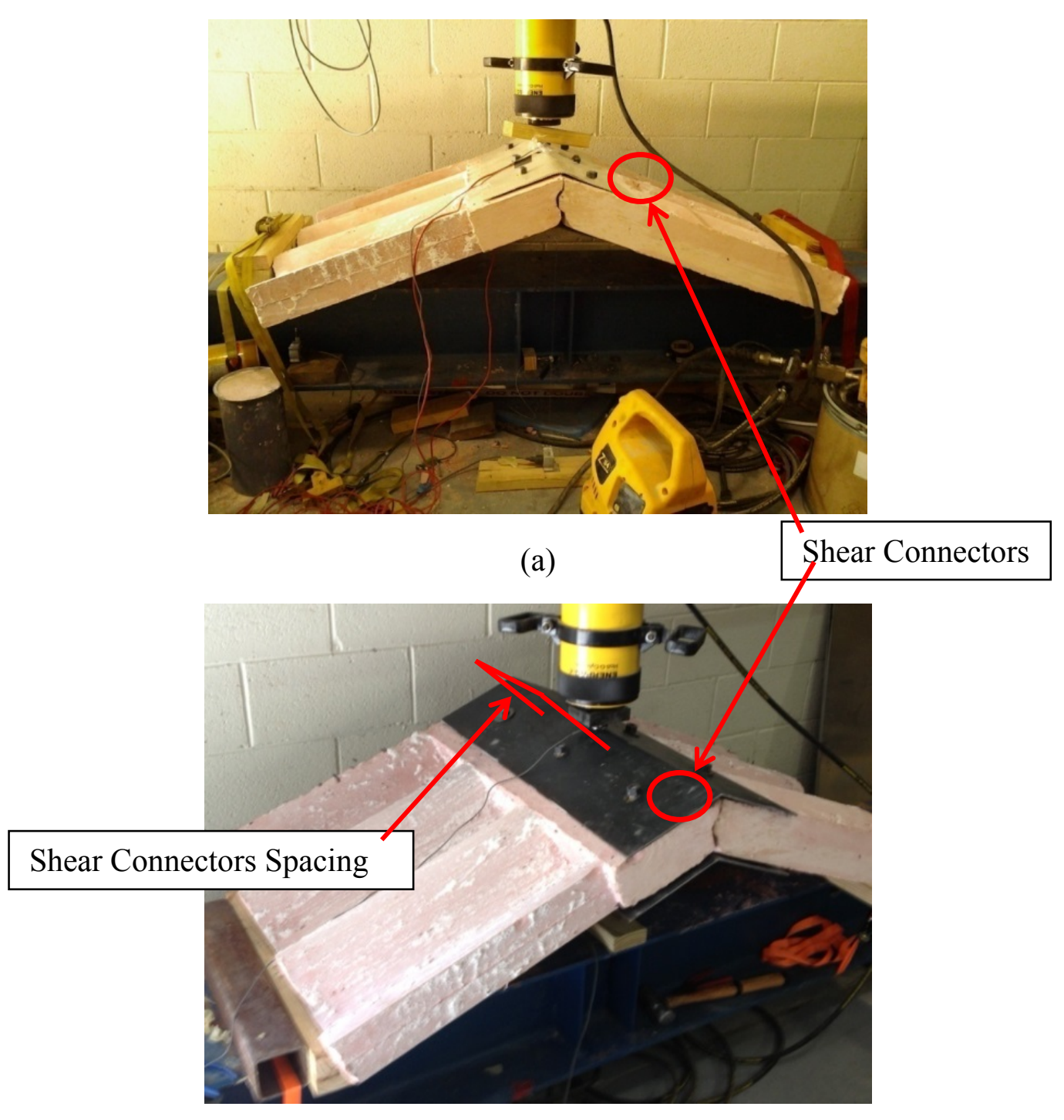

(b)

Figure 3.11. Ridge Connection Tests with Shear Connections Made of (a) FRP, and (b) Steel 


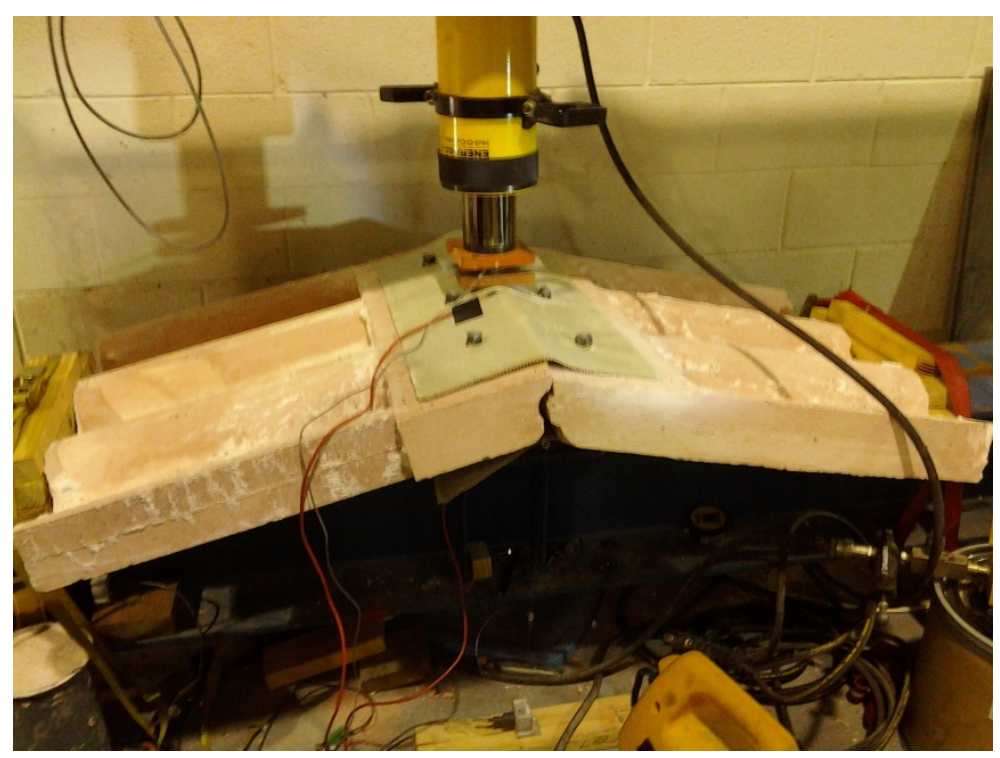

(a)

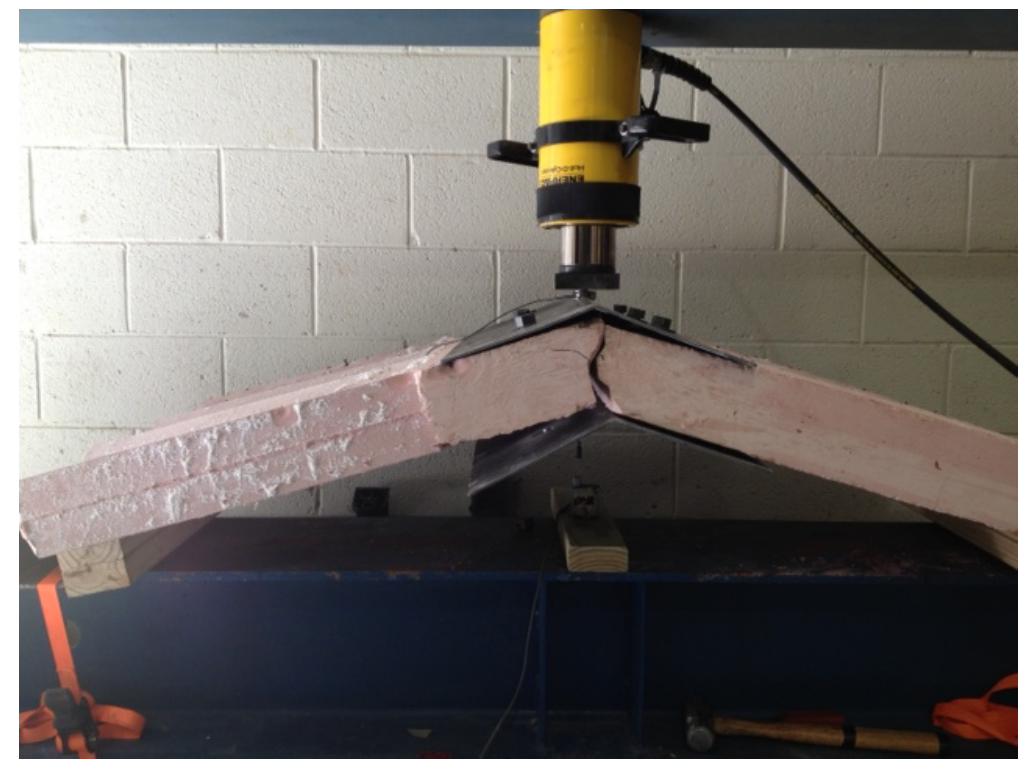

(b)

Figure 3.12. Ridge Failure (a) FRP, and (b) Steel 

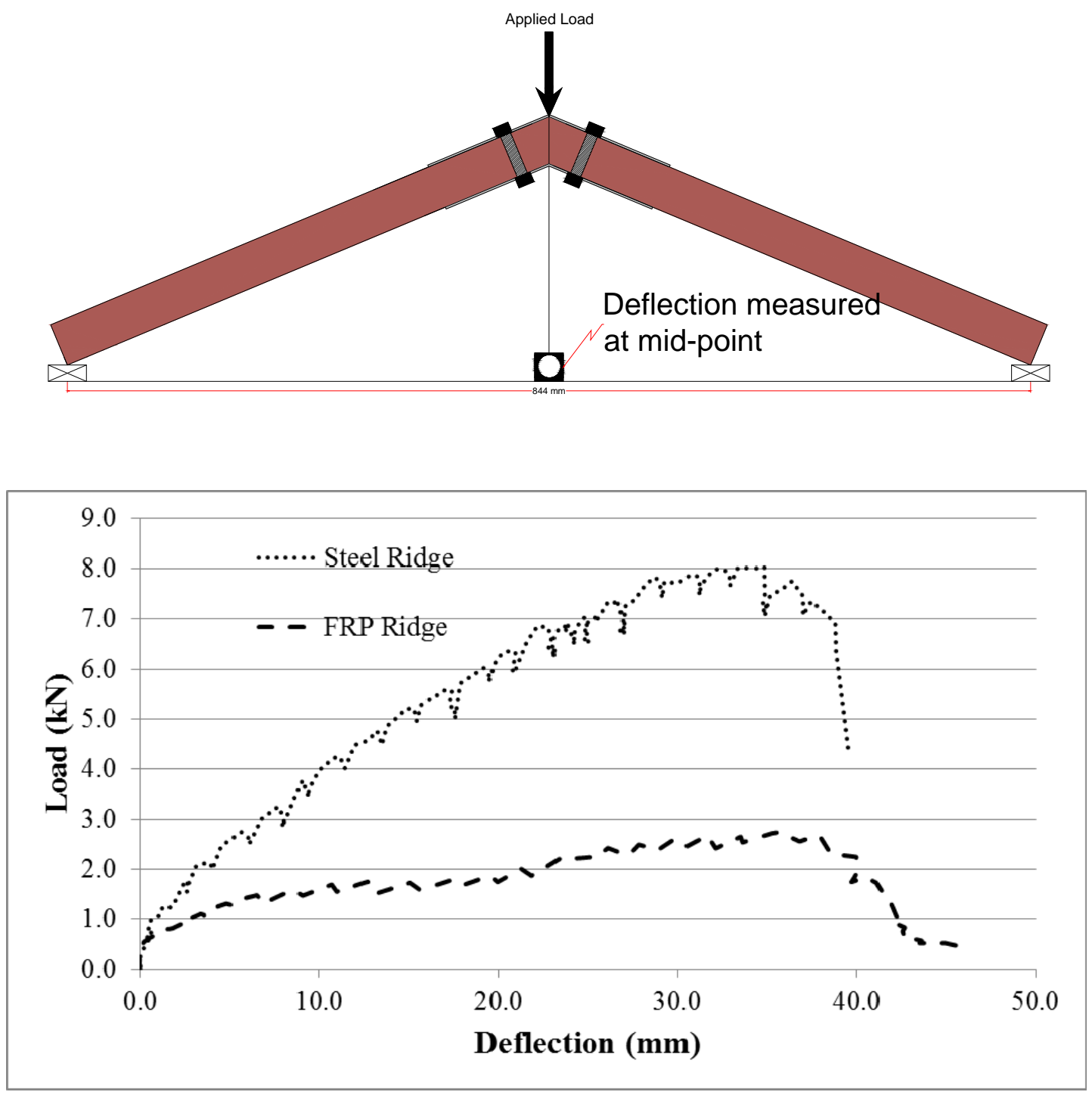

Figure 3.13. Moment-Deflection Demand Curves for Ridge Tests with FRP and Steel Plates 


\title{
4. FULL-SCALE TESTING OF A PRECAST CONCRETE SUPTERTILE ROOFING SYSTEM FOR HURRICANE MITIGATION
}

Brandon Mintz, Amir Mirmiran, Nakin Suksawang, and Arindam Gan Chowdhury

\section{Prepared for ASCE Journal of Architectural Engineering}

\begin{abstract}
Roofing is one of the most vulnerable parts of the building envelope in residential construction and is often damaged by extreme winds and wind-borne debris. Traditional roofing systems are damaged under high wind-induced suction that cause failure of roof coverings such as tiles or shingles. Workmanship-related issues, such as inadequate spacing of nails or poor application of foam adhesive, are also responsible for damages to many roofing systems due to failures of inter-component connections and roof sheathing. Such damages can lead to subsequent rain intrusion and loss of interior contents. This paper focuses on a new composite roofing system, which consists of large precast concrete structural panels designed to replicate the architectural shape of high profile roof tiles. The system allows the components and cladding $(C \& C)$, usually placed onto the structure, to be incorporated into the main wind force resisting system (MWFRS). The roofing panels, therefore, serve both as a structural system and as a highly robust, architecturally pleasing building envelope, eliminating vulnerable roof cladding elements (e.g. roof tiles/shingles) and minimizing inter-component connections to reduce the risk of poor workmanship related failures. This paper presents results of full-scale testing to evaluate the system-level performance of the new roofing system, including its connections. The results are used to predict the limits of the system for strength and
\end{abstract}


serviceability. The performance in tests under a combination of loading scenarios simulating high wind-induced pressures indicated that the structure could resist extreme hurricane- induced loading. The results also allowed design tables to be developed for the new roofing system for buildings located in various geographical regions.

Keywords: Wind mitigation; Residential roofing; Fiber-Reinforced Polymers (FRP);

Precast concrete

\subsection{Background}

Roofing is one of the most vulnerable parts of the building envelope in residential construction and is often damaged during extreme wind events, which can lead to further damage to the structure or surrounding structures. Manning and Nichols (1991) found that damage or destruction of the roof structural system may cause walls to lose lateral support, leading to building collapse. Post-hurricane disaster surveys have shown the impact that hurricanes can have on residential structures through the damage that is caused to roofs and the resulting damage to the rest of the structure (NAHB, 1993).

Hurricane Hugo, which made landfall as a Category 4 storm in 1989 (Bright, 2010), caused damage with an estimated $80 \%$ of losses attributable to roofing failure (Cook, 1991; Manning and Nichols, 1991). During hurricane Andrew negative pressures on the roofs, and subsequent increases in the internal pressure after the building envelope was compromised, led to loss of the stability provided by the sheathing and subsequent roof failures (Ayscue, 1996; FEMA, 1992). In spite of changes to local building codes after Hurricane Andrew, more recent storms have continued to reveal problems with conventional roofing (MDC-BCCO, 2006). Innovative improvements of roofs are therefore in order. 


\subsubsection{Conventional Residential Roofing Systems}

Conventional roof elements are categorized as either Main Wind Force Resisting System (MWFRS) or Components and Cladding (C\&C). Both have their design provisions based upon the ASCE 7-10 Standard (2010). The purpose of the MWFRS is to support the structure against the wind pressure. The $\mathrm{C} \& \mathrm{C}$ forms the water resistant building envelope and includes the tiles or shingles. These items are typically connected together on-site.

Conventional residential building roofing systems mostly consist of timber trusses, plywood sheathing, underlayment, and roof coverings such as tiles or shingles. The various parts of these systems have weak links. In particular, roof covering damage, caused by wind-induced failures of tiles and shingles, has been common (Li 2012). Failures of secondary water barriers under high wind-induced suction were documented by Bitsuamlak et al (2009). Roof sheathing damages due to inadequate connections were reported by Cheng (2004) and van de Lindt (2010). Local failures lead to cascading failures of larger roof portions and to significant water intrusion. Also, roof to wall connections can fail under loading due to the increase of building internal pressures caused by the breach of the building envelope (Chowdhury, et al, 2013).

Much of the damage caused by winds occurs due to lack of quality control during construction and poor workmanship (van de Lindt, 2010). This is particularly the case for the mass residential market where low- and mid-rise houses are constructed using traditional methods by a multitude of contractors of varying levels of competence, experience, and workmanship. Maintaining quality in such a market is a very difficult task. Water intrusion can occur if flashing is not properly installed along offsets. Missing or out-of-place fasteners may compound the problems. However, if a building can be 
assembled from a few large engineered components using well engineered connection methods, then quality control moves from the building site to the much more easily controlled conditions of the factory floor. For these reasons a desirable feature of novel roofing systems is a reduced number of system components and thus a reduced number of inter-component connections. Alternative roofing systems need to be developed that are strong, constructible, and adequate from an aesthetics point of view.

\subsubsection{Novel Roofing System}

For the current work, a new roofing system has been developed, which consists mainly of large precast concrete structural panels that reproduce the architectural shape of high profile roof tiles. Such roofing panels, named as Supertiles, serve both as a highly robust structural system and as an architecturally satisfying building envelope, while eliminating vulnerable roof cladding elements (e.g. roof tiles/shingles) and minimizing intercomponent connections to reduce the risk of failures due to poor workmanship. This is accomplished in the new system by incorporating the C\&C into the MWFRS. Preliminary estimates suggest that the composite system is comparable in cost to traditional roofing systems as it replaces not only roof covering, underlayment, and sheathing but also trusses by spanning from the wall to a roof ridge connection. This allows for vaulted ceilings by leaving the attic space open (Briscoe, et al, 2010), or for a false ceiling that creates an uninterrupted attic space usable for storage.

The proposed panel system reproduces the general shape of a conventional residential roof with high profile barrel tiles and effectively employs the shape to provide structural strength. The reinforcing elements used in the panels are non-corrosive, thus 
eliminating the need for maintenance to prevent rusting, especially in humid environments.

The proposed roof panels use lightweight concrete, fiber reinforced polymer (FRP) bars as primary reinforcement, and an FRP grid as secondary transverse mesh, which can also improve the impact resistance of the panels. Figure 4.1 shows a schematic of the panel section. As can be observed, the aesthetic barrel shape of the panels is intrinsic to the design, while enhancing the moment of inertia of the section, providing stiffness to the panel. The strong barrel sections, shown in the schematic, act as embedded beams integrated into the natural contours of the tile shaped geometry, and are the means by which the trusses can be eliminated. The panels are designed to resist the gravity and wind loads, thereby fulfilling the function of trusses.

The proposed composite roofing system, including the connections, was designed, manufactured, and tested as a full-scale system to demonstrate the flexural capacity of the panel and the strength of the connections. The paper presents results of the full-scale testing to evaluate the system-level performance, including its connections. The performance under a combination of loading scenarios, including simulated high wind loading, validated the efficacy of the new roofing system. The tests, conducted on panels with 12-ft wall-to-wall span length, yielded system-level data on the panels' moment capacity and the performance of the connections For panels with cross-sectional properties identical to those of the panels being tested, the data on the panels' moment capacity providing, for can be used to calculate the span length consistent with wind loads specified for buildings with various heights located in various geographical regions. For those buildings compliance with serviceability criteria on panel deflections are 
checked as well, and estimates are presented of the requisite spacing between connections, based on the connections' capacities and a sufficiently large safety margin.

\subsection{Design of the Novel Roofing System}

\subsubsection{Developing Structural Capacity and Architectural Shape}

A shell barrel section simulating a typical architectural shape of high profile tiles was used to design the strong barrel sections acting as embedded beams. The strong barrel section [see Fig. 4.1 (a)] is designed using basic reinforced concrete design principles (see, e.g., Wight and MacGregor, 2005). The compressive strength of the FRP is neglected. For design purposes the positive bending of the beam is critical, since the uplift typically does not control, owing to the dead load of the panel that counteracts its effect.

\subsubsection{Connections for the New Roofing System}

The roof-to-wall connection consists of a bolt embedded in the wall and passing through the panel. This allows transferring the uplift and shear loads from the roof to the walls. For the full-scale test, a wall was built in the laboratory and a threaded rod insert was placed into the wall at an average spacing of $380 \mathrm{~mm}$. The threaded rods were then inserted through holes cast in the panels and were screwed into the inserts. Testing showed that the capacity of these connections was determined by the shear strength of the bolts. The threaded rods used were $9.5 \mathrm{~mm}$ in diameter. A detail for the roof to wall connection is shown in Fig. 4.2.

The panel-to-panel connection transfers shear between adjacent panels. This connection is of the tongue-in-groove type as shown in Fig. 4.3. The shear strength of the tongue must transfer the load from panel to panel. Wind induces position-dependent 
negative pressures along the roof edges which tend to move the end panels relative to adjacent panels. The shear strength of the tongue in the panel-to-panel connection needs to be sufficient to restrain this movement. The ridge connection uses steel plates above and underneath the panels. Bolts, used as shear connectors, are embedded into the panels, and the plates sandwich the windward and leeward panels. The shear connectors for the test were spaced at an average of $265 \mathrm{~mm}$. The shear connectors were cast monolithically into the panels and the top and bottom plates were connected as shown in Fig. 4.4. The strengths used for each connection are provided in Table 4.1.

\subsection{Preliminary Cost Analysis for the New Roofing System}

A preliminary comparison between initial costs of materials in conventional roofing and the new roofing system (Tables 4.2 and 4.3) suggests that the new system can be competitive. Local contractor pricing for the Miami, Florida area was used to estimate the costs of conventional roofing systems listed in Table 4.2. Data has shown that the costs of conventional construction can in fact be much higher (Taylor, 2014). In addition, the performance, which will be discussed later, of the new system is superior in terms of the need for maintenance and the lower risks of damage and water intrusion, meaning that life-time costs would be further reduced for the new system.

\subsection{Section Design}

Three loading combinations were considered from the Florida Building Code (FBC, 2010) as:

$0.9 \mathrm{D}+1.0 \mathrm{~W}$, considered with case 1 in Fig. 4.5

1.2D $+1.6 \mathrm{~L}+0.5 \mathrm{~W}$, considered with cases 2 and 3 in Fig. 4.5

1.2D + 0.5 $\mathrm{L}+1.0 \mathrm{~W}$, considered with cases 2 and 3 in Fig. 4.5 
These three load combinations account for all combinations involving dead load, live load, and wind loading that will lead to maximum effects. Figure 4.5 provides loading scenarios for the windward and leeward panels. The dead load was the dead load was estimated based on a lightweight concrete design used with our system. The live load for roofs used in this study is specified by the Florida Building Code (FBC, 2010). The value of 958 Pa specified in the Florida Building Code was employed. Wind load calculations were carried out based upon ASCE 7-10, which provides a maximum wind speed of 78.3 $\mathrm{m} / \mathrm{s}$ for Miami-Dade County (ASCE 7-10). The values for external and internal pressure were taken from ASCE 7-10 and are provided in Fig. 4.5, in which the three conditions considered above are presented showing the coefficients for the windward and leeward sides of the structure.

The loading conditions for the windward and leeward panels must be considered. To prevent failure prior to testing all loading configurations it was decided that the panels should be loaded up to the design rather than the ultimate loads. The loading steps considered are as shown in Table 4.4. The results from each load step indicated the loading condition that produced the largest stresses under the design loads. The specimen was then subjected, under that condition, to loading in excess of the design load up to the limits allowed by the test setup.

The panels as designed for actual construction have half of a strong barrel section with a concave panel-to-panel tongue-in-groove connection, a complete strong barrel section in the middle, and a half strong barrel section with a convex panel-to-panel connection at the end, as shown in Fig. 4.6. The region between barrels replaces the sheathing and acts as a diaphragm to transfer the load and protect against puncture. The 
panels fit together at the ridge to connect to the panels on the opposite side of the roof. The longitudinal reinforcement used in this test was C-bar. A product of Marshall Composite Systems, LLC, C-bar is a glass fiber-reinforcement (GFRP) that does not corrode as steel reinforcement would (Marshall Composites, 1999). The mesh reinforcement was C-grid, carbon fiber-reinforced polymer (CFRP) (Chomarat, 2010). This product is made by Chomarat. The concrete strength near the time of testing was at least 38.3 MPa, which was assumed for design purposes. The general properties of the reinforcement used are provided in Table 4.5.

\subsection{Test Setup and Instrumentation}

\subsubsection{Test specimens}

Using the shape mimicking a roof tile, four specimens were created for total span length (i.e. wall to wall) of $3.66 \mathrm{~m}$. These specimens were placed onto walls that were built in the laboratory to demonstrate the constructibility of the system. The width of the four panel specimens was half the width of the panel as designed for actual use in construction, as can be seen in Fig. 4.6. The panel specimens were connected to a precast wall section, which was tied down to the laboratory's strong floor. The setup enables all connections to be simultaneously tested while testing the flexural capacity of the section.

\subsubsection{Connections}

The connections used in the system are the roof-to-wall connection, the panel-to-panel connection, and the ridge connection. Please refer to Table 4.1 where the strengths for each connection are outlined.

The roof-to-wall connection was designed to be embedded in the wall and extend up to the roof panel sections. A $15 \mathrm{~mm}$ rod was used, that was screwed into an 
embedding device inserted into the wall. The spacing of the roof-to-wall connection averaged $377 \mathrm{~mm}$. The roof sections were suspended in place and the threaded rods were inserted through the panels.

The panel-to-panel connections were created by using molds with the tongue and the corresponding groove was cast into the panels. The reinforcement was fixed to either side of the mold and then placed inside the formwork to create the completed section.

The ridge was created using a $15 \mathrm{~mm}$ thick plate that was connected to the top and bottom of the section. The panels were positioned in place with the shear connectors protruding through the plates. The shear connectors were steel threaded rods that were also $15 \mathrm{~mm}$ in diameter. The average spacing of the shear connectors for the full-scale test was $251 \mathrm{~mm}$.

\subsubsection{Loading Procedure}

The load was applied with two reversible jacks. The jacks were typically controlled by two separate pumps so that the upward and downward motion could be controlled independently. The only exception was when all the loading was in the upward direction. In that case the jacks were connected to the same pump to ensure that the loading would be increased equally on both sides of the roof. Figure 4.7 shows the loading device (pumps shown in yellow) and illustrates how the system was tied down to reproduce the loading of the specimens by both positive and negative pressures.

Steel angles were placed at the midspan of each side of the specimen on both its top and bottom sides, and a steel rectangular section was placed across the bottom midspan portion. Steel plates with a $25.4 \mathrm{~mm}$ hole were welded onto the rectangular section in four points, a threaded rod was passed through the holes in the plates, and nuts 
were placed and secured to the outside of the threaded rod. A jack was fitted with a converting screw section so that it could be connected to the load cell above. The specimen could be loaded in either direction without changing the loading mechanism. Figure 4.7 demonstrates the loading setup. The specimens fit together as is shown in Fig. 4.8. Together the specimens fit together at the panel-to-panel connection to form the width of a proposed panel shown in Fig. 4.1. The panel to wall connections used for testing purposes are shown in Fig. 4.9. The section and the reinforcement details are shown in Fig. 4.6 along with the sectional properties of the section tested on both the leeward and windward sides.

The deflection was monitored through the use of string potentiometers. The string potentiometers were placed on both sides of the structure and in the middle to monitor the ridge movement. Three string potentiometers were placed on the leeward side. Two midspan deflections were measured, one at the middle or panel-to-panel connection and one at the outside half barrel section. The third string potentiometer was used to measure the lateral movement of one of the specimens at the wall support. Identical string potentiometers were placed on the windward side to measure the deflection at the midspan of the windward panels. The Instrumentation used for the testing is shown in a schematic in Fig. 4.10.

Strain was measured in the specimen using strain gauges placed on the top and bottom at various locations in the specimen. The strain was measured at the load point on the top and bottom, on the outside of the specimen in the half barrel region on the top and bottom, and at the ridge in the steel section itself, also on the top and at the bottom. The 
strain gauges were identical for the leeward and windward sides of the specimen. They were used to find the maximum stresses induced in the specimens.

\subsection{Results and Discussion}

There are two limits for any structural system that need to be addressed. A system is limited by the maximum stress the system is able to withstand and the maximum deflection that is allowed at the service load. For instance, in the Florida Building Code the wind load considered for structural design is allowed to be reduced by a factor of 0.42 when considering deflection requirements (FBC, 2010). That reduced load is permitted to induce a deflection of at most $\mathrm{L} / \mathrm{c}$, where $\mathrm{L}$ denoted the span length and $\mathrm{c}$ is a number specified in building codes or by the building owner or user. For this paper, c $=240$, i.e.,

a maximum allowable deflection L/240; although, the possibility is left open of using different codes. It was determined that $\mathrm{c}=240$ was representative of the appropriate deflection for a ceiling without a plaster finish (FBC, 2010) The maximum span length allowable based upon both strength and serviceability will be averaged in the analysis to determine the maximum span length.

Sections 6.1 to 6.4 consider the system's flexural behavior and its connections. Section 6.5 presents examples tables showing span lengths and required distances between connections calculated as functions of panel and connection capacities for various building heights and locations subjected to winds with design velocities specified in building codes.

\subsubsection{Flexural Behavior}

In Table 4.6 the average pressure applied at each load step is the total load applied to the panel divided by the total area of the panel being loaded. The bending moment was 
calculated by considering the line loads applied to the panels through the steel bars. The deflection at the midspan of each panel was found by measuring the midspan panel displacement and subtracting the ridge displacement. Based upon the span length of $3,658 \mathrm{~mm}$, the limiting deflection was assumed to be $3,658 / 240 \approx 15 \mathrm{~mm}$ (e.g. FBC, 2010). Under Load Steps 1-5, this deflection was never exceeded. The deflection was much higher for Load Steps 6 and 7 because the connection of the wall to the floor became loosened due to repeated loading, a condition that is in no way related to the behavior of the roof system. Deflection criteria vary among individual building codes; as noted earlier the criterion $\mathrm{L} / 240$, where $\mathrm{L}$ denotes span, was considered in this work.

In Table 4.7, the maximum strains were found from the strain gauge data for both the windward and leeward panels. In the uplift condition the panels experienced tension stresses (indicated by positive strain values) at the top and compression stresses (indicated by negative strain values) at the bottom. The opposite was true under downward loading condition. Note that the strain in Table 4.7 never reaches compressive failure level for concrete, about 3,000 microstrain. This was confirmed during testing where concrete compressive failure was never observed during any load step.

\subsubsection{Panel-to-Wall Connections}

Based upon the results in Table 4.6, the average load on each panel-to-wall connection did not exceed $4.40 \mathrm{kN}$. This load is far smaller than the connection's capacity due to its $9.5 \mathrm{~mm}$ diameter steel rods. The capacity of this connection with a factor of safety of four is provided in Table 4.1. The visual observations during the tests confirmed the satisfactory behavior of the connections. 


\subsubsection{Panel-to-Panel Connections}

During the testing for panel bending the same loads were applied to two adjacent panels connected by a tongue-and-groove connection. Under those loads the panels experienced the same downward or upward motion and no separation between the panels was observed. Given the building parameters and design wind speeds for a given building at a given location the required shear capacity of the panel-to-panel connection can be calculated as a function of the wind loading distribution on the panels. Due to the concealed nature of the connection, observations were limited during testing; however, no separation was observed to indicate that the connection failed during testing.

\subsubsection{Ridge}

Table 4.8 presents the stress results for the ridge. In Load Steps 1, 6, and 7 the panels on the windward and leeward sides were both loaded in the uplift condition. This caused the panels to rotate about the walls, which resulted in the compression of both the top and bottom plates of the ridge connection, Load Steps 2 and 5, for which the loading was downwards for the windward side and upwards for the leeward side, resulted in stresses at the ridge lower than those corresponding to Loads 1, 6 and 7. For Load Steps 3 and 4, when both windward and leeward panels were loaded downwards, the ridge participated in the beam action and compression was observed at the top plate while tension was observed in the bottom plate. However, the stresses indicated that, for design purposes, the ridge may be considered to be a hinge. The visual observations confirmed that, while some restraint may be expected during loading, it safe to assume that most of the loading will be allowed confirming that this connection is best modeled as a hinge. 


\subsubsection{Example Tables}

If the data obtained in the tests are used, it for buildings with various heights at locations subjected to winds with various specified design velocities span lengths can be calculated as functions of panel strength. Calculations were performed for the case of gable roofs with 5:12 slope. Using the system's moment capacities observed in the testing, span lengths were evaluated for various roof mean roof heights with various design wind speeds. Using the line load that would induce the moment calculated for each combination of span length and wind speed, the deflection could be calculated under the assumption that the panels are simply supported at the wall and ridge. The deflection so obtained was compared to the limit $\mathrm{L} / 240$ ( $\mathrm{L}=$ span length) to determine whether the deflection requirement is satisfied. If that requirement is not satisfied the serviceability (deflection) requirement controls the maximum span length.

Table 4.9 shows the calculated allowable span lengths as functions of design wind speed and height of the structure. The calculation of the span length (measure as the wall to the wall) was first based upon the strength of the panel as determined during. Next the deflection was calculated and compared to the allowable deflection. The maximum span length for each was averaged in Table 4.9. As can be noted, a roof with a mean roof height of $9.14 \mathrm{~m}$ in Bar Harbor, Maine will have a maximum allowable span of $11.34 \mathrm{~m}$ from the wall to the opposite wall. A similar roof in Key West, Florida will have a maximum allowable span of $11.10 \mathrm{~m}$. Similar tables can be constructed by varying roof slopes and other building parameters.

Tables were produced for the panel-to-wall connections, the distance between connections being the controlling parameter (Table 4.10), and for the ridge, with the 
shear connector spacing being the controlling parameter (Table 4.11). Based upon the calculated span lengths, the reaction at the wall and ridge can be found. The requisite spacing between connections corresponding to the results of Table 4.9 was determined next. The values listed in Table 4.1 were used to calculate the capacities of the panel-towall and ridge connections. A factor of safety of four was then applied to the calculated connection capacities.

\subsection{Conclusions}

A composite roofing system has been developed that is designed to combine the contributions of the MWFRS and C\&C into a single system. This novel system with its connections was subjected to full-scale testing. Four panel specimens were constructed, two for the windward panels and two for the leeward panels. The panels were joined together by panel-to-panel connections, connected to the walls by roof-to-wall connections, and connected at the ridge by a ridge connection with a top and bottom plate. Two-way hydraulic jacks were placed under the windward and leeward spans of the panels to mimic the effects of wind loading.

The specimens were loaded under the most unfavorable load combinations. The performance of the panels during the tests was fully satisfactory from the strength and rigidity points of view. The individual components also displayed functionality and load bearing ability. The performance of the roof-to-wall connection against the uplift force from the jacks was excellent. The panel-to-panel connections did not fail under bending

of the panels. The ridge proved to act as a hinge and showed good performance during the testing. 
From these tests, example tables were constructed based on the test data. For roofs with a specified slope, the maximum allowable span was determined as a function of building height and design wind speed, using the condition that the capacity of the panels and the connections, as determined in the tests and reduced by appropriate load factors, are not exceeded. The deflection was then checked to determine the deflection that would not exceed 1/240 times the span length. These values were then averaged. It was determined that, based upon the requirements of a particular code, the maximum span length from wall to wall may be over $11 \mathrm{~m}$.

Future research should focus on alternative section shapes. The dead load also needs to be a focus of future research as its reduction will help to provide better span capability. Given that typical roofs can have complex shapes, research is needed on the possible design of panels that can fit together to form a hip roof or hip and gable roof combination.

\section{Acknowledgements}

Support for this study was provided by the Center of Excellence in Hurricane Damage Mitigation and Product Development at Florida International University (FIU). All experiments were conducted at the Titan America Structures and Construction Testing Laboratory at FIU. The writers would like to thank Juan Cesin and Andres Urrego for assisting with the tests, and Dr. Emil Simiu for helpful comments. The opinions expressed are those of the writers alone and not necessarily the views of the sponsors. 


\section{References}

ASCE 7 (2010). Minimum design loads for buildings and other structures. American Society of Civil Engineers (ASCE), Washington, DC.

Ayscue, J. (1996). "Hurricane damage to residential structures: risk and mitigation." Natural Hazards Research Working Paper \#94, The Johns Hopkins University.

Bitsuamlak. G. T. , Chowdhury, A. G. , Sambare, D. (2009). "Application of a full-scale testing facility for assessing wind-driven-rain intrusion." Building and Environment 44 (12), 2430-2441.

Briscoe, C. R., Mantell, S. C., Davidson, J. H., and Okazaki, T. (2010) "Design procedures for web core sandwich panels for residual roofs." Journal of Sandwich Structures and Materials, 13, 23-58.

Bright, R. (2010) "NWS Charleston, SC-Hurricane Hugo." National Weather Service, February 16, 2010. < http://www.erh.noaa.gov/chs/events/hugo.shtml>

Cheng, J. (2004) "Testing and analysis of the toe-nailed connection in the residential roof-to-wall system.” Forest Products Journal, 54 (4), 58-65.

Chomarat (2010) "Technical data sheet-C50-1.8 x 1.6." Chomarat.com < http://www.chomarat.com/wp-content/uploads/2011/06/C50-1.8x1.6.pdf>

Chowdhury, A.G., Canino, I, Mirmiran, A., Suksawang, N., and Baheru, T. (2013) "Wind-loading effects on roof-to-wall connections of timber residential buildings." ASCE-Journal of Engineering Mechanics, 1-10.

Cook, R. (1991) "Lessons learned by a roof consultant." Hurricane Hugo One Year Later, Proceedings of a Symposium and Public Forum, Sill, B. L. and P. R. Sparks, eds. American Society of Civil Engineers, 144-152.

FEMA (1992) "Building performance: Hurricane Andrew in Florida." Federal Emergency Management Agency, December 21, 1992.

Florida Building Code (FBC) (2010). "Chapter 15: Roof assemblies and rooftop structures." Florida Code. 15.1.

Li, R. (2012). "Effects of architectural features of air-permeable roof cladding materials on wind-induced uplift loading." ProQuest ETD Collection for FIU. Paper AAI3541803. 
Manning, B. R., and Nichols G.G. (1991) "Hugo lessons learned." Hurricane Hugo one year later. In: Sill B.A., Sparks P.R., eds. New York: American Society of Civil Engineers.

Marshall Composites Systems, LLC (1999) "C-bar-Product guide specification." Marshallcomposites.com < http://www.marshallcomposite.com/c_bar_specs.pdf $>$

MDC-BCCO (2006). "Post hurricane Wilma progress assessment." Miami-Dade County Building Code Compliance Office, Miami, FL, 2006:1-22.

NAHB (1993) "Assessment of damage to single-family homes caused by hurricane Andrew and Iniki." NAHB Research Center Report. Upper Marlboro (MD).

Taylor, H. (2014) “Cost of constructing a home.” HousingEconomics.com, NAHB.

van de Lindt, J. W., Dao, T. N. (2010)."Construction quality issues in performance-based wind engineering: effect of missing fasteners." Wind and Structures, 13(3), 221234.

Wight, J. K. and MacGregor, J. G. (2009) "Reinforced Concrete: Mechanics \& Design." Pearson Education, Inc.. Upper Saddle River, New Jersey. 
Table 4.1 Strength of the Connections

\begin{tabular}{ccc}
\hline Connection & Strength & Unit \\
\hline Roof to Panel (per connection) & 4.40 & $\mathrm{kN}$ \\
Panel to Panel & Use a Tongue thickness of $25.4 \mathrm{~mm}$ \\
$\begin{array}{c}\text { Ridge Connection (per } \\
\text { connection) }\end{array}$ & 4.45 & $\mathrm{kN}$ \\
\hline
\end{tabular}

Table 4.2 Construction Costs for Conventional Roofing Systems

\begin{tabular}{ccc}
\hline Item & Cost & \\
\hline Trusses (Taylor, 2014) & $\$ 22.50$ & $\mathrm{~m}^{2}$ \\
Sheathing (Market value) & $\$ 15.07$ & $\mathrm{~m}^{2}$ \\
Underlayment (Market value) & $\$ 1.18$ & $\mathrm{~m}^{2}$ \\
Concrete Tiles (Taylor, 2014) & $\$ 32.72$ & $\mathrm{~m}^{2}$ \\
Material Total & $\$ 71.47$ & $\mathrm{~m}^{2}$ \\
\hline
\end{tabular}

Table 4.3 Anticipated Initial Material Cost of the Novel Roofing System

\begin{tabular}{|c|c|c|c|}
\hline Item & Product & Company & Cost \\
\hline Concrete & $\mathrm{N} / \mathrm{A}$ & $\mathrm{N} / \mathrm{A}$ & $\$ 0.12 \mathrm{~m}^{2}$ \\
\hline GFRP Rods & C-Bar & $\begin{array}{l}\text { Marshall Composites } \\
\text { Technologies }\end{array}$ & $\$ 23.14 \mathrm{~m}^{2}$ \\
\hline \multirow[t]{2}{*}{ CFRP Mesh } & C-grid & Chomarat & $\$ 34.01 \mathrm{~m}^{2}$ \\
\hline & & Material Total & $\$ 57.37 \mathrm{~m}^{2}$ \\
\hline
\end{tabular}


Table 4.4 Calculated Loading and Actual Loading Applied for Each Load Step

\begin{tabular}{cccc}
\hline Load & \multicolumn{3}{c}{ Windward } \\
\cline { 2 - 4 } Step & Calculated Loading & Load Direction & $\begin{array}{c}\text { Actual Load } \\
\text { Applied } \\
\mathbf{k N}\end{array}$ \\
$\mathbf{1}$ & $\mathbf{k N}$ & & -3.75 \\
$\mathbf{2}$ & -3.87 & UP & 4.3 \\
$\mathbf{3}$ & 4.27 & DOWN & 4.15 \\
$\mathbf{4}$ & 3.89 & DOWN & 8.10 \\
$\mathbf{5}$ & 7.80 & DOWN & 9.01 \\
$\mathbf{6}$ & 8.54 & DOWN & -7.88 \\
$\mathbf{7}$ & -7.75 & UP & -11.04 \\
\hline & Anticipated Failure & UP & Actual Load \\
Load & & Load Direction & Applied \\
Step & Calculated Loading & & -3.83 \\
& $\mathbf{k N}$ & UP & -4.20 \\
$\mathbf{1}$ & & UP & 3.22 \\
$\mathbf{2}$ & -3.87 & DOWN & 7.60 \\
$\mathbf{3}$ & -4.17 & DOWN & -8.78 \\
$\mathbf{4}$ & 2.58 & UP & -8.31 \\
$\mathbf{5}$ & 5.16 & UP & -14.79 \\
$\mathbf{6}$ & -8.34 & UP & \\
$\mathbf{7}$ & -7.75 & &
\end{tabular}

Table 4.5 Properties of C-grid and C-bar

\begin{tabular}{cccc}
\hline Product & Manufacturer & $\begin{array}{c}\text { Modulus of } \\
\text { Elasticity }\end{array}$ & $\begin{array}{c}\text { Ultimate Strain in } \\
\text { Tension }\end{array}$ \\
\hline C-grid & Chomarat & $235 \mathrm{GPa}$ & $0.76 \%$ \\
C-bar & $\begin{array}{c}\text { Marshall } \\
\text { Composites }\end{array}$ & $42 \mathrm{GPa}$ & $1.90 \%$ \\
\hline
\end{tabular}


Table 4.6 Maximum Moment and Vertical Panel Deflections

\begin{tabular}{cccc}
\hline Load & \multicolumn{3}{c}{ Windward } \\
\cline { 2 - 4 } Step & $\begin{array}{c}\text { Average } \\
\text { Pressure } \\
\mathbf{( P a )}\end{array}$ & $\begin{array}{c}\text { Average } \\
\text { Moment } \\
\mathbf{( k N - m )}\end{array}$ & $\begin{array}{c}\text { Average } \\
\text { Deflection } \\
\mathbf{( m m )}\end{array}$ \\
$\mathbf{1}$ & -1236.01 & -3.45 & 13.34 \\
$\mathbf{2}$ & 1419.17 & -3.87 & -1.03 \\
$\mathbf{3}$ & 1370.39 & 3.59 & -10.84 \\
$\mathbf{4}$ & 2672.47 & 7.31 & -9.92 \\
$\mathbf{5}$ & 2974.23 & 4.18 & -0.94 \\
$\mathbf{6}$ & -2600.64 & -7.32 & 85.92 \\
$\mathbf{7}$ & $\begin{array}{c}\text { Maximum } \\
\text { Pressure }\end{array}$ & $\begin{array}{c}\text { Maximum } \\
\text { Moment } \\
\text { (kN-m) }\end{array}$ & $\begin{array}{c}\text { Maximum } \\
\text { Deflection } \\
(\mathbf{m m})\end{array}$ \\
& $\mathbf{( P a )}$ & -10.55 & 121.53 \\
\hline & -3644.27 & - &
\end{tabular}

\begin{tabular}{|c|c|c|c|c|}
\hline \multirow[b]{2}{*}{$\begin{array}{l}\text { Load } \\
\text { Step }\end{array}$} & \multicolumn{3}{|c|}{ Leeward } & \multirow[b]{2}{*}{$\begin{array}{c}\text { Ridge Deflection } \\
\text { (mm) }\end{array}$} \\
\hline & $\begin{array}{c}\text { Average } \\
\text { Pressure } \\
\text { (Pa) }\end{array}$ & $\begin{array}{c}\text { Average } \\
\text { Moment } \\
(\mathrm{kN}-\mathrm{m})\end{array}$ & $\begin{array}{c}\text { Average } \\
\text { Deflection } \\
\text { (mm) }\end{array}$ & \\
\hline & -1262.85 & -3.49 & 13.17 & 14.51 \\
\hline 1 & -1384.98 & -1.90 & 8.64 & 3.69 \\
\hline 2 & 1061.47 & 3.16 & -9.35 & -11.31 \\
\hline 3 & 2508.61 & 7.08 & -9.68 & -9.49 \\
\hline 4 & -2743.68 & -3.98 & 11.79 & 4.68 \\
\hline 5 & -2743.68 & -7.52 & 82.39 & 95.60 \\
\hline 6 & $\begin{array}{c}\text { Maximum } \\
\text { Pressure } \\
\text { (Pa) }\end{array}$ & $\begin{array}{c}\text { Maximu } \\
\text { m } \\
\text { Moment } \\
\text { (kN-m) }\end{array}$ & $\begin{array}{c}\text { Maximum } \\
\text { Deflection } \\
\quad(\mathbf{m m})\end{array}$ & $\begin{array}{c}\text { Ridge Deflection } \\
(\mathbf{m m})\end{array}$ \\
\hline 7 & -4263.77 & -11.41 & 120.89 & 140.37 \\
\hline
\end{tabular}


Table 4.7 Maximum Strains at the Midspan

\begin{tabular}{|c|c|c|c|c|}
\hline \multirow[b]{2}{*}{$\begin{array}{l}\text { Load } \\
\text { Step }\end{array}$} & \multicolumn{2}{|c|}{ Windward } & \multicolumn{2}{|c|}{ Leeward } \\
\hline & $\begin{array}{c}\text { Top Strain } \\
\text { Concrete } \\
\text { Midspan } \\
\text { (microstrain) }\end{array}$ & $\begin{array}{c}\text { Bottom } \\
\text { Strain } \\
\text { Concrete } \\
\text { Midspan } \\
\text { (microstrain) }\end{array}$ & $\begin{array}{c}\text { Top Strain } \\
\text { Concrete } \\
\text { Midspan } \\
\text { (mircrostrain) }\end{array}$ & $\begin{array}{l}\text { Bottom Strain } \\
\text { Concrete } \\
\text { Midspan } \\
\text { (microstrain) }\end{array}$ \\
\hline 1 & 79 & -610 & 19 & -629 \\
\hline 2 & -382 & 534 & 21 & -719 \\
\hline 3 & -360 & 354 & -160 & 389 \\
\hline 4 & -603 & 819 & -454 & 1026 \\
\hline 5 & -712 & 1171 & 253 & -1432 \\
\hline 6 & 152 & -1836 & 253 & -1380 \\
\hline 7 & 129 & -990 & 618 & -1992 \\
\hline
\end{tabular}

Table 4.8 Maximum Stresses at the Ridge

\begin{tabular}{ccccc}
\hline \multirow{2}{*}{$\begin{array}{c}\text { Load } \\
\text { Step }\end{array}$} & $\begin{array}{c}\text { Top Stress } \\
\text { Ridge } \\
\mathbf{M P a )}\end{array}$ & $\begin{array}{c}\text { Bottom Stress } \\
\text { Ridge } \\
\mathbf{( M P a )}\end{array}$ & $\begin{array}{c}\text { Top Stress } \\
\text { Ridge } \\
\mathbf{( M P a )}\end{array}$ & $\begin{array}{c}\text { Bottom Stress } \\
\text { Ridge } \\
\mathbf{( M P a )}\end{array}$ \\
$\mathbf{1}$ & -31.07 & -29.96 & -28.58 & -36.14 \\
$\mathbf{2}$ & -12.47 & -0.97 & -7.46 & -18.15 \\
$\mathbf{3}$ & -6.31 & 2.64 & -1.92 & -8.09 \\
$\mathbf{4}$ & -4.54 & 10.10 & -1.24 & 6.55 \\
$\mathbf{5}$ & -7.17 & 19.13 & -1.81 & -0.22 \\
$\mathbf{6}$ & -19.68 & -43.94 & -4.42 & -39.05 \\
$\mathbf{7}$ & -49.01 & -130.76 & -55.42 & -136.02 \\
\hline
\end{tabular}


Table 4.9 Design Wind Tables for Span Length Based on Mean Roof Height and Wind Velocity (Note: Spacing is in terms of meters from wall to wall)

\begin{tabular}{ccccc}
\hline Wind Region (V in m/s) & \multicolumn{4}{c}{ Mean Roof Height (m) } \\
\hline & $\mathbf{3 . 0 5}$ & $\mathbf{6 . 1 0}$ & $\mathbf{9 . 1 4}$ & $\mathbf{1 2 . 1 9}$ \\
Bar Harbor, Maine (52) & 11.36 & 11.35 & 11.34 & 11.33 \\
Boston, Massachusetts (57) & 11.33 & 11.32 & 11.30 & 11.29 \\
Southampton, New York (62) & 11.30 & 11.29 & 11.27 & 11.25 \\
Galveston, Texas (67) & 11.26 & 11.25 & 11.22 & 11.21 \\
Miami Beach, Florida (76) & 11.19 & 11.17 & 11.15 & 11.13 \\
Key West, Florida (80) & 11.16 & 11.14 & 11.10 & 11.08 \\
\hline
\end{tabular}

Table 4.10 Design Wind Tables for Panel to Roof Connections Based on Mean Roof Height and Wind Velocity (Note: Spacing is in terms of millimeters)

\begin{tabular}{ccccc}
\hline Wind Region (V in m/s) & \multicolumn{4}{c}{ Mean Roof Height (m) } \\
\hline Bar Harbor, Maine (52) & $\mathbf{3 . 0 5}$ & $\mathbf{6 . 1 0}$ & $\mathbf{9 . 1 4}$ & $\mathbf{1 2 . 1 9}$ \\
Boston, Massachusetts (57) & 640 & 639 & 638 & 637 \\
Southampton, New York (62) & 634 & 636 & 634 & 633 \\
Galveston, Texas (67) & 630 & 628 & 626 & 624 \\
Miami Beach, Florida (76) & 623 & 621 & 618 & 616 \\
Key West, Florida (80) & 619 & 617 & 614 & 611 \\
\hline
\end{tabular}

Table 4.11 Design Wind Tables for Ridge Connection Shear Connector Spacing Based on Mean Roof Height and Wind Velocity (Note: Spacing is in terms of millimeters)

\begin{tabular}{ccccc}
\hline Wind Region (V in m/s) & \multicolumn{5}{c}{ Mean Roof Height (m) } \\
\hline Bar Harbor, Maine (52) & 539 & $\mathbf{6 . 1 0}$ & $\mathbf{9 . 1 4}$ & $\mathbf{1 2 . 1 9}$ \\
Boston, Massachusetts (57) & 536 & 535 & 537 & 536 \\
Southampton, New York (62) & 533 & 532 & 531 & 532 \\
Galveston, Texas (67) & 530 & 529 & 527 & 525 \\
Miami Beach, Florida (76) & 524 & 523 & 520 & 518 \\
Key West, Florida (80) & 521 & 519 & 517 & 515 \\
\hline
\end{tabular}




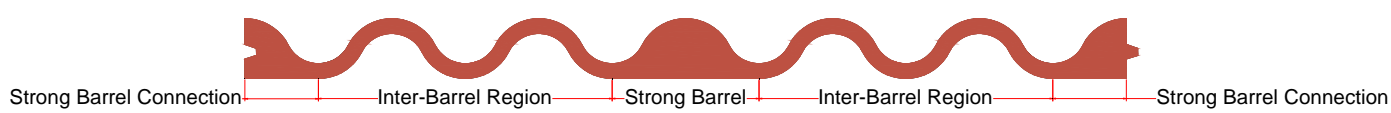

(a)

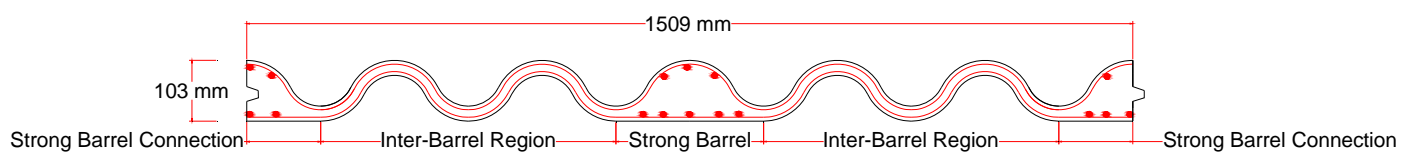

(b)

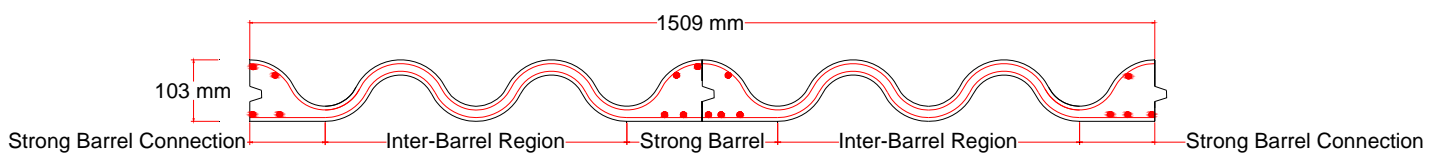

(c)

Figure 4.1 New Panel System (a) View of the panel shape; (b) Panel reinforcement; (c) Test panel section

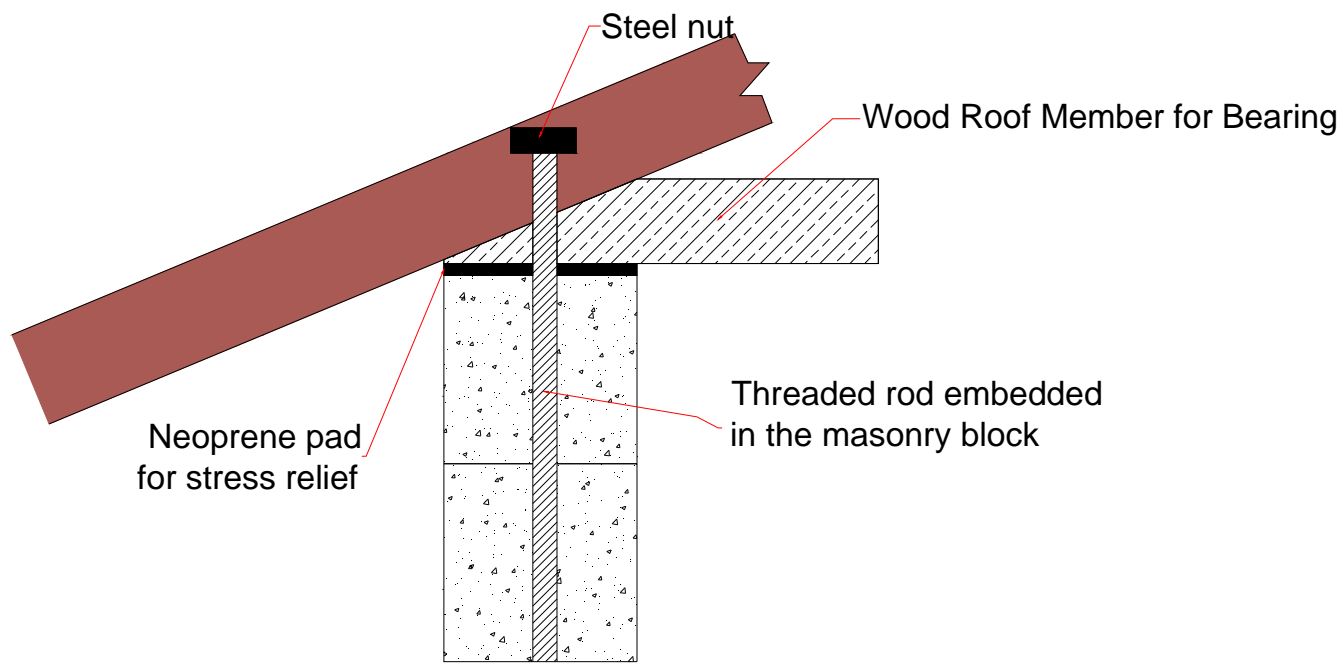

Figure 4.2 Roof to Wall Connection Detail 


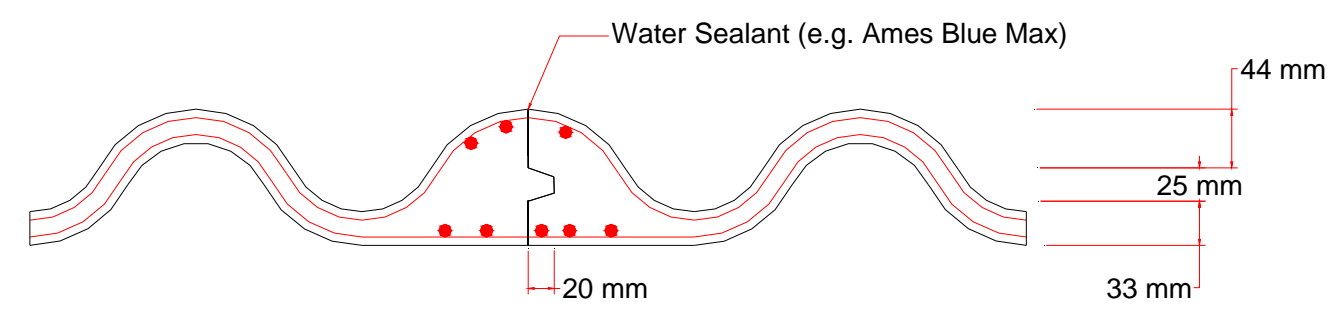

Figure 4.3 Panel to Panel Connection

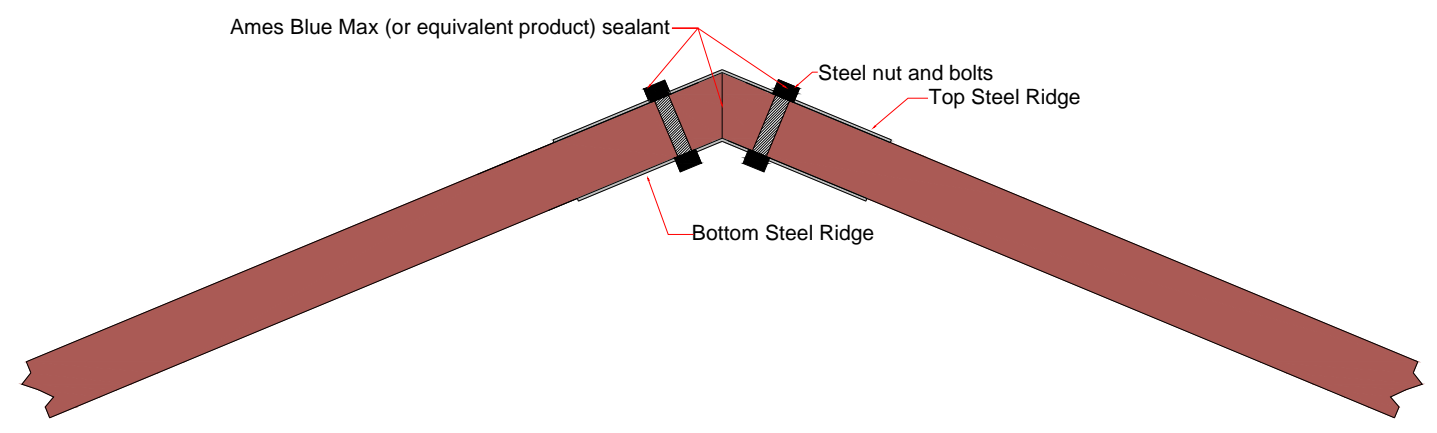

Figure 4.4 Ridge Connection Detail 


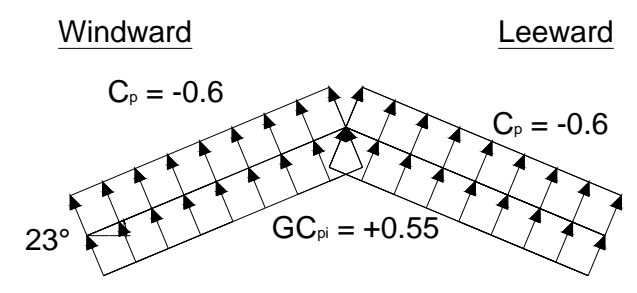

Case A

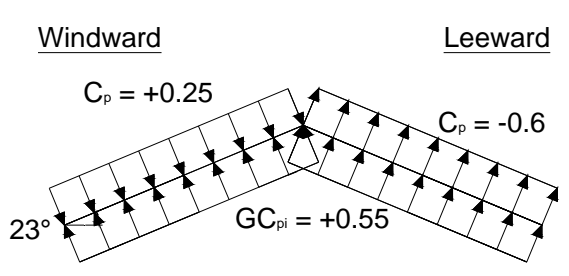

Windward Leeward

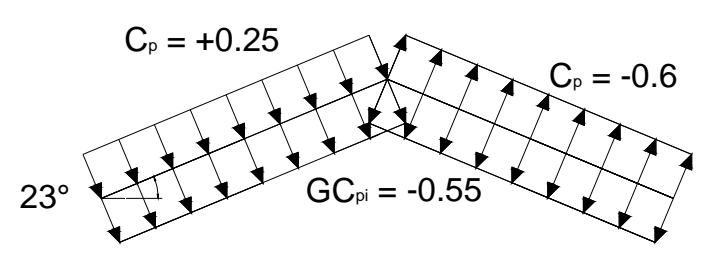

Case C

Figure 4.5 Load Case Scenarios

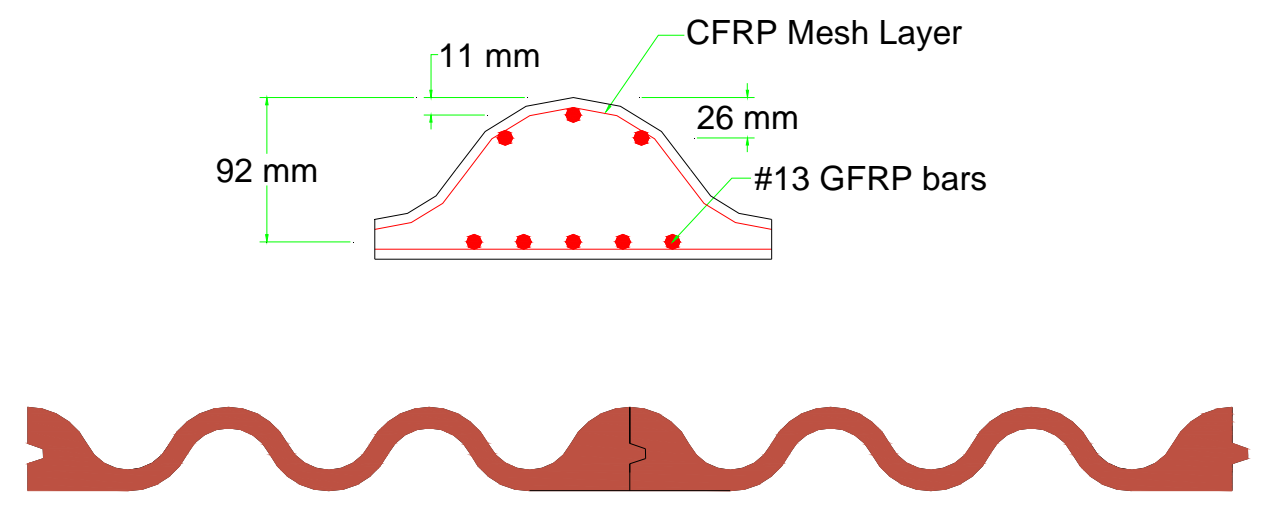

Figure 4.6 Strong Barrel Section and Testing Panels 


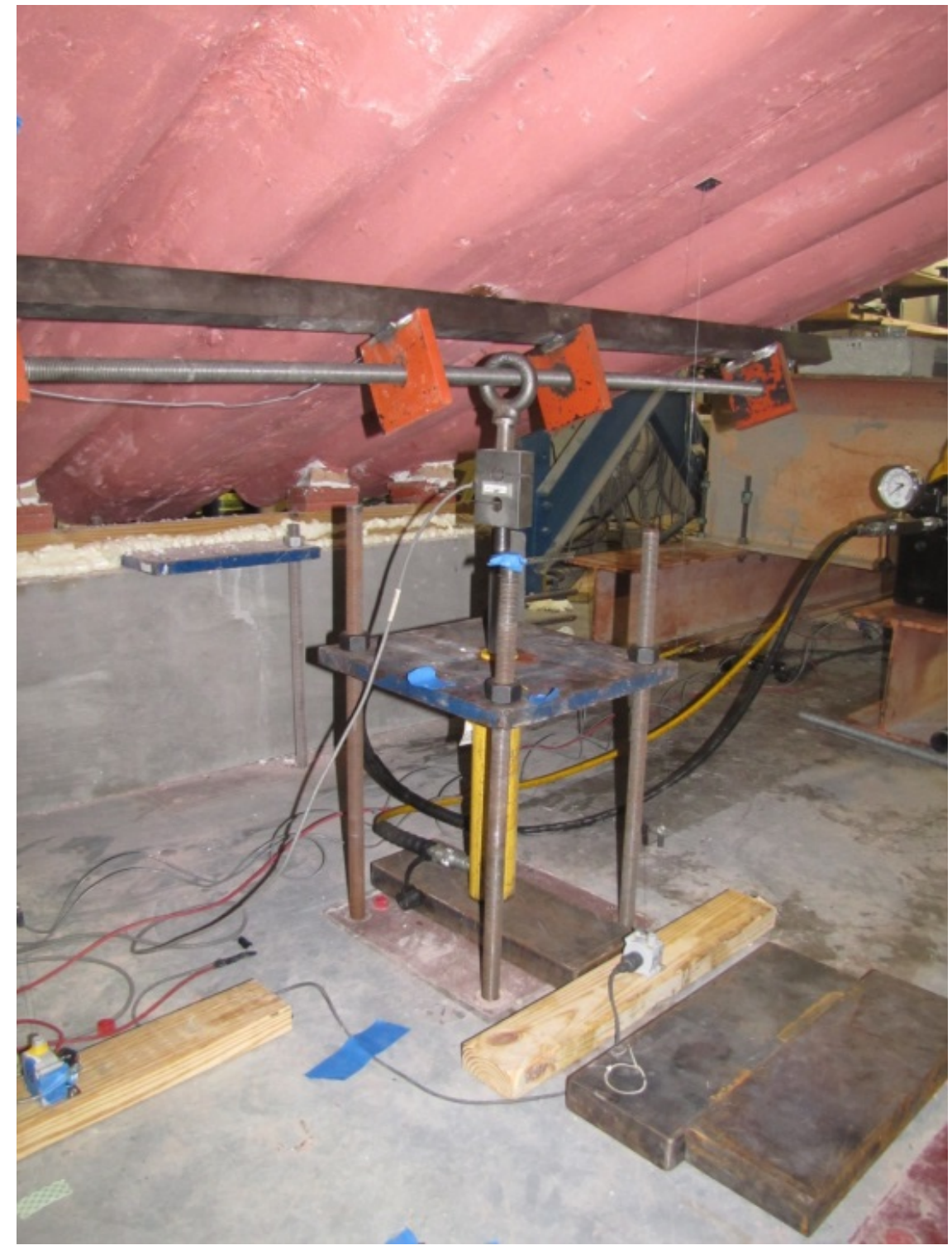

Figure 4.7 Load Application Device Can Apply both Positive and Negative Pressure 


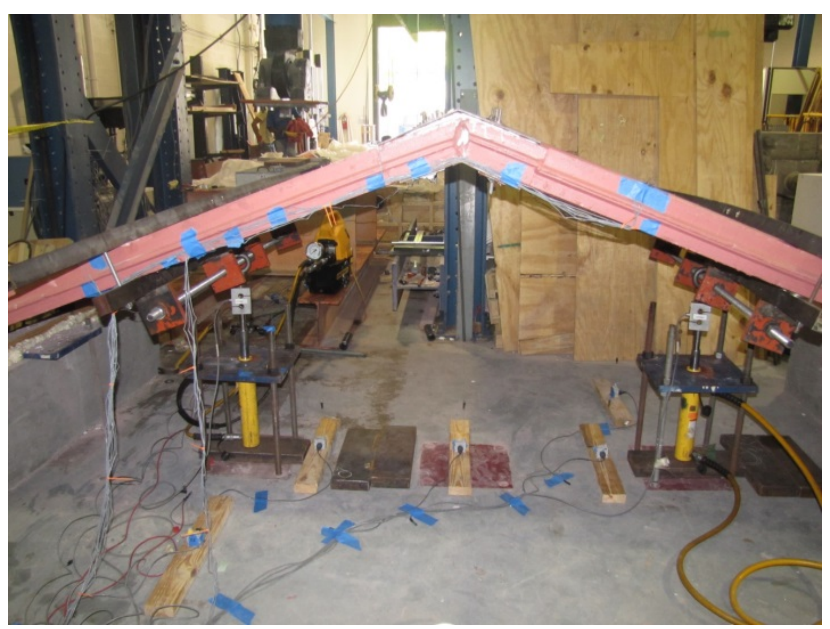

(a)

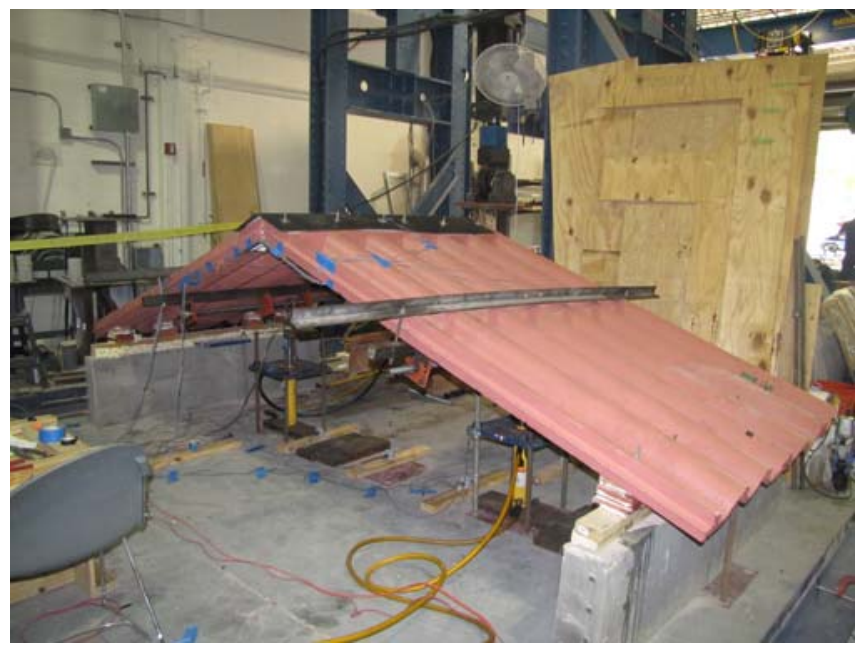

(b)

Figure 4.8 Full-Scale Test Setup (a) Load application; (b) Isometric view 


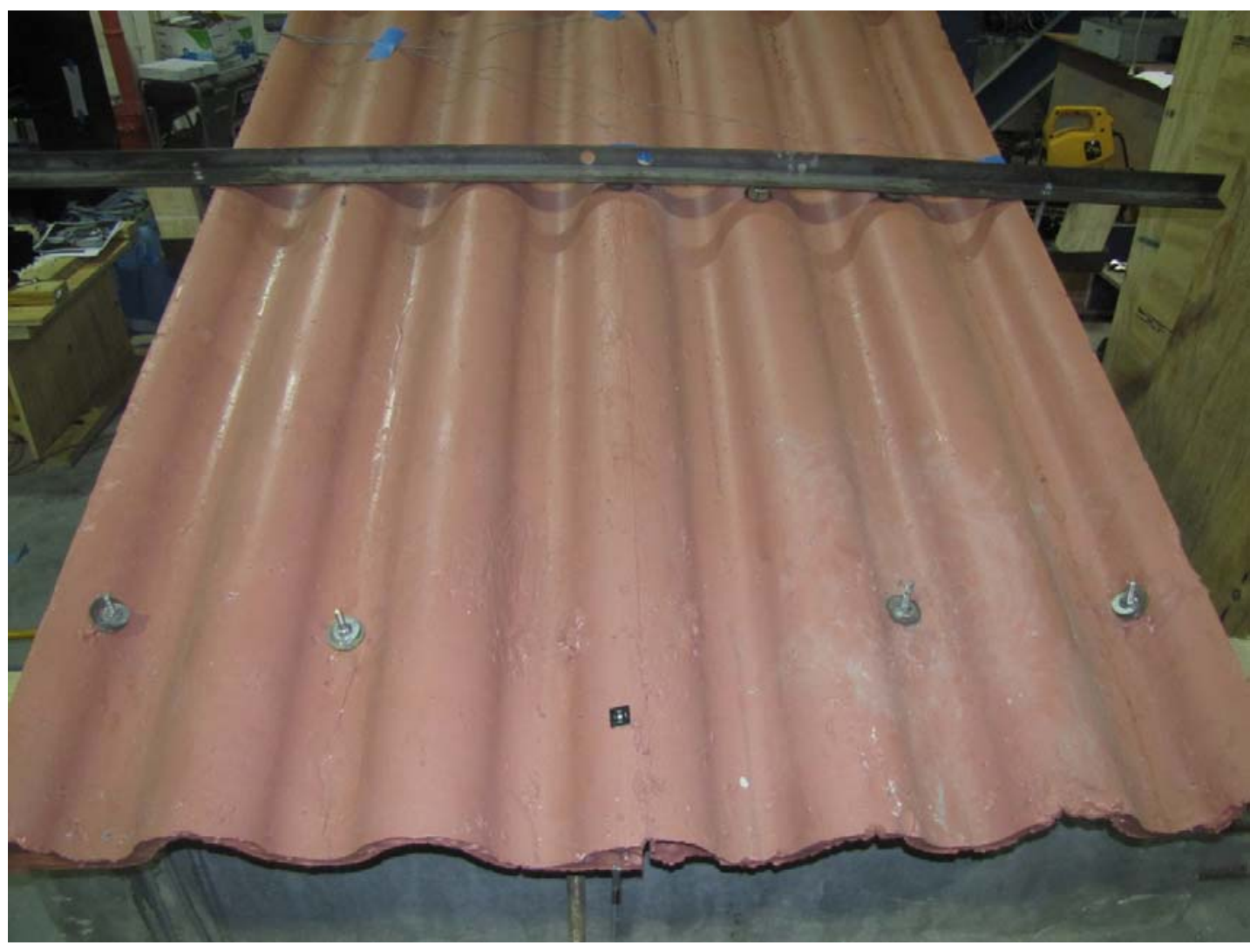

Figure 4.9 Roof to Wall Connections 

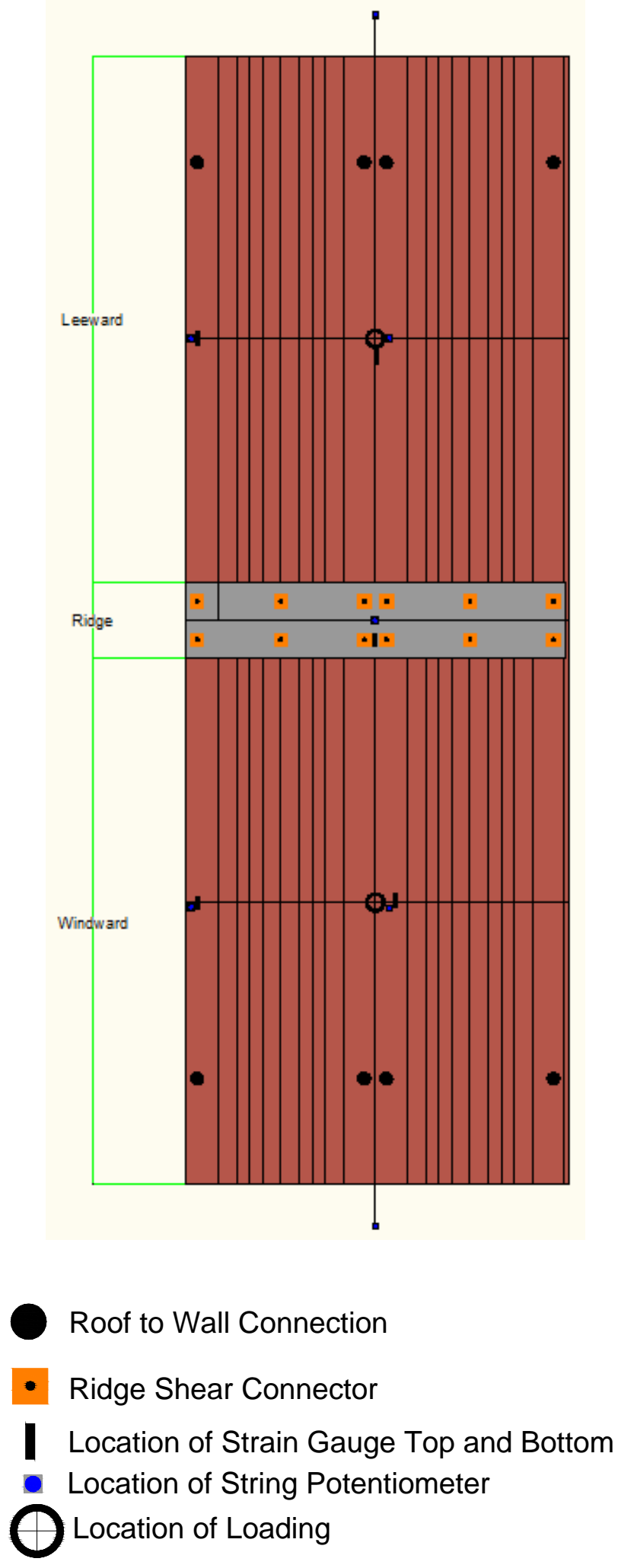

Figure 4.10 Instrumentation Schematic for the Full-Scale Test 


\section{SUMMARY AND CONCLUSIONS}

A novel Supertile system has been devised and presented that seeks to mitigate the problems of conventional roofing construction in residential structures during extreme wind events. The major components have been designed conceptually individually and then tested together to determine the behavior of the system. Together, the system devised is essentially one of potentially many systems that employ an architectural shape and then contain the structural reinforcement in the system to provide exceptional structural performance. During extreme wind events, both the wind pressure and wind borne debris must be mitigated without compromising the structure itself or endangering surrounding structures through the dislodging of cladding elements. The Supertile system does both through the use of reinforced concrete and innovative materials. The following are the conclusions and scientific contributions for each component of the study as presented in the preceding document.

\subsection{Design Concept for a Supertile System}

The following conclusions are reached for the concepts that were the driving force in the design of the system.

1) The Suptertile system has exceptional structural behavior, not only from strength, but also from ductility; although the ductility could also be a problem is not controlled. The strength achieved by the strong barrel section is able to withstand $175 \mathrm{mph}$ winds at a span length that is reasonable for residential homes. The ductility allows for the system to move without causing breaks in the system that could lead to water intrusion and damage to contents. 
2) The Supertile roofing system is a highly constructible system that has the potential to provide competitive material costs. It is anticipated that the initial costs of the system will be competitive with traditional construction and offset by savings in construction. The system presented in this paper only requires one contractor to install the panels rather than each component of a conventional roofing system. Intangible costs, such as savings on insurance premiums, can lead to very small payback periods, if they are needed at all. The construction steps have been laid out.

3) Energy efficient options are available for use with the Supertile system that provide complete insulation coverage. Added benefits of some options can lead to lower costs and easier constructibility. The system also allows the water proofing membrane to be placed beneath the structure and minimizes the effect of thermal bridging.

\subsection{Component Design Parameters}

Each component is designed for its own parameter. The conclusions reached for each component studied are as follows:

1) The flexural strength of the system can be varied with the spacing of the strong barrel section. Care should be taken towards the dead load, which remains the important factor for low-rise buildings such as residential structures. The span lengths found for varied wind speeds provides the ability to be placed on roofs of many different sizes and shapes in various wind demand regions. 
2) The roof to wall connections can be spaced as needed to protect against uplift. The dead load of the structure acts against the uplift force. Examining the roof to wall connections should always be considered with a load combination that reduces dead load and does not consider live load. The typical spacing of roof to wall connections of 2 feet $(610 \mathrm{~mm})$ would seem to be typical for high velocity situations. The roof to wall connection was found to provide a method for a load path from the roof to the wall.

3) Panel to panel connections are determined by the shear strength of the concrete, which is a parameter of the compressive strength of concrete. Throughout the test, we used a typical compressive strength of about 5,000 psi. This compressive strength gave enough shear capacity to the tongue in groove connection so that shear reinforcement would not be needed in most applications. We used a tongue thickness of about $1 \mathrm{in}$., which would provide enough shear capacity to withstand the movement of the panels relative to each other.

4) The ridge's parameter is the spacing of the shear connectors. In the study, we used a spacing of about 10-12 inches. This was judged to provide a certain level of constructibility. A full-scale test was needed to fully understand the behavior and design assumptions of the ridge.

\subsection{Full-scale Conclusions.}

The full-scale test was carried out for different load combinations to demonstrate both the positive and negative load bearing potential and ability of the system. The following conclusions have been reached for this study: 
1) The ridge behaves like a hinge in the structure. During testing, the walls were observed to rotate due to the testing setup. This rotation would be reduced with a proper foundation system as would be found in a residential home. The ridge would provide load transferring ability at a point, although it was observed that it will rotate and is best considered to be a hinge.

2) The inter-barrel regions provide a significant level of flexural resistance. The stress experienced in the structure did not approach failure while testing the system up to the $175 \mathrm{mph}$ pressure for both positive and negative pressure considering all load combinations. The span length used from wall to ridge was about 6 feet. Using this span, we found the system to have good load bearing resistance and behavior.

3) The overall load bearing ability of the system is exceptional with the windward and leeward panels assisting each other in bearing the load. The connections all displayed a significant ability to act within the system and provided sufficient strength for typical loading bearing or transferring situations. None of the connections failed while loading the full-scale system.

\subsection{Future Research}

The following are points that came out of the study for points of future research:

1) The manufacturing process needs to be examined to create a system to cast the panels in a time and labor efficient manner. This is a process that needs to be streamlined to create maximum potential for profit. The analysis for cost hangs on this component of the study. 
2) The behavior of different panel shapes should be considered. Typical roofs are not merely gable end roofs, but are combinations of different slopes. These systems need to be examined for both the transfer of the load between different shapes and the connections that will go with these systems.

3) Incorporating different aesthetic shapes into the system should be calculated to provide more options for the appearance of the roof. While the tile shape provides optimal aesthetic shape, different shapes could allow the system to be used in different geographical regions. 
VITA

BRANDON MINTZ

April 11, 1984

2002-2007

2004-2007

2007-2008

2007-2013

2008-2014

2009

2010
Born, Miami, Florida

Bachelors of Science in Civil Engineering Florida International University Miami, Florida

Tutor and Tutorial Coordinator Multicultural Programs and Services Florida International University Miami, Florida

Masters of Science in Civil Engineering Florida International University Miami, Florida

Graduate Teaching/Research Assistant Florida International University Miami, Florida

Doctor of Philosophy in Civil Engineering Florida International University

Miami, Florida

Suksawang, Nakin, Brandon Mintz, Amir Mirmiran (2009). "Remedial Action for Failed Pole/Base Plate Weld on High Mast Lighting Pole (HMLP)." Florida Department of Transportation. December 1, 2009. $<$ http://www.dot.state.fl.us/researchcenter/Completed_Proj/Summary_STR/FD OT_BD015-23_rpt.pdf>

Mintz, Brandon, Rebecca Dahdah, Lilian Marrero, Hector Nava (2010). "Capacity Building in Communities: Tichia Project." Engineers Without Border-USA Southeast Regional Workshop, Chapel Hill, North Carolina. October 23, 2010. 
Mintz, Brandon, Suksawang, Nakin, and Amir Mirmiran (2012). "Evaluation of the Performance of Cazaly Hangers in Prestressed Concrete Joists". Proceedings of the 2012 PCI Convention and National Bridge Conference. Nashville, Tennessee. Sept. 29-Oct. 3, 2012.

2013-present

Submitted 2014

Under Preparation 2014
Forensic Engineer

Twenty First Century Engineering

Fort Lauderdale, Florida

Mintz, Brandon, Chowdhury, Arindam Gan, Mirmiran, Amir, Suksawang, Nakin, and Ramtin Kargarmoakhar (2014). "Design Procedures and Testing of a Supertile Roofing System". Submitted to ASCE Journal of Composites in Construction.

Mintz, Brandon, Mirmiran, Amir, Suksawang, Nakin, and Arindam Gan Chowdhury (2014). "Full-Scale Testing of a Precast Concrete Supertile Roofing System for Hurricane Mitigation". For Submittal in ASCE Journal of Architectural Engineering. 